\title{
Evaluation of a multi-model, multi-constituent assimilation framework for tropospheric chemical reanalysis
}

\author{
Kazuyuki Miyazaki ${ }^{1,2}$, Kevin W. Bowman ${ }^{1}$, Keiya Yumimoto ${ }^{3}$, Thomas Walker $^{4}$, and Kengo Sudo ${ }^{5,2}$ \\ ${ }^{1}$ Jet Propulsion Laboratory, California Institute of Technology, Pasadena, CA, USA \\ ${ }^{2}$ Earth Surface System Research Center, Japan Agency for Marine-Earth Science and Technology (JAMSTEC), \\ Yokohama, 236-0001, Japan \\ ${ }^{3}$ Research Institute for Applied Mechanics, Kyushu University, Kasuga Park 6-1, Fukuoka, 816-8580, Japan \\ ${ }^{4}$ Department of Civil and Environmental Engineering, Carleton University, Ottawa, Ontario, Canada \\ ${ }^{5}$ Graduate School of Environmental Studies, Nagoya University, Nagoya, Japan
}

Correspondence: Kazuyuki Miyazaki (kazuyuki.miyazaki@jpl.nasa.gov)

Received: 14 July 2019 - Discussion started: 7 August 2019

Revised: 5 November 2019 - Accepted: 19 December 2019 - Published: 24 January 2020

\begin{abstract}
We introduce a Multi-mOdel Multi-cOnstituent Chemical data assimilation (MOMO-Chem) framework that directly accounts for model error in transport and chemistry, and we integrate a portfolio of data assimilation analyses obtained using multiple forward chemical transport models in a state-of-the-art ensemble Kalman filter data assimilation system. The data assimilation simultaneously optimizes both concentrations and emissions of multiple species through ingestion of a suite of measurements (ozone, $\mathrm{NO}_{2}, \mathrm{CO}, \mathrm{HNO}_{3}$ ) from multiple satellite sensors. In spite of substantial model differences, the observational density and accuracy was sufficient for the assimilation to reduce the multi-model spread by $20 \%-85 \%$ for ozone and annual mean bias by $39 \%-97 \%$ for ozone in the middle troposphere, while simultaneously reducing the tropospheric $\mathrm{NO}_{2}$ column biases by more than $40 \%$ and the negative biases of surface $\mathrm{CO}$ in the Northern Hemisphere by $41 \%-94 \%$. For tropospheric mean $\mathrm{OH}$, the multi-model mean meridional hemispheric gradient was reduced from $1.32 \pm 0.03$ to $1.19 \pm 0.03$, while the multimodel spread was reduced by $24 \%-58 \%$ over polluted areas. The uncertainty ranges in the a posteriori emissions due to model errors were quantified in $4 \%-31 \%$ for $\mathrm{NO}_{x}$ and $13 \%-35 \%$ for CO regional emissions. Harnessing assimilation increments in both $\mathrm{NO}_{x}$ and ozone, we show that the sensitivity of ozone and $\mathrm{NO}_{2}$ surface concentrations to $\mathrm{NO}_{x}$ emissions varied by a factor of 2 for end-member models, revealing fundamental differences in the representation of fast chemical and dynamical processes. A systematic inves-
\end{abstract}

tigation of model ozone response and analysis increment in MOMO-Chem could benefit evaluation of future prediction of the chemistry-climate system as a hierarchical emergent constraint.

\section{Introduction}

Data assimilation is a technique for combining different observational data sets with a model, taking into consideration of the characteristics of individual measurements and model dynamics (e.g., Kalnay, 2003; Lahoz and Schneider, 2014). Atmospheric composition and chemical data assimilation using advanced data assimilation techniques such as four-dimensional variational data assimilation (4D-Var) and ensemble Kalman filter (EnKF) allows the propagation of observational information in time and space from a limited number of observed species to a wide range of chemical components (e.g., Lahoz et al., 2007; Sandu and Chai, 2011; Bocquet et al., 2015). Data assimilation provides global fields that are statistically consistent with individual observations. Various studies have demonstrated the capabilities of chemical data assimilation systems in the analysis of chemical species in the troposphere and stratosphere (e.g., Parrington et al., 2009; Kiesewetter et al., 2010; Flemming et al., 2011; Coman et al., 2012; Emili et al., 2014; Miyazaki et al., 2012a, b, 2015, 2019; van der A et al., 2015), emissions optimization (e.g., Miyazaki et al., 2012a; 2014; Miyazaki 
and Eskes, 2013; Stavrakou et al., 2013; Streets et al., 2013; Inness et al., 2015; Jiang et al., 2018), and chemical reanalyses to provide long-term data assimilation products (Inness et al., 2013; Gaubert et al., 2016; Miyazaki et al., 2015; Flemming et al., 2017). Chemical data assimilation frameworks have also been used to evaluate observing system impacts through observation system simulation experiments (OSSEs) (Yumimoto, 2013; Lahoz and Schneider, 2014; Bocquet et al., 2015; Abida et al., 2017; Liu et al., 2017) and evaluate chemistry-climate model simulations (Miyazaki and Bowman, 2017; Kuai et al., 2020).

Developments of advanced data assimilation techniques and satellite retrievals have contributed to improving data assimilation analysis and prediction of atmospheric composition (e.g., Skachko et al., 2016; Boersma et al., 2018a). However, a limiting factor in the accuracy of these systems is the performance of forecast models, which have limited fidelity in the representation of atmospheric dynamics and chemistry. For example, intercomparison studies of the Atmospheric Chemistry and Climate Model Intercomparison Project (ACCMIP) (Bowman et al., 2013; Young et al., 2013; Stevenson et al., 2013) and the Chemistry-Climate Model Initiative (CCMI) (Morgenstern et al., 2017; Kuai et al., 2020) revealed a large diversity in simulations of tropospheric composition owing to differences in model processes and input data. The choice of forecast model, thus, largely influences the a priori uncertainty in chemical data assimilation and the a posteriori data assimilation analysis.

As opposed to 4D-variational techniques that require a model adjoint, EnKF systems are independent from forecast model code and therefore can readily integrate multiple models into a multi-model data assimilation framework (Houtekamer and Zhang, 2016). EnKF techniques have been successfully applied to multiple different chemical transport models (CTMs) in our previous studies (e.g., Miyazaki et al., 2012b, 2015, 2017, 2019), which have been used to assimilate multi-constituent composition measurements from multiple sensors where both the chemical states and emissions of various species were simultaneously optimized. However, the sensitivity of concentrations to emissions, such as ozone response to $\mathrm{NO}_{x}$ emissions, is strongly model dependent and therefore has a first-order impact on the performance in a multi-constituent data assimilation framework. Consequently, quantification of this impact is important not only for analysis but also for Observing System Simulation Experiments (OSSEs) used to assess and design new observing systems. Nevertheless, the importance of forecast model performance on chemical data assimilation has not been demonstrated using a common data assimilation framework for tropospheric chemistry analysis. A multi-model framework can also be used to provide multi-model integrated analysis fields, which are less dependent on individual model performance.

Data assimilation that relies on a single model may lead to biased estimation and underestimate model uncertainty by under-sampling the relevant model space. The limitations with a single model could be overcome by integrating multi-model information in data assimilation in various ways. First, ensembles of models can be used to construct a flow-dependent analysis system. For instance, Xue and Zhang (2014) extended data assimilation to the multi-model Bayesian model averaging analysis framework, in which the posterior model weight for each model is determined through Bayes' theorem reflecting the prior probability of each model and the analysis consistency with the observations. This approach requires a framework to execute and update multiplemodel states continuously, which is difficult with multiple state-of-the-art CTMs that have been optimized using different platforms. Another way to integrate multiple-model information is to apply a common data assimilation framework with multiple models. By assimilating the same sets of observations, this framework can be used to demonstrate the importance of forecast model performance on data assimilation analysis, while uncertainty information of individual analyses can be evaluated consistently by using a same data assimilation framework. Uncertainty-weighed multi-model integrated analysis fields would provide unique information that is less dependent on individual model performance and is fundamentally different from averages of individual data assimilation analyses. Quantifying model performance with a multi-model integration is difficult when using different data assimilation frameworks.

This study demonstrates, for the first time, the importance of forecast model performance on data assimilation analysis of tropospheric composition and emissions, by utilizing four different CTM frameworks and applying a common EnKF approach. As illustrated in Fig. 1, an EnKF data assimilation system based on the GEOS-Chem model is newly developed in this study. Using the same data assimilation settings and assimilating almost the same multi-constituent observations from multiple satellite sensors, we examine how model bias affects tropospheric chemistry data assimilation performance, including emission estimation, and provide integrated data assimilation analysis fields from an ensemble of analyses that ingested multiple models and multi-constituent measurements.

\section{Methodology}

\subsection{Data assimilation module}

The data assimilation technique is based on a local ensemble transform Kalman filter (LETKF) approach developed by Hunt et al. (2007). The LETKF uses an ensemble forecast to estimate the background error covariance matrix and generates an analysis ensemble mean and covariance that satisfy the Kalman filter equations for linear models. In the forecast step, a background ensemble, $\boldsymbol{x}_{i}^{\mathrm{b}}(i=1, \ldots, k)$, is obtained from the evolution of an ensemble model forecast. Here, $\boldsymbol{x}$ 


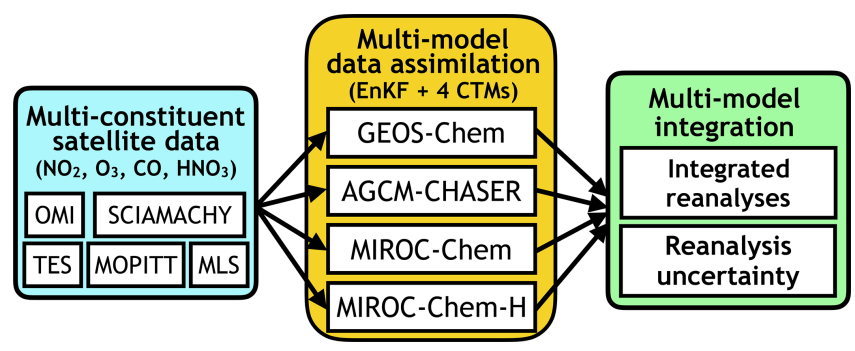

Figure 1. Schematic diagram of the MOMO-Chem framework. The MOMO-Chem utilizes four different CTMs and applies a common EnKF approach to investigate the importance of forecast model performance and model sensitivities for data assimilation analysis. This framework also provides multi-model integrated analysis fields and its uncertainty ranges.

represents the model variable, $\mathrm{b}$ indicates the background state, and $k$ is the ensemble size ( 32 in this study). The background ensemble mean $\overline{x^{\mathrm{b}}}$ and its perturbation $\mathbf{X}^{\mathrm{b}}$ are then estimated as follows:

$\overline{\boldsymbol{x}^{\mathrm{b}}}=\frac{1}{k} \sum_{i=1}^{k} \boldsymbol{x}_{i}^{\mathrm{b}}$

$\mathbf{X}_{i}^{\mathrm{b}}=\boldsymbol{x}_{i}^{\mathrm{b}}-\overline{x^{\mathrm{b}}}$.

The background error covariance is then estimated at each time step at each grid point as follows:

$\mathbf{P}^{\mathrm{b}}=\mathbf{X}^{\mathrm{b}}\left(\mathbf{X}^{\mathrm{b}}\right)^{T}$

The background ensemble is converted into the observation space, $\boldsymbol{y}_{i}^{\mathrm{b}}=H\left(\boldsymbol{x}_{i}^{\mathrm{b}}\right)$, using the observation operator $H$, which is the composite of a spatial interpolation operator and a satellite retrieval operator (see Sect. 2.3). An ensemble of background perturbation is defined as $\mathbf{Y}_{i}^{\mathrm{b}}=\boldsymbol{y}_{i}^{\mathrm{b}}-\overline{\boldsymbol{y}^{\mathrm{b}}}$.

Using the covariance matrices of observation and background error, the data assimilation determines the relative weights of the observation and background and subsequently transforms a background ensemble into an analysis ensemble, $\boldsymbol{x}_{i}^{\mathrm{a}}(i=1, \ldots, k)$. The analysis ensemble mean $\overline{\boldsymbol{x}^{\mathrm{a}}}$ is obtained by updating the background ensemble mean as follows:

$\overline{x^{\mathrm{a}}}=\overline{\boldsymbol{x}^{\mathrm{b}}}+\mathbf{X}^{\mathrm{b}} \tilde{P}^{\mathrm{a}}\left(\mathbf{Y}^{\mathrm{b}}\right)^{T} \mathbf{R}^{-1}\left(\boldsymbol{y}^{\mathrm{o}}-\overline{y^{\mathrm{b}}}\right)$,

$\tilde{P}^{\mathrm{a}}=\left[\frac{(k-1)}{1+\Delta} \mathbf{I}+\left(\mathbf{Y}^{\mathrm{b}}\right)^{T} \mathbf{R}^{-1} \mathbf{Y}^{\mathrm{b}}\right]^{-1}$,

where $\tilde{P}^{\mathrm{a}}$ is the $k \times k$ local analysis error covariance in the ensemble space, $\boldsymbol{y}^{\mathrm{o}}$ is the observation vector, and $\mathbf{R}$ is the observation error covariance. A covariance inflation factor ( $\triangle, 6 \%$ in this study for all the models, following the setting in Miyazaki et al., 2015) is applied to inflate the forecast error covariance.
The observation-minus-forecast $(\mathrm{OmF})$, that is known as the observational increment, is defined as

$\boldsymbol{y}^{\mathrm{o}}-\overline{\boldsymbol{y}^{\mathrm{b}}}$.

The analysis increment is defined as the correction made by data assimilation as follows:

$\overline{x^{\mathrm{a}}}-\overline{x^{\mathrm{b}}}$

The analysis ensemble perturbation matrix in the model space $\left(\mathbf{X}^{\mathrm{a}}\right)$ is obtained by transforming the background ensemble as follows and is used in the subsequent forecast step as the initial condition:

$\mathbf{X}^{\mathrm{a}}=\mathbf{X}^{\mathrm{b}}\left[(k-1) \tilde{P}^{\mathrm{a}}\right]^{1 / 2}$.

In the data assimilation analysis, covariance localization is applied so that the covariance among unrelated or weakly related variables is neglected. This removes the influence of spurious correlations resulting from the limited size of the ensemble. Further, it removes the influence of remote observations that may cause sampling errors. The data assimilation settings such as localization length used in this study are given in Sect. 2.6. Estimation of emissions is based on a state augmentation technique that uses the background error correlations for each grid point to determine the relationship between the concentrations and emissions of various species (Miyazaki et al., 2012a). A more detailed description of the basic data assimilation framework is available in Miyazaki et al. (2017).

\subsection{Forecast models}

We applied the same data assimilation system to four CTM frameworks: GEOS-Chem, AGCM-CHASER, MIROC$\mathrm{Chem}$, and MIROC-Chem-H. The specifications of these systems are summarized in Table 1. The major differences among the models are the meteorological input data, the complexity of the chemical mechanisms (simplest in AGCMCHASER for the troposphere), emission inventories (oldest in GEOS-Chem), vertical coordinate (sigma in AGCMCHASER only), and spatial resolution (highest in MIROCChem-H).

\subsubsection{GEOS-Chem}

The GEOS-Chem model is driven by assimilated meteorological data from the Goddard Earth Observing System (GEOS-5) of the NASA Global Modeling and Assimilation Office (GMAO). The adjoint model version 35 (Henze et al., 2007), which corresponds to version 9 of the forward model, with a horizontal resolution of $2^{\circ} \times 2.5^{\circ}$ and 47 vertical levels extending from the surface to $0.1 \mathrm{hPa}$, was used as a forward forecast model (i.e., without adjoint calculations) in this study. Although newer and improved versions of the forward 
Table 1. Summary of the forecast models used in this study.

\begin{tabular}{|c|c|c|c|c|}
\hline & GEOS-Chem & $\begin{array}{l}\text { AGCM-CHASER } \\
\text { (TRC-1) }\end{array}$ & MIROC-Chem & $\begin{array}{l}\text { MIROC-Chem-H } \\
\text { (TCR-2) }\end{array}$ \\
\hline Horizontal resolution & $2^{\circ} \times 2.5^{\circ}$ & $2.8^{\circ} \times 2.8^{\circ}$ & $2.8^{\circ} \times 2.8^{\circ}$ & $1.1^{\circ} \times 1.1^{\circ}$ \\
\hline Vertical resolution & $\begin{array}{l}47 \text { layers to } 0.1 \mathrm{hPa} \\
\text { (hybrid) }\end{array}$ & $\begin{array}{l}32 \text { layers to } 4 \mathrm{hPa} \\
\text { (sigma) }\end{array}$ & $\begin{array}{l}32 \text { layers to } 4 \mathrm{hPa} \\
\text { (hybrid) }\end{array}$ & $\begin{array}{l}32 \text { layers to } 4 \mathrm{hPa} \\
\text { (hybrid) }\end{array}$ \\
\hline Forecast model & $\begin{array}{l}\text { GEOS-Chem v9 } \\
\text { (adjoint v35) }\end{array}$ & $\begin{array}{l}\text { CCSR/NIES/FRCGC } \\
\text { AGCM-CHASER }\end{array}$ & MIROC-Chem & MIROC-Chem \\
\hline Chemistry & 43 species, 318 reactions & 47 species, 88 reactions & 92 species, 262 reactions & 92 species, 262 reactions \\
\hline Meteorological data & GEOS-5 & $\begin{array}{l}\text { Nudged to } \\
\text { NCEP-DOE/AMIP-2 }\end{array}$ & Nudged to ERA-Interim & Nudged to ERA-Interim \\
\hline Assimilated data & $\begin{array}{l}\mathrm{OMI} \mathrm{NO}_{2} \text { (DOMINO2), } \\
\text { SCIAMACHY NO} \\
\text { (DOMINO2), } \\
\text { TES ozone (v5) } \\
\text { MOPITT CO (v6 NIR) } \\
\text { MLS ozone \& } \mathrm{HNO}_{3}(\mathrm{v} 3.3)\end{array}$ & $\begin{array}{l}\mathrm{OMI} \mathrm{NO}_{2}(\mathrm{DOMINO} 2), \\
\text { SCIAMACHY } \mathrm{NO}_{2} \\
\text { (DOMINO2), } \\
\text { TES ozone (v5) } \\
\text { MOPITT CO (v6 NIR) } \\
\text { MLS ozone \& } \mathrm{HNO}_{3}(\mathrm{v} 3.3)\end{array}$ & $\begin{array}{l}\mathrm{OMI} \mathrm{NO}_{2}(\mathrm{DOMINO} 2), \\
\text { SCIAMACHY NO} \\
\text { (DOMINO2), } \\
\text { TES ozone (v5) } \\
\text { MOPITT CO (v6 NIR) } \\
\text { MLS ozone \& } \mathrm{HNO}_{3}(\mathrm{v} 3.3)\end{array}$ & $\begin{array}{l}\mathrm{OMI} \mathrm{NO}_{2}(\mathrm{QA4ECV}), \\
\text { SCIAMACHY NO} \\
(\mathrm{QA4ECV}), \\
\text { TES ozone (v6) } \\
\text { MOPITT CO (v7J) } \\
\text { MLS ozone \& } \mathrm{HNO}_{3}(\mathrm{v} 3.3)\end{array}$ \\
\hline A priori emissions & $\begin{array}{l}\text { EDGAR 3, NEI2008, } \\
\text { RETRO, GFED2 }\end{array}$ & $\begin{array}{l}\text { EDGAR 4.2, GFED 3.1, } \\
\text { GEIA }\end{array}$ & $\begin{array}{l}\text { EDGAR 4.2, GFED 3.1, } \\
\text { GEIA }\end{array}$ & HTAP v2, GFED 4, GEIA \\
\hline State vector & $\begin{array}{l}\text { Concentrations of } 43 \\
\text { species }+ \text { emissions }\left(\mathrm{NO}_{x} \text {, }\right. \\
\left.\mathrm{CO}, \mathrm{LNO}_{x}\right)\end{array}$ & $\begin{array}{l}\text { Concentrations of } 35 \\
\text { species + emissions }\left(\mathrm{NO}_{x},\right. \\
\text { diurnal variability, } \mathrm{CO}, \\
\left.\mathrm{LNO}_{x}\right)\end{array}$ & $\begin{array}{l}\text { Concentrations of } 35 \\
\text { species + emissions }\left(\mathrm{NO}_{x},\right. \\
\text { diurnal variability, } \mathrm{CO}, \\
\left.\mathrm{LNO}_{x}\right)\end{array}$ & $\begin{array}{l}\text { Concentrations of } 35 \\
\text { species }+ \text { emissions }\left(\mathrm{NO}_{x} \text {, }\right. \\
\text { diurnal variability, } \mathrm{CO}, \\
\left.\mathrm{SO}_{2}, \mathrm{LNO}_{x}\right)\end{array}$ \\
\hline Reference (forecast model) & Henze et al. (2007) & Sudo et al. (2002) & Watanabe et al. (2011) & Sekiya et al. (2018) \\
\hline Reference (data assimilation) & This study & $\begin{array}{l}\text { Miyazaki et al. (2012a, b, } \\
2014,2015)\end{array}$ & Miyazaki et al. (2017) & Miyazaki et al. (2019) \\
\hline
\end{tabular}

model are available, we chose this version (the latest version of the adjoint model) so that an intercomparison study of 4DVar and EnKF using the same modeling system can be conducted in a separate study. The core of GEOS-Chem computes the local changes in atmospheric concentrations due to emissions, chemical reactions, and deposition. Further, it can simulate coupled aerosol-oxidant chemistry in the troposphere and stratosphere. This model uses the advection algorithm developed by Lin and Rood (1996) on the rectilinear grid. Convective transport is computed from the convective mass fluxes available in the meteorological archive. The application of the EnKF chemical data assimilation system based on the GEOS-Chem model is newly developed in this manuscript.

The a priori emission data for $\mathrm{NO}_{x}$ and $\mathrm{CO}$ were obtained from the Emission Database for Global Atmospheric Research (EDGAR) version 3 inventory (Olivier and Berdowski, 2001) for global anthropogenic emissions and from the monthly the Global Fire Emissions Database (GFED) version 2 inventory (van der Werf, 2006) for biomass burning emissions. Volatile organic compound (VOC) emission data were obtained from the RETRO inventory (Schultz et al., 2008). Emission data for North America were replaced with the 2008 National Emissions Inventory (NEI).

\subsubsection{AGCM-CHASER}

The chemical atmospheric general circulation model for the study of atmospheric environment and radiative forcing (CHASER; Sudo et al., 2002) simulates tracer transport, wet and dry deposition, and emissions. It has a horizontal resolution of T42 $\left(2.8^{\circ} \times 2.8^{\circ}\right)$ and $32 \sigma$ levels from the surface to $4 \mathrm{hPa}$. This model is coupled to the Center for Climate System Research/National Institute for Environmental Studies (CCSR/NIES) atmospheric general circulation model (AGCM) version 5.7b. The AGCM fields in this model are nudged towards the National Centers for Environmental Prediction Department of Energy Atmospheric Model Intercomparison Project II (NCEP-DOE/AMIP-II) reanalyses (Kanamitsu et al., 2002) at each time step of the AGCM (i.e., every $20 \mathrm{~min}$ ) to reproduce past meteorological conditions. The data assimilation system based on the AGCM-CHASER model (Miyazaki et al., 2012a, b; Miyazaki and Eskes, 2013) was used to conduct our first chemical reanalysis calculation for 2005-2012 (TCR-1; Miyazaki et al., 2015) and elucidate the 3-D structures of lightning-induced $\mathrm{NO}_{x}\left(\mathrm{LNO}_{x}\right)$ sources (Miyazaki et al., 2014).

The anthropogenic $\mathrm{NO}_{x}$ and $\mathrm{CO}$ emissions were obtained from EDGAR version 4.2. Emissions from biomass burning are based on the GFED version 3.1 (van der Werf et al., 2010), while those from soils are based on the monthly 
Global Emissions Inventory Activity (GEIA) (Graedel et al., 1993). Using the settings reported by LOTOS-EUROS (Schaap et al., 2008) and Boersma et al. (2008), a diurnal variability scheme developed by Miyazaki et al. (2012a) was applied for surface $\mathrm{NO}_{x}$ emissions depending on the dominant category for each area (anthropogenic, biogenic, and soil emissions). $\mathrm{LNO}_{x}$ sources were determined based on the relationship between lightning activity and cloudtop height (Price and Rind, 1992) and using the convection scheme of the AGCM. Biogenic emissions from vegetation are considered for non-methane hydrocarbons (NMHCs) based on Guenther et al. (2006). Oxidations of ethane, propane, ethene, propene, isoprene, and terpenes were included explicitly.

\subsubsection{MIROC-Chem}

MIROC-Chem is the chemistry component of the MIROC Earth system model (ESM) and is coupled to the MIROCAGCM version 4 (Watanabe et al., 2011). It has a horizontal resolution of $\mathrm{T} 42\left(2.8^{\circ} \times 2.8^{\circ}\right)$ and 32 hybrid vertical levels from the surface to $4.4 \mathrm{hPa}$. Its tropospheric chemistry was developed based on the CHASER model with updates related to chemical reactions and emissions. MIROCChem considers the fundamental chemical cycle of $\mathrm{O}_{x}-$ $\mathrm{NO}_{x}-\mathrm{HO}_{x}-\mathrm{CH}_{4}-\mathrm{CO}$ along with oxidation of non-methane VOCs (NMVOCs) to accurately represent ozone chemistry in the troposphere. Its stratospheric chemistry simulates chlorine- and bromine-containing compounds, chlorofluorocarbons (CFCs), hydrofluorocarbons (HFCs), carbonyl sulfide (OCS) and $\mathrm{N}_{2} \mathrm{O}$. Further, it simulates the formation of polar stratospheric clouds (PSCs) and the associated heterogeneous reactions on their surfaces. The simulated meteorological fields were nudged towards the 6-hourly ERA-Interim reanalysis (Dee et al., 2011). An EnKF system that is based on MIROC-Chem has been used to study decadal changes in $\mathrm{NO}_{x}$ emissions (Miyazaki et al., 2017; Jiang et al., 2018). The emission data and $\mathrm{LNO}_{x}$ scheme for this model are the same as in the AGCM-CHASER.

\subsubsection{MIROC-Chem-H}

A high-resolution $\left(1.1^{\circ} \times 1.1^{\circ}\right)$ version of the MIROC-Chem model, MIROC-Chem-H (Sekiya et al., 2018), was also used. This model utilizes the same chemical and transport module as MIROC-Chem (see Sect. 2.2.3) and has been used to study processes controlling air quality in east Asia during the KORUS-AQ aircraft campaign (Miyazaki et al., 2019; Thompson et al., 2019) and conduct the second Tropospheric Chemistry Reanalysis (TCR-2; Jet Propulsion Laboratory, 2019) for 2005-2018. Kanaya et al. (2019) demonstrated the overall good performance of the ozone and $\mathrm{CO}$ analyses in TCR-2 over remote oceans using observations from research vessels.
Data for anthropogenic emissions of $\mathrm{NO}_{x}$ and $\mathrm{CO}$ were obtained from the HTAP version 2 inventory for 2010 (Janssens-Maenhout et al., 2015). This inventory combines nationally reported emissions data with data from regional scientific inventories of the European Monitoring and Evaluation Programme (EMEP), Environmental Protection Agency (EPA), Greenhouse Gas-Air Pollution Interactions and Synergies (GAINS), and Regional Emission Inventory in Asia (REAS). Emissions from biomass burning were based on the monthly GFED version 4.2 inventory (Randerson et al., 2018) for $\mathrm{NO}_{x}$ and $\mathrm{CO}$, while those from soils were based on the monthly GEIA inventory (Graedel et al., 1993) for $\mathrm{NO}_{x}$. Emission data for other compounds were taken from the HTAP version 2 and GFED version 4 inventories.

As summarized in Table 1 and described in Sect. 2.3, the satellite products used in MIROC-Chem-H were more recent than those used in the other three models. Diversity among the data assimilation systems was enhanced by the use of different assimilated data. Although the effects of varying assimilated measurements need careful evaluation, the recently developed retrieval products reveal rather similar characteristics in general. We thus expect that the forecast model performance has a greater influence on data assimilation analysis.

\subsection{Assimilated measurements}

To assimilate satellite measurements, we have developed an observation operator $(H)$ for individual assimilated measurements. This operator includes the spatial interpolation operator $(\mathbf{S})$, a priori profile for the satellite retrievals $\left(\boldsymbol{x}_{\text {apriori }}\right)$, and averaging kernel (A), which maps the model fields $\left(\boldsymbol{x}_{i}^{\mathrm{b}}\right)$ into the retrieval space $\left(\boldsymbol{y}^{\mathrm{b}}\right)$, as follows:

$\boldsymbol{y}_{i}^{\mathrm{b}}=H\left(\boldsymbol{x}_{i}^{\mathrm{b}}\right)=\boldsymbol{x}_{\text {apriori }}+\mathbf{A}\left(\mathbf{S}\left(\boldsymbol{x}_{i}^{\mathrm{b}}\right)-\boldsymbol{x}_{\text {apriori }}\right)$.

The averaging kernel captures the vertical sensitivity profiles of the retrievals (e.g., Eskes and Boersam, 2003; Jones et al., 2003; Migliorini et al., 2008). Even though the retrieval $\boldsymbol{y}^{\mathrm{o}}$ and the model equivalent $\boldsymbol{y}_{i}^{\mathrm{b}}$ depend on the a priori profile, using the averaging kernel removes the dependence of the analysis on model-retrieval comparison.

Biases in the assimilated satellite retrievals can degrade data assimilation performance. The ozone analysis bias is not solely determined by bias in the assimilated ozone measurements in the multi-constituent data assimilation approach. Miyazaki et al. (2015) demonstrated that the assimilation of measurements other than TES measurements led to corrections in the lower and middle tropospheric ozone. Application of a bias correction procedure for multiple measurements could improve the data assimilation analysis quality. However, we did not apply any bias correction because of the difficulty in estimating the bias structure that could vary temporally and spatially. Meanwhile, since the data are the same for all comparisons with different models, the differences with respect to independent observations are relatively independent of those biases. 


\subsubsection{OMI and SCIAMACHY $\mathrm{NO}_{2}$}

The tropospheric $\mathrm{NO}_{2}$ column retrievals from the DOMINO version 2 for Ozone Monitoring Instrument (OMI) and Scanning Imaging Absorption Spectrometer for Atmospheric Chartography (SCIAMACHY) (Boersma et al., 2011), obtained from the Tropospheric Emission Monitoring Internet Service (TEMIS) website (http://www.temis.nl, last access: 1 June 2019) were used for the GEOS-Chem, AGCMCHASER, and MIROC-Chem systems. For MIROC-Chem$\mathrm{H}$, retrievals from the QA4ECV version 1.1 level 2 (L2) product for OMI (Boersma et al., 2017a) and SCIAMACHY (Boersma et al., 2017b) were used. Low-quality data were excluded following the published recommendations (Boersma et al., 2011, 2018b).

We employed a super-observation approach to produce representative data with the horizontal resolution of each forecast model, following the approach of Miyazaki et al. (2012a). Super-observation error was estimated using the provided retrieval uncertainty and considering an error correlation of $15 \%$ among the individual satellite observations within a model grid cell and representativeness errors in all the systems.

\subsubsection{TES ozone}

The Tropospheric Emission Spectrometer (TES) ozone retrievals used are the version 5 level 2 nadir data obtained from the global survey mode (Bowman et al., 2006; Herman and Kulawik, 2013) for the GEOS-Chem, AGCM-CHASER, and MIROC-Chem systems. The version 6 level 2 nadir data were used for the MIROC-Chem-H system. This data set consists of 16 daily orbits with a spatial resolution of 5-8 km along the orbit track. The standard quality flags were used to exclude low-quality data. The data assimilation of the TES ozone retrievals was performed based on the logarithm of the mixing ratio following the retrieval product specification (Bowman et al., 2006).

\subsubsection{MLS ozone and $\mathrm{HNO}_{3}$}

The Microwave Limb Sounder (MLS) data used were the version 3.3 ozone and $\mathrm{HNO}_{3} \mathrm{~L} 2$ products (Livesey et al., 2011) for all models except MIROC-Chem-H, which used the version 4.2 data. We used MLS data for pressures of less than $215 \mathrm{hPa}$ for ozone and less than $150 \mathrm{hPa}$ for $\mathrm{HNO}_{3}$, while tropical-cloud-induced outliers were excluded. The provided accuracy and precision of the measurement error were included as the diagonal element of the observation error covariance matrix.

\subsubsection{MOPITT CO}

The version 6 level 2 thermal infrared (TIR) products (Deeter et al., 2013) of the Measurement of Pollution in the Troposphere (MOPITT) were used for all models except the
MIROC-Chem-H, for which the version 7 level 2 TIR-nearinfrared (NIR) total column CO data were used (Deeter et al., 2017). The version 7 products have been improved from the version 6 products with respect to overall retrieval biases, bias variability and bias drift uncertainty (Deeter et al., 2017). Owing to data quality problems, we excluded data poleward of $65^{\circ}$ and nighttime data. For the version 6 TIR products, data at $700 \mathrm{hPa}$ were used for constraining surface $\mathrm{CO}$ emissions. For the version 7 TIR-NIR products, the total column averaging kernel was used in the observation operator to estimate simulated total columns. The uncertainty information provided in the retrievals was used in the observation error. Like in the case of $\mathrm{NO}_{2}$ measurements, the super-observation approach was applied for MOPITT measurements as well.

\subsection{Validation data}

\subsubsection{WOUDC ozonesonde data}

All available ozonesonde observations taken from the World Ozone and Ultraviolet Radiation Data Center (WOUDC) database (available at http://www.woudc.org, last access: 1 June 2019) were used as validation data. All ozonesonde profiles have been interpolated to a common vertical pressure grid, with a bin of $25 \mathrm{hPa}$. The ozone fields from the control and data assimilation calculations were linearly interpolated to the time and location of each measurement, with a bin of $25 \mathrm{hPa}$, and then compared with the measurements at $4^{\circ} \times 4^{\circ}$ grid points. The observation error is $5 \%-10 \%$ between the surface and $30 \mathrm{~km}$ (Smit et al., 2007).

\subsubsection{WDCGG surface carbon monoxide}

Surface CO concentration observations were obtained from the World Data Centre for Greenhouse Gases (WDCGG) operated by the World Meteorological Organization (WMO) Global Atmospheric Watch program (http://ds.data.jma.go. jp/gmd/wdcgg/, last access: 1 June 2019). Hourly and event observations from 59 stations were used to validate surface $\mathrm{CO}$ concentrations from the control and data assimilation runs at $5^{\circ} \times 5^{\circ}$ grid points.

\subsection{Multi-model analysis}

We construct integrated data assimilation analysis using multiple models combined with multiple-species measurements (Fig. 1). The multi-model integrated analysis $\overline{\boldsymbol{x}_{\mathrm{m}}}\left(\overline{\boldsymbol{x}_{\text {multimodel }}}\right)$ is obtained by combining data assimilation analyses $\left(x_{j}^{\mathrm{a}}\right)$ weighted by analysis uncertainties $\left(\sigma_{j}^{2}\right)$ of individual models $(j=1-4)$ as follows:

$\overline{\boldsymbol{x}_{\mathrm{m}}}=\frac{\sum\left(\boldsymbol{x}_{j}^{\mathrm{a}} / \sigma_{j}^{2}\right)}{\sum\left(1 / \sigma_{j}^{2}\right)}$. 
The analysis uncertainties $\left(\sigma_{j}^{2}\right)$ are estimated from the root mean square of the analysis ensemble perturbation matrix $\left(\mathbf{X}^{\text {a }}\right.$; see Eq. 8) that is obtained by transforming the background ensemble using the local analysis error covariance (see Eq. 5). The integrated analysis $\left(\overline{\boldsymbol{x}_{\mathrm{m}}}\right)$ provides unique information on atmospheric states, which are less dependent on the characteristics of individual models used for data assimilation, and considers the uncertainty of individual data assimilation analyses. The uncertainty of the integrated analysis $\left(\bar{\sigma}_{\mathrm{m}}^{2}\right)$ is defined as follows:

$\bar{\sigma}_{\mathrm{m}}^{2}=\frac{1}{\sum\left(1 / \sigma_{j}^{2}\right)}$.

We apply this approach for estimating multi-model mean ozone fields in this study. Because of the predefined minimum values of the standard deviations applied to surface emissions of $\mathrm{CO}$ and $\mathrm{NO}_{2}$ to prevent covariance underestimation during data assimilation (see Sect. 2.6), the analysis spreads of near-surface $\mathrm{NO}_{x}$ and $\mathrm{CO}$ concentrations tend to be similar among the models due to the artificial adjustments and are not fully meaningful. Therefore, for the concentrations and emissions of $\mathrm{CO}$ and $\mathrm{NO}_{x}$ their multi-model mean and uncertainty were estimated as a standard ensemble mean and spread, without using the analysis uncertainty of individual models. The multi-model integrated analysis fields were produced at the highest horizontal resolution of the models $\left(1.1^{\circ} \times 1.1^{\circ}\right)$ after linearly interpolation. Given the small number of models $(j=1-4)$ used in this study, the multimodel integration would suffer from sampling biases. With an increase in the number of models in future studies, this approach would provide more robust statistics.

\subsection{Experimental setting}

We conducted 1 year of data assimilation calculations and forward model simulations (i.e., control run) from 1 January 2007, with a 2-month spin up from 1 November 2006, using the four systems. This assimilation period was chosen to provide comprehensive constraints by OMI measurements while avoiding the influences of OMI row anomalies (December 2009 onwards) (Schenkeveld et al., 2017) and reduced numbers of the TES measurements (2010 onwards). A control run was performed in each system using the same model settings as the data assimilation run but without performing data assimilation. The validation results for the control and data assimilation runs were compared to measure the improvements achieved through data assimilation in each system.

Almost the same data assimilation settings were used for the four systems as follows. The state vector includes the chemical concentrations of various species as well as the surface sources of $\mathrm{NO}_{x}$ and $\mathrm{CO}$ and $\mathrm{LNO}_{x}$ sources. The $\mathrm{LNO}_{x}$ source optimization is based on the scheme developed by Miyazaki et al. (2014). For the MIROC-Chem-H system, the state vector also includes surface $\mathrm{SO}_{2}$ emissions, as implemented in Miyazaki et al. (2019). The state vectors for the MIROC-Chem and MIROC-Chem-H systems include a correction factor for emission diurnal variability to improve the representation of diurnal emission variability using the OMI and SCIAMACHY retrievals obtained at different overpass times, based on the scheme developed by Miyazaki et al. (2017).

Covariance inflation was applied to analyses of both concentrations and emissions to prevent underestimation of background error covariance and filter divergence caused by sampling errors associated with the limited ensemble size and by model errors, following the settings used by Miyazaki et al. (2015). Further, localization was applied to avoid the influence of remote observations that may cause sampling errors, with a cutoff radius of approximately $1650 \mathrm{~km}$ for $\mathrm{NO}_{x}$ emissions and $2000 \mathrm{~km}$ for $\mathrm{CO}$ emissions, $\mathrm{LNO}_{x}$ sources, and chemical concentrations, as in Miyazaki et al. (2015). We also applied covariance localization for different variables in the state vector (Kang et al., 2011), by setting the covariance among unrelated or weakly related variables to zero. The analysis of surface emissions of $\mathrm{NO}_{x}$ and $\mathrm{CO}$ allowed for error correlations with $\mathrm{NO}_{2}$ and $\mathrm{CO}$ concentrations only, respectively. For $\mathrm{LNO}_{x}$ sources, covariances with $\mathrm{CO}$ data were neglected. Assimilation of MOPITT CO data was used to constrain surface $\mathrm{CO}$ emissions only. Concentrations of $\mathrm{NO}_{y}$ species and ozone were optimized from TES ozone, OMI and SCIAMACHY $\mathrm{NO}_{2}$, and MLS ozone and $\mathrm{HNO}_{3}$ observations.

The a priori error was set to $40 \%$ for surface emissions of $\mathrm{NO}_{x}$ and $\mathrm{CO}$ and $60 \%$ for $\mathrm{LNO}_{x}$ sources, which are comparable to the reported emission uncertainty (e.g., Schumann and Huntrieser, 2007; Kaiser et al., 2012; Li et al., 2017). To prevent covariance underestimation and maintain emission variability during the long-term assimilation calculation, we applied covariance inflation to the emission source factors in the analysis step. The standard deviation of the emission source factors was artificially inflated to a minimum predefined value (30\% of the initial standard deviation) at each analysis step.

The data assimilation cycle was set to be $6 \mathrm{~h}$ for the AGCM-CHASER, MIROC-Chem, and MIROC-Chem-H systems and $6 \mathrm{~h}$ for the GEOS-Chem system because of the limitation associated with meteorological data input in GEOS-Chem. The emission and concentration fields were analyzed and updated at each analysis step in all the systems. We have confirmed that the results of data assimilation can differ when the data assimilation cycle is changed from $2 \mathrm{~h}$ to $6 \mathrm{~h}$ using the AGCM-CHASER system. This occurs, in particular, for the analysis of short-lived species with strong diurnal variability and $\mathrm{NO}_{x}$ emission estimates. The performance of the GEOS-Chem data assimilation can thus be expected to differ with the use of a $2 \mathrm{~h}$ data assimilation cycle and meteorological data inputs with higher temporal frequency for short-lived species. 
In summary, there are differences in the assimilated measurements (updated retrievals were used in MIROC-Chem$\mathrm{H}$ ), diurnal emission variability (data assimilation corrections were made in the MIROC-Chem and MIROC-Chem$\mathrm{H}$ systems only) and data assimilation cycle (6 $\mathrm{h}$ in GEOSChem) of the four systems. These differences will lead to discrepancies in the data assimilation analyses of the four systems attributable to assimilation system configuration rather than the forward models themselves. While impact of these configurations can be further refined in future studies, the major discrepancies in the data assimilation analyses are still primarily attributable to the models themselves.

\section{Data assimilation statistics}

\subsection{Analysis increment}

The analysis increment (Eq. 7) information is a measure of the adjustment made in the analysis step, which is estimated from the differences between the forecast and the analysis after each analysis step. As shown in Fig. 2a, the annual mean analysis increments are largely different among the models, reflecting different systematic model biases. For individual systems, the analysis increments are in good agreement with the OmF (Eq. 6). This confirms that the model errors were effectively reduced using data assimilation.

In the ozone concentration field at $500 \mathrm{hPa}$, the AGCMCHASER system gives large positive increments in the extratropics of both hemispheres, with annual mean values in the range of $1-3 \mathrm{ppb} \mathrm{d}^{-1}$, whereas the increments are negative at low latitudes (up to $-1.5 \mathrm{ppbv} \mathrm{d}^{-1}$ ). The standard deviations of the analysis increment are $0.8-1.7 \mathrm{ppb} \mathrm{d}^{-1}$ in the extratropics and $0.2-0.4 \mathrm{ppbd}^{-1}$ at low latitudes. The analysis increments are relatively low in GEOS-Chem (up to $-1.8 \mathrm{ppbv} \mathrm{d}^{-1}$ ) and MIROC-Chem (up to $1.4 \mathrm{ppbv} \mathrm{d}^{-1}$ ) in the Northern Hemisphere (NH) extratropics; in GEOSChem $\left(-0.5-1.5 \mathrm{ppbv} \mathrm{d}^{-1}\right.$ ) and MIROC-Chem-H (up to $-1.0 \mathrm{ppbv} \mathrm{d}^{-1}$ ) in the tropics; and in MIROC-Chem (up to $1.4 \mathrm{ppbv} \mathrm{d}^{-1}$ ) in the Southern Hemisphere ( $\mathrm{SH}$ ) extratropics. GEOS-Chem exhibits negative increments except over central Africa and northern South America, with large negative increments (up to 2 ppbv d $^{-1}$ ) over the Southern Ocean and the US west coast in the strong westerlies and Aleutian Low regions. The positive increments over central Africa and northern South America could imply underestimated ozone productions due to biomass burning or VOC emissions.

The analysis increments differed significantly between the lower and upper troposphere as well as among seasons in all the systems (figure not shown). GEOS-Chem shows large positive increments $\left(0.5-2.2 \mathrm{ppbv} \mathrm{d}^{-1}\right)$ in the extratropics at $700 \mathrm{hPa}$, in contrast to negative increments (up to $-2.0 \mathrm{ppbv} \mathrm{d}^{-1}$ ) at low latitudes and midlatitudes at $350 \mathrm{hPa}$. In AGCM-CHASER and MIROC-Chem, the increments changed from positive at $700 \mathrm{hPa}$ (up to $2.2 \mathrm{ppbd}^{-1}$ in AGCM-CHASER and $0.5 \mathrm{ppbd}^{-1}$ in MIROC-Chem) to negative at $350 \mathrm{hPa}$ (up to -2.5 and $-1.2 \mathrm{ppb} \mathrm{d}^{-1}$ ) in the extratropics of both hemispheres. The positive increments in MIROC-Chem-H decreased with height in the extratropical troposphere. As the increments in the troposphere are mainly introduced by the TES assimilation, the vertical structures suggest that the assimilated TES ozone measurements have independent information regarding the lower- and uppertropospheric ozone. Using observing system experiments (OSEs), our previous studies (Miyazaki et al., 2012b, 2015, 2019) revealed that the TES ozone data assimilation dominates the corrections in the tropospheric ozone analysis, whereas the use of measurements other than TES measurements (mainly $\mathrm{NO}_{2}$ measurements) led to corrections in the lower- and middle-tropospheric ozone during the forecast. Jourdain et al. (2007) showed that the TES retrievals have 1-2 DOFs (degrees of freedom) in the troposphere, with the highest number of DOFs for the clear-sky tropics and subtropics. The seasonal changes in the analysis increment reflect variations in the short-term systematic model errors and observational constraints, which also differed significantly among the models.

\subsection{Analysis uncertainty}

The analysis uncertainty, which is estimated as the standard deviation of the analyzed concentrations across the ensemble (Eq. 8) in individual systems, can be used as a measure of the uncertainty of each data assimilation analysis. The analysis uncertainty is due to errors in the model input data, model processes, and assimilated measurements and is reduced as the analyses converge to the true state. Because the model input data and assimilated measurements are almost the same among the models, differences in model processes such as response of ozone to perturbed emissions and chemical lifetimes should be primarily responsible for the analysis spreads among the models through the forecast step. Detailed investigation on the impact of different model processes for each region and season would be helpful to interpret the results but is beyond the scope of this paper. The simultaneous emissions and concentration optimization were important in producing appropriate ensemble perturbations in ozone, especially in the lower and middle troposphere.

The ozone analysis uncertainty at $500 \mathrm{hPa}$ shown in Fig. $2 b$ is generally smaller in the tropics than in the extratropics, likely a consequence of the higher sensitivities in the TES ozone retrievals in the tropics. Because common settings were applied to the ensemble size and covariance inflation, the obtained inter-model differences in the spread reflect different systematic model errors related to the assimilation window size. The annual mean analysis uncertainty is generally larger in AGCM-CHASER and MIROC-Chem than in GEOS-Chem and MIROC-Chem-H. In the tropics, the analysis uncertainty is approximately $2-5 \mathrm{ppb}$ in GEOS-Chem and MIROC-Chem-H and approximately $5-11 \mathrm{ppb}$ in AGCM- 
(a) Analysis increment
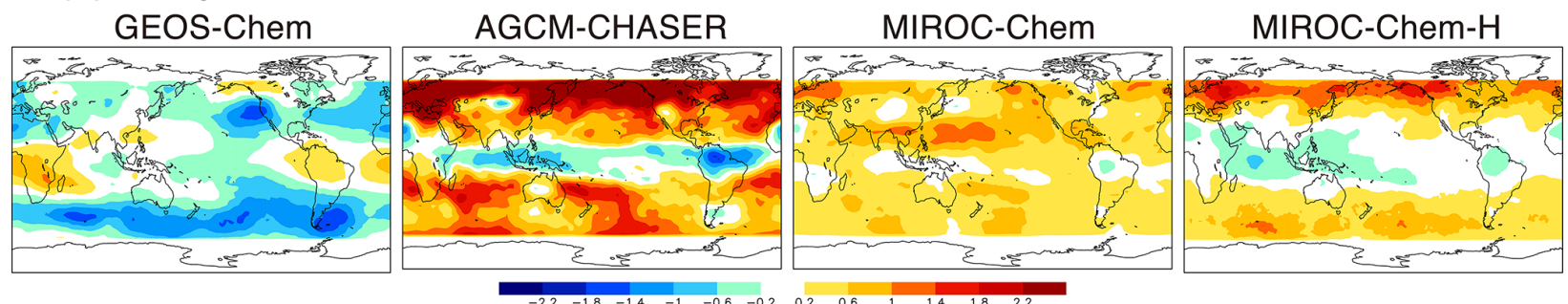

(b) Analysis uncertainty GEOS-Chem
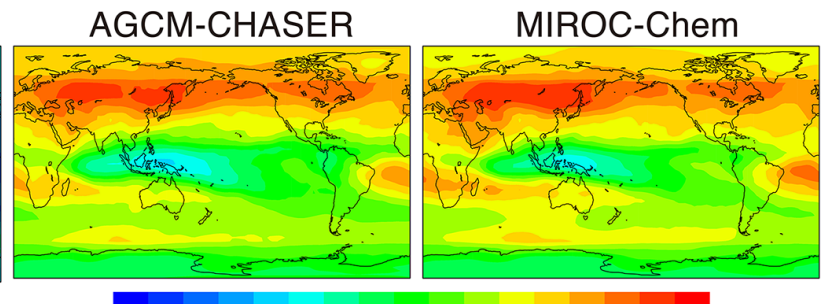

MIROC-Chem-H
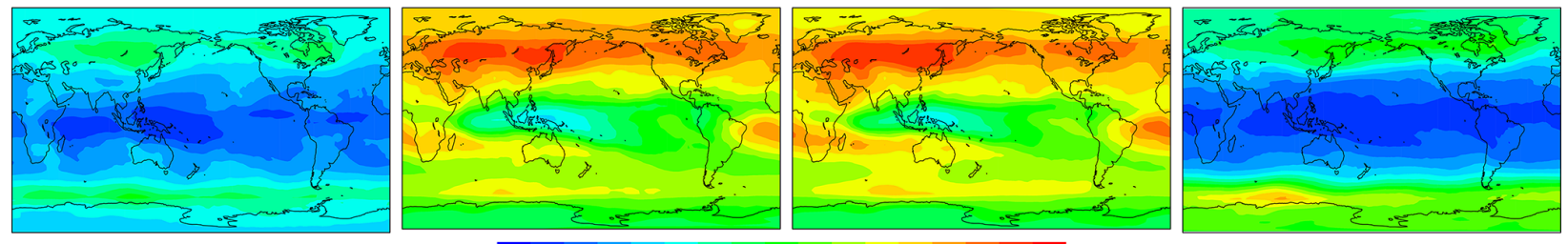

Figure 2. Spatial distributions of (a) analysis increment $\left(\mathrm{ppbv} \mathrm{d}^{-1}\right)$ and (b) analysis uncertainty (ppb) of ozone at $500 \mathrm{hPa}$ averaged over 2007 from the four systems.

CHASER and MIROC-Chem. In the extratropics, the analysis spread is approximately 6-10 ppb in GEOS-Chem and MIROC-Chem-H and 10-16 ppb in AGCM-CHASER and MIROC-Chem. The analysis increments are generally similar among the models (see Fig. 2a). These results suggest that the model forecasts tended to diverge more quickly in AGCM-CHASER and MIROC-Chem, likely as a result of larger differences in the equilibrium state between the model and assimilation. In the upper troposphere-lower stratosphere (UTLS) region, the analysis uncertainty is relatively smaller in the extratropics than in the tropics because of the high accuracy of the MLS measurements. The spatial patterns in GEOS-Chem and MIROC-Chem-H are remarkably similar, but the CHASER and MIROC patterns are much more similar.

The multi-model standard deviation of the ozone analyses (typically $<5 \mathrm{ppb}$ for the globe, Fig. $3 \mathrm{c}$ ) is significantly lower than the analysis uncertainty in AGCM-CHASER and MIROC-Chem (Fig. 2b). As will be discussed in Sect. 4.1, mean errors against independent observations are also significantly smaller than the analysis uncertainty in these models. These results indicate that the analysis uncertainty depends on the choice of forward model and was possibly overestimated in AGCM-CHASER and MIROC-Chem because of a large diversity in forecast trajectories. The overestimated analysis error covariance was also confirmed by smaller chi squares (e.g., Ménard and Chang, 2000) in these models (not shown). To measure the analysis spread corresponding to the actual analysis uncertainties, additional observational information and optimizing the covariance inflation to the forecast error covariance would be required.

\subsection{Multi-model integrations}

Figure 3a shows the integrated ozone analysis fields, $\overline{\boldsymbol{x}_{\mathrm{m}}}$ defined in Eq. (10), that were created using MOMO-Chem. The annual and multi-model mean ozone concentrations at $500 \mathrm{hPa}$ are high in the $\mathrm{NH}$ extratropics (55-70 ppbv) and low over the Maritime Continent and the tropical western Pacific (22-35 ppbv). Because the analyses from the GEOSChem and MIROC-Chem-H systems exhibit smaller analysis spreads (see Sect. 3.2), they exert a strong control on the integrated fields. At $500 \mathrm{hPa}$, the estimated uncertainty of the integrated fields, $\overline{\sigma_{\mathrm{m}}^{2}}$ defined in Eq. (11), is $2-4.5 \mathrm{ppbv}$ in the $\mathrm{NH}, 0.5-2 \mathrm{ppbv}$ in the tropics and 3-5.5 ppbv in the $\mathrm{SH}$ (Fig. 3b). These values are smaller than the uncertainties of the individual model analyses (Fig. 2b), demonstrating that the integrated fields can provide more reliable and unique information. The multi-model spread of individual data assimilation analysis (Fig. 3c) is typically smaller than the multimodel mean integrated uncertainty (Fig. 3b). Again, with the multi-model spread (Fig. 3c) and the differences with the ozonesonde measurements (Sect. 4.1) being smaller than the multi-model mean uncertainty (Fig. 3b), the comparisons suggest that the analysis uncertainty might be overestimated in some of the analyses.

Over northern South America, the larger multi-model spread compared to the multi-model mean uncertainty suggests that the background errors might have been underestimated, as rapid error growths due to deep convection and biomass burning might not have been accounted for properly. Differences in isoprene emissions and chemistry could also enhance the multi-model spread over the region (Archibald et al., 2010). Techniques such as adaptive inflation for back- 
(a) Multi-model mean analysis

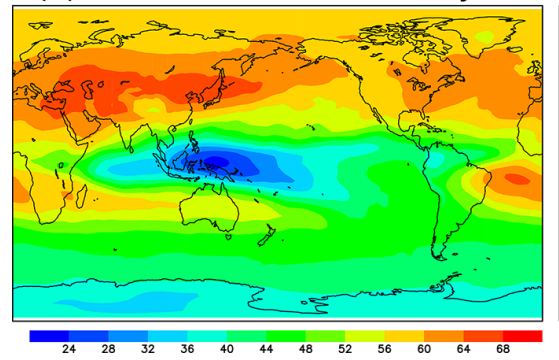

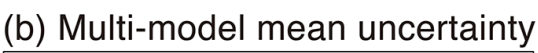

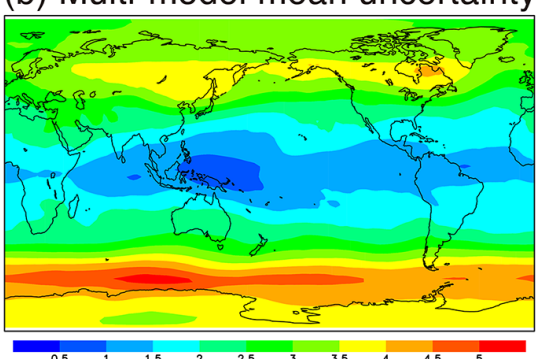

\section{(c) Multi-model analysis spread}

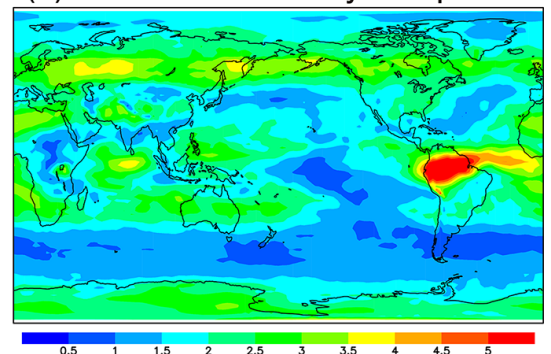

Figure 3. Spatial distributions of the multi-model mean values of (a) data assimilation analysis and (b) its uncertainty of annual mean ozone at $500 \mathrm{hPa}$ estimated using Eqs. (10) and (11), respectively. Panel (c) shows the standard deviation (i.e., multi-model spread) of the annual mean ozone analysis among the four models.

ground error covariance (e.g., Anderson, 2007) would be helpful to represent rapid changes in background errors in the individual models.

\section{Validation results}

\subsection{Ozone profiles}

\subsubsection{Comparisons against TES observations}

Figure 4 compares the annual zonal mean ozone from the lower to upper troposphere. In comparison with the TES measurements, at $750 \mathrm{hPa}$, all the control runs underestimate the mean ozone in the $\mathrm{NH}$ extratropics (by -4.4 to $-3.2 \mathrm{ppb}$ at $50^{\circ} \mathrm{N}$ ). At low latitudes, the mean ozone in MIROC-Chem- $\mathrm{H}$ is underestimated by -6 to -3 ppbv. In the SH extratropics, all the models reproduced the lower tropospheric ozone well. At $510 \mathrm{hPa}$, the zonal mean biases differ obviously among the models, with multi-model standard deviations of $1.5-4 \mathrm{ppv}$ in the $\mathrm{SH}, 3.2-5 \mathrm{ppb}$ in the tropics, and 3-6.6 ppb in the $\mathrm{NH}$. The biases are largely negative in GEOS-Chem $\left(-7.4 \mathrm{ppb}\right.$ at $\left.50^{\circ} \mathrm{N}\right)$ and AGCMCHASER ( $-5.3 \mathrm{ppb})$ in the NH extratropics; they are negative in MIROC-Chem-H ( -11 to $-6 \mathrm{ppb})$ at low latitudes and positive in the models except GEOS-Chem (3.2 to $5.1 \mathrm{ppb}$ at $50^{\circ} \mathrm{S}$ ) in the $\mathrm{SH}$ extratropics. Similarly, at $316 \mathrm{hPa}$, the biases obtained using the models are quite different, with large positive biases in MIROC-Chem and MIROC-Chem$\mathrm{H}$ in the extratropics of both hemispheres and large negative biases in MIROC-Chem-H in the tropics. Global total budgets and the production rates of tropospheric ozone can also differ, as suggested by multi-model intercomparison studies including GEOS-Chem and MIROC-Chem (Young et al., 2013, 2018; Hu et al., 2017). Sekiya et al. (2018) demonstrated that the ozone chemical productions are smaller in MIROC-Chem-H (4647 $\mathrm{Tg} \mathrm{yr}^{-1}$ for 2008) than in MIROCChem $\left(4809 \mathrm{Tg} \mathrm{yr}^{-1}\right)$.

After the data assimilation, all the models are in good agreement with the assimilated TES measurements as expected and demonstrate improved inter-model consistency.
In the $\mathrm{NH}$, the mean bias at $750 \mathrm{hPa}$ is reduced by $19 \%-73 \%$ to between -4.1 and $-0.4 \mathrm{ppb}\left(\right.$ at $50^{\circ} \mathrm{N}$ ) in all the models. At $510 \mathrm{hPa}$, the large negative model biases in GEOSChem and AGCM-CHASER are reduced by $76 \%$ and $92 \%$ at $50^{\circ} \mathrm{N}$, respectively. In the $\mathrm{SH}$, most of the large model biases in MIROC-Chem-H are removed throughout the troposphere.

Figure 5 shows the spatial distributions of the annual mean ozone concentrations at $510 \mathrm{hPa}$. The general structure of tropospheric ozone is well reproduced by the control runs, such as the low ozone concentrations over the tropical western Pacific and the high over the Middle East. The annual and zonal mean model biases are negative in the tropics in all the models, with large negative biases over the southern Atlantic; the bias is largest in MIROC-Chem-H (by up to 20 ppbv). After data assimilation, most of the model biases are removed for the globe. In the extratropical UTLS (figure not shown), the remaining mean bias was close to the mean observational error of the MLS ozone measurements in all the systems.

As shown in Fig. 6a, the multi-model standard deviation of the annual mean ozone at $510 \mathrm{hPa}$ obtained from the control runs, with applying the TES averaging kernels (AKs), is typically $5-10 \mathrm{ppb}$ from the tropics to the NH high latitudes and $1-5 \mathrm{ppb}$ in the SH extratropics. After the data assimilation, the standard deviation mostly becomes smaller than 5 and $3 \mathrm{ppb}$ for these regions, respectively, with reductions for the zonal mean values by $20 \%-60 \%$ in the $\mathrm{NH}$ and $30 \%-$ $85 \%$ in the SH. The results demonstrate that the assimilation framework provides highly consistent analysis fields among the systems, less dependent on the performance of the individual models. The obtained multi-model standard deviation after data assimilation (Fig. 6b) is comparable to the mean model errors relative to the TES measurements for most regions, which could thus be used as an estimate of the mean data assimilation uncertainty. The mean retrieval uncertainty of the TES measurements is typically between 5 and $10 \mathrm{ppb}$ in the $\mathrm{SH}$ and between 10 and $15 \mathrm{ppb}$ in the $\mathrm{NH}$, which is larger than the multi-model spread and the mean model errors after data assimilation. 

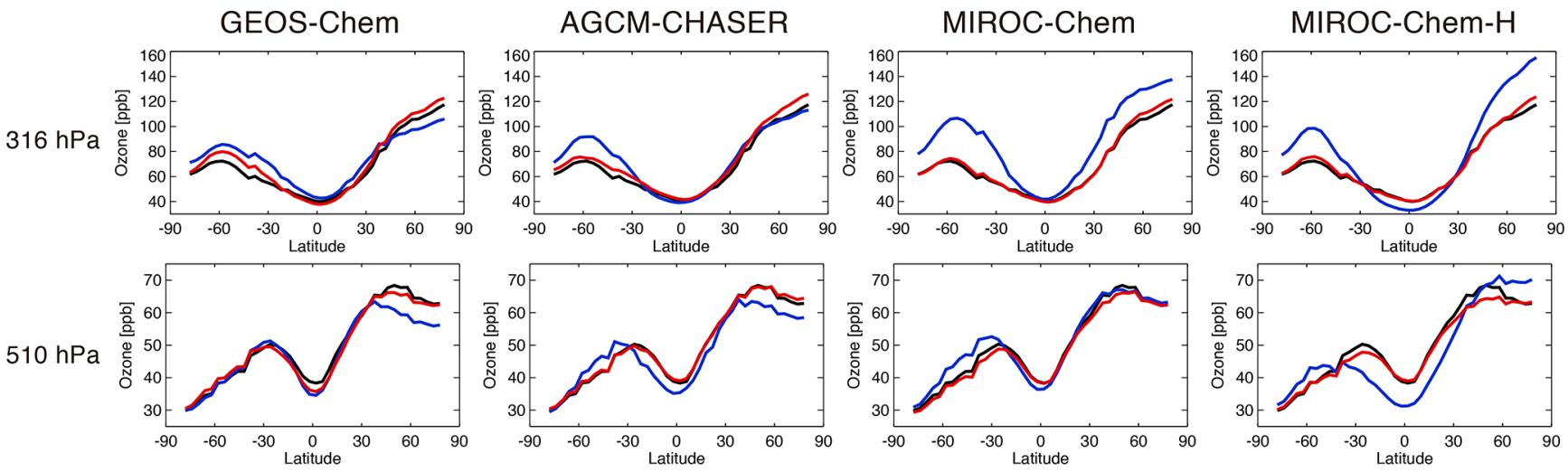

$750 \mathrm{hPa}$
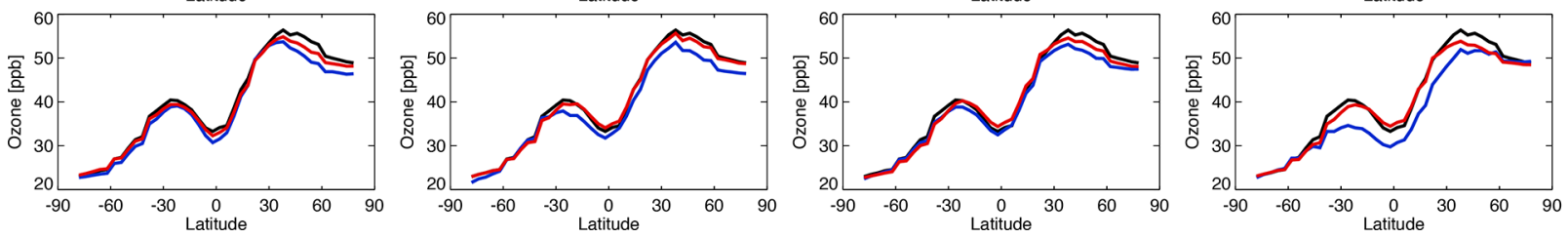

Figure 4. Comparisons of latitudinal distributions of annual and zonal mean ozone concentrations between the TES measurements (black line), control runs (blue line), and data assimilation analyses (red line) at $316 \mathrm{hPa}$ (upper panels), $510 \mathrm{hPa}$ (middle panels), and $750 \mathrm{hPa}$ (lower panels) in 2007 for the four systems.

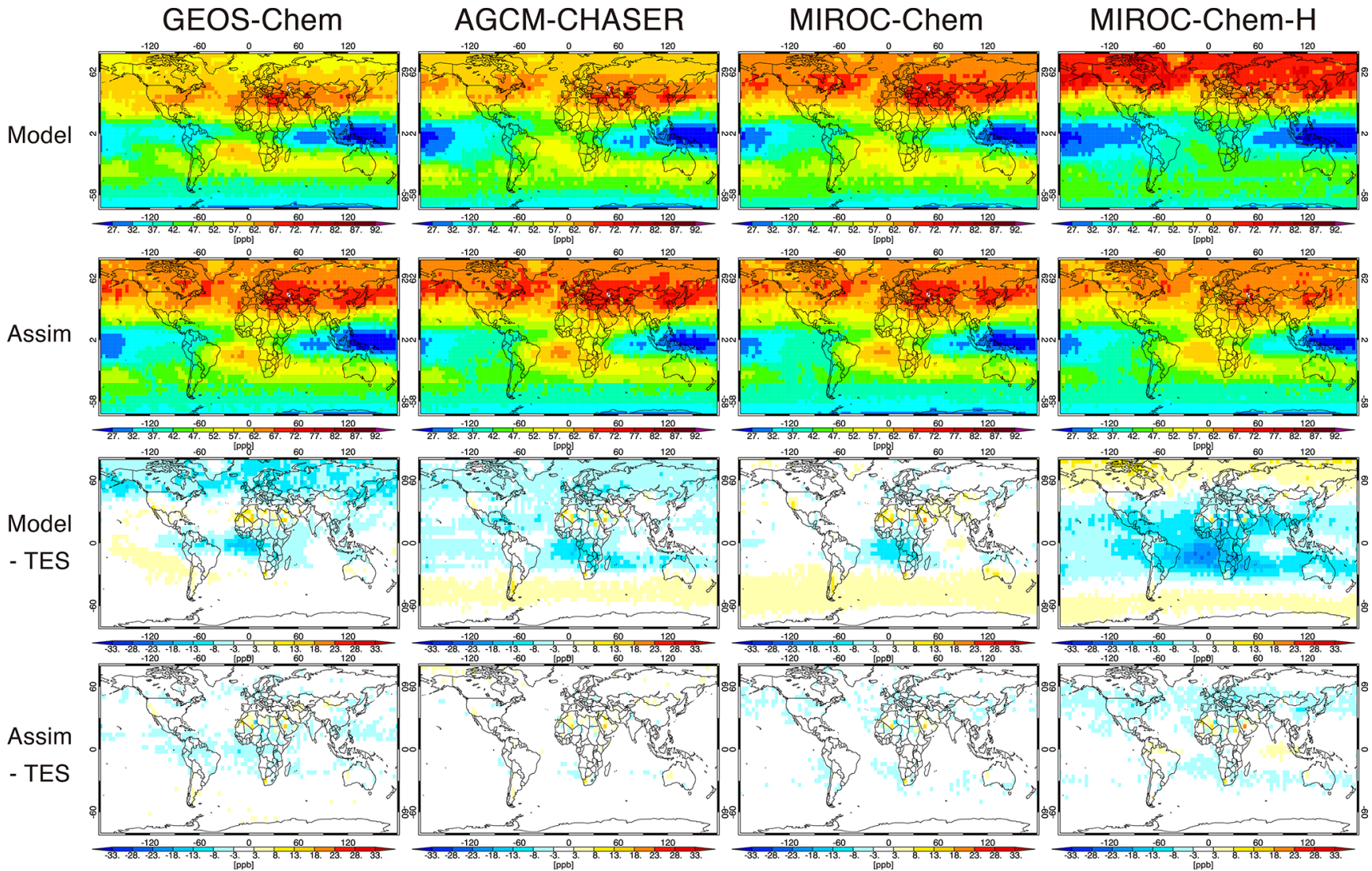

Figure 5. Comparisons of the spatial distributions of annual mean ozone concentrations between the TES measurements, control runs, and data assimilation analyses at $510 \mathrm{hPa}$ in 2007 . Unit is parts per billion by volume. 


\section{(a) Standard deveation among the models}

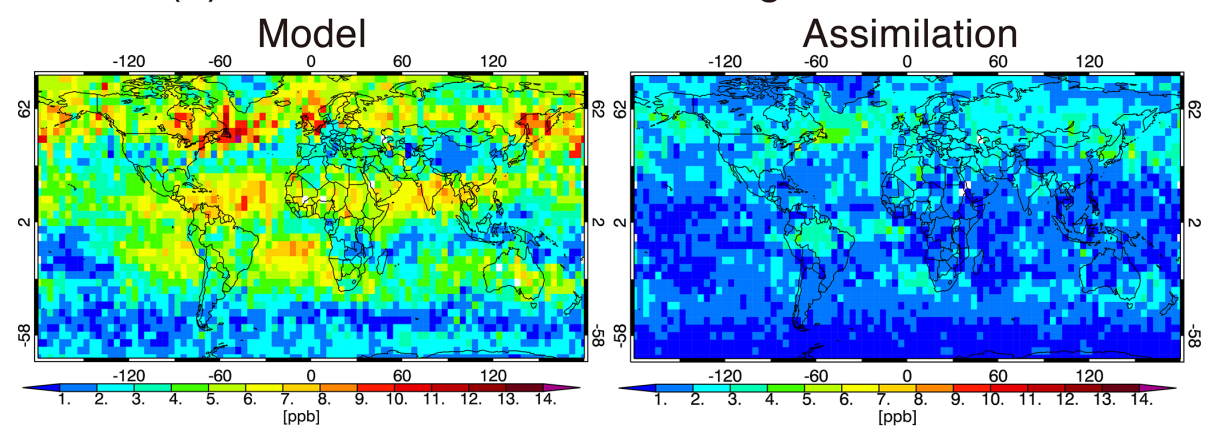

(b) Multi-model mean of analysis error against TES Model Assimilation

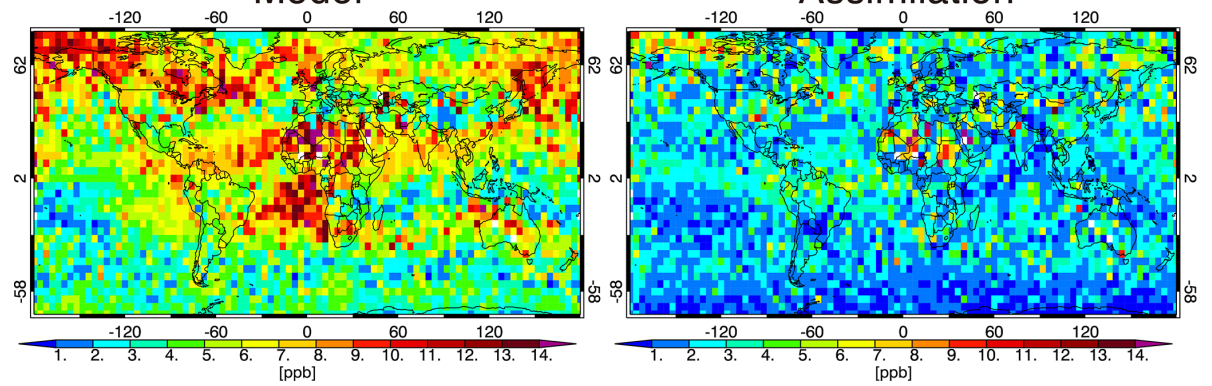

Figure 6. (a) Standard deviation among the models for the data assimilation analysis with application of the TES AK at $510 \mathrm{hPa}$. (b) Spatial distributions of multi-model mean (root mean square) values of error against TES measurements for the control runs (left) and data assimilation analyses (right) at $510 \mathrm{hPa}$.

\subsubsection{Comparisons against ozonesonde observations}

The current ozonesonde network is heterogeneously distributed globally with a sampling intervals of typically a week or longer. Model errors are also expected to vary greatly in time and space at various scales. As a consequence, the ozonesonde measurements suffer from significant sampling bias. Miyazaki and Bowman (2017) demonstrated that this ozonesonde sampling bias in the evaluated model bias for the seasonal mean concentration relative to global coverage reaches $80 \%$ for the global tropics. Nevertheless, the ozonesonde network provides a critical independent validation of the data assimilation products, while the data assimilation products are advantageous for evaluating actual regionally and seasonally representative model performance, which are required for model improvements. The synergy of the two provides a mechanism to characterize chemical reanalysis evaluation of chemistry-climate models (Miyazaki and Bowman, 2017).

Figure 7 compares the seasonal variation in ozone with the WOUDC global ozonesonde measurements from the lower troposphere to the lower stratosphere. In the lower troposphere $(850-500 \mathrm{hPa})$, all the models mostly underestimate ozone at $\mathrm{NH}$ midlatitudes and high latitudes, except for GEOS-Chem at NH midlatitudes in boreal summer. The negative model biases are large at $\mathrm{NH}$ high latitudes in boreal spring, with an annual mean bias of -4.7 to $-2.6 \mathrm{ppbv}$ (as summarized in Table 2) and large multi-model spreads. In the tropical lower troposphere, the models, other than MIROCChem-H, mostly overestimate ozone except in SeptemberOctober, whereas MIROC-Chem-H underestimates the annual mean ozone by $5.8 \mathrm{ppbv}$. In the $\mathrm{SH}$, all the models underestimate ozone throughout the year, with an annual mean bias of -6.2 to $-0.7 \mathrm{ppbv}$ at midlatitudes and -4.6 to $-2.2 \mathrm{ppbv}$ at high latitudes. The negative model biases in the SH have been found in most of the chemistry-climate models in the ACCMIP project (Bowman et al., 2013; Young et al., 2013).

In the middle and upper troposphere (500-200 hPa), the model biases reveal a large diversity at $\mathrm{NH}$ high latitudes. The enhanced multi-model spread in spring could be associated with the different representations of the stratospheretroposphere exchange (STE) processes. At NH midlatitudes, MIROC-Chem and MIROC-Chem-H overestimate annual mean ozone by 16.1 and $4.1 \mathrm{ppbv}$, respectively. In the tropics, the models, other than MIROC-Chem-H, overestimate ozone in boreal winter and underestimate it in boreal autumn, thus underestimating the seasonal amplitudes. In the $\mathrm{SH}$, all the models overestimate ozone with an annual mean bias of 2.8 $20.5 \mathrm{ppbv}$ at midlatitudes and 8.7-29.9 ppbv at high latitudes. In the upper troposphere and lower stratosphere (UTLS, 200 $80 \mathrm{hPa}$ ), the large multi-model spread can primarily be due to 

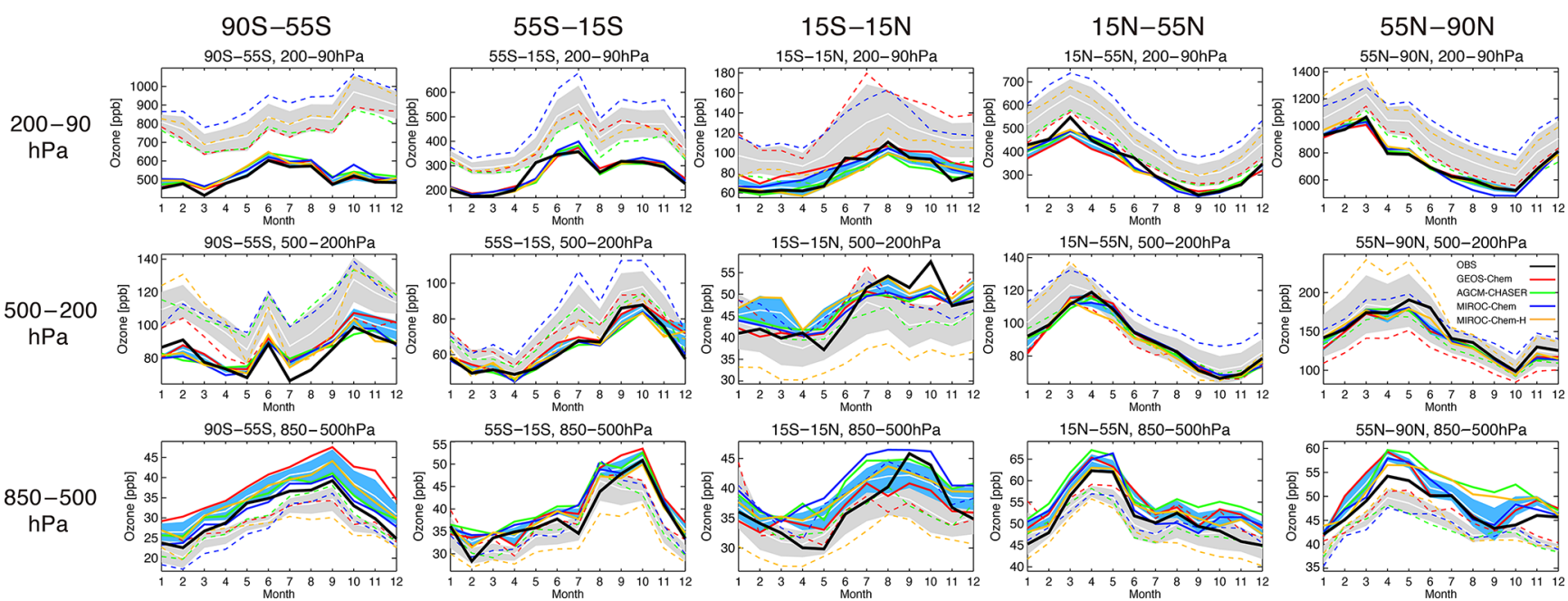

Figure 7. Comparison of seasonal variation in ozone concentration between the ozonesonde observations (black solid line), model simulations (colored dotted lines), and data assimilation (colored solid lines) averaged between $90-55^{\circ} \mathrm{S}, 55-15^{\circ} \mathrm{S}, 15^{\circ} \mathrm{S}-15^{\circ} \mathrm{N}, 15-55^{\circ} \mathrm{N}$, and $55-90^{\circ} \mathrm{N}$ for 2007 . From top to bottom, results are shown for concentrations averaged over 80-200, 200-500, and 500-850 hPa. The $\pm 1 \sigma$ deviation among the four models (i.e., model spread) is shown in gray for the control runs and in light blue for the data assimilation results.

Table 2. Annual mean bias of the mean ozone concentrations (ppbv) between the data assimilation or control run (in brackets) and the ozonesonde observations from the WOUDC network for 850-500 and 500-200 hPa in parts per billion for five latitudinal bands, SH high latitudes $\left(55-90^{\circ} \mathrm{S}\right)$, SH midlatitudes $\left(15-55^{\circ} \mathrm{S}\right)$, tropics $\left(15^{\circ} \mathrm{S}-15^{\circ} \mathrm{N}\right)$, NH midlatitudes $\left(15-55^{\circ} \mathrm{N}\right)$, and $\mathrm{NH}$ high latitudes $\left(55-90^{\circ} \mathrm{N}\right)$. The results are shown for individual models, multi-model mean (mean $\pm 1 \sigma)$, and integrated analysis $\left(\overline{\boldsymbol{x}_{\mathrm{m}}} \pm \overline{\boldsymbol{\sigma}_{\mathrm{m}}^{2}}\right.$ ).

\begin{tabular}{|c|c|c|c|c|c|c|}
\hline & & $90-55^{\circ} \mathrm{S}$ & $55-15^{\circ} \mathrm{S}$ & $15^{\circ} \mathrm{S}-15^{\circ} \mathrm{N}$ & $15-55^{\circ} \mathrm{N}$ & $55-90^{\circ} \mathrm{N}$ \\
\hline \multirow[t]{11}{*}{$850-500 \mathrm{hPa}$} & GEOS-Chem & $(-2.3)$ & $(-0.7)$ & $(-1.2)$ & (1.4) & $(-2.6)$ \\
\hline & & 7.4 & 2.2 & 0.0 & 3.4 & 2.3 \\
\hline & AGCM-CHASER & $(-2.2)$ & $(-2.0)$ & $(-1.0)$ & $(-2.0)$ & $(-4.7)$ \\
\hline & & 2.4 & 2.7 & 3.6 & 5.2 & 4.3 \\
\hline & MIROC-Chem & $(-4.6)$ & $(-1.5)$ & (2.2) & $(-1.3)$ & $(-4.7)$ \\
\hline & & 0.9 & 1.9 & 4.6 & 2.6 & 1.7 \\
\hline & MIROC-Chem-H & $(-4.5)$ & $(-6.2)$ & $(-5.8)$ & $(-5.1)$ & $(-3.6)$ \\
\hline & & 3.6 & 1.0 & 2.3 & 1.9 & 3.2 \\
\hline & Multi-model mean & $(-3.4 \pm 2.0)$ & $(-2.5 \pm 2.5)$ & $(-1.4 \pm 3.1)$ & $(1.8 \pm 2.7)$ & $(-3.9 \pm 1.4)$ \\
\hline & & $3.6 \pm 2.5$ & $1.9 \pm 1.1$ & $2.7 \pm 1.8$ & $3.3 \pm 1.6$ & $2.9 \pm 1.7$ \\
\hline & Integrated analysis & $4.0 \pm 3.7$ & $1.6 \pm 2.6$ & $1.6 \pm 1.1$ & $2.8 \pm 2.7$ & $2.2 \pm 3.0$ \\
\hline \multirow[t]{11}{*}{$500-200 \mathrm{hPa}$} & GEOS-Chem & (8.7) & $(10.5)$ & (1.3) & $(-4.0)$ & $(-29.9)$ \\
\hline & & 4.7 & 3.0 & -0.3 & -0.9 & -9.2 \\
\hline & AGCM-CHASER & (29.9) & (8.6) & $(-3.2)$ & $(0.3)$ & $(-13.5)$ \\
\hline & & 1.6 & -1.9 & 0.3 & -1.9 & -6.2 \\
\hline & MIROC-Chem & (28.7) & (20.5) & $(0.4)$ & $(16.1)$ & (12.9) \\
\hline & & 1.0 & -1.3 & -0.2 & -0.2 & -6.1 \\
\hline & MIROC-Chem-H & $(24.8)$ & (2.8) & $(-11.8)$ & (4.1) & (29.7) \\
\hline & & 1.4 & 0.3 & 3.0 & -2.5 & -5.5 \\
\hline & Multi-model mean & $(23.0 \pm 10.7)$ & $(10.6 \pm 7.2)$ & $(-3.3 \pm 5.3)$ & $(4.1 \pm 8.6)$ & $(-0.2 \pm 24.0)$ \\
\hline & & $2.2 \pm 2.6$ & $0.3 \pm 2.4$ & $0.7 \pm 1.5$ & $-1.4 \pm 2.1$ & $-6.7 \pm 3.0$ \\
\hline & Integrated analysis & $3.4 \pm 6.7$ & $1.1 \pm 4.0$ & $1.7 \pm 1.7$ & $-1.5 \pm 4.8$ & $-8.4 \pm 8.0$ \\
\hline
\end{tabular}


the different representations of the stratospheric chemistry, STE, and convective transport in the tropics. Large positive model biases exist in MIROC-Chem and MIROC-Chem-H in the NH extratropics, MIROC-Chem and GEOS-Chem in the tropics, and all the models in the SH extratropics.

Because of data assimilation, the large negative model biases in the lower troposphere are largely reduced in the $\mathrm{NH}$ lower troposphere in boreal spring. Nevertheless, the annual mean concentrations in all the systems become too high in the NH lower troposphere, with an annual mean bias from 1.7 to $4.3 \mathrm{ppb}$ at high latitudes and from 1.9 to $5.2 \mathrm{ppb}$ at midlatitudes, while the underestimation in the seasonal amplitude is reduced in all the models. The weak sensitivity of the assimilated measurements and the changes made to the precursor emissions (see Sect. 6) could be responsible for the overestimations. In the tropics, the negative model bias in boreal autumn is reduced via data assimilation, thus enhancing the seasonal amplitudes in the whole system, whereas the analyzed concentrations become too high in AGCM-CHASER and MIROC-Chem-H in boreal summer. In the SH, the data assimilation reduced the negative model biases of MIROCChem- $\mathrm{H}$ at midlatitudes (from $-6.2 \mathrm{ppb}$ to $1.0 \mathrm{ppbv}$ annual mean bias) and MIROC-Chem and MIROC-Chem-H at high latitudes (from -4.6 to $-4.5 \mathrm{ppbv}$ to 0.9 to $3.6 \mathrm{ppbv}$ ). The observed rapid increases during August-October at SH midlatitudes are reproduced well after data assimilation in all the systems. At high latitudes of both hemispheres, some of the models exhibit too high concentrations after data assimilation. An inaccurate balance between the midlatitudes and high latitudes in model transport and the lack of direct observational constraints could limit the effectiveness of data assimilation at high latitudes. Conducting observational impact analysis would help suggesting a framework to obtain a better global tropospheric ozone analysis.

Both the agreements against the observation and the multimodel consistency are greatly improved via data assimilation from the middle troposphere to the lower stratosphere for the globe, with annual mean bias reductions from -29.9 to 29.7 ppbv to -9.2 to -6.2 ppbv (i.e., by $53 \%-81 \%$ ) at $\mathrm{NH}$ high latitudes, from -4.0 to $16.1 \mathrm{ppbv}$ to -2.5 to $-0.2 \mathrm{ppbv}$ (by 39\%-76\% except for AGCM-CHASER) at NH midlatitudes, from -11.8 to $1.3 \mathrm{ppbv}$ to -0.3 to $3.0 \mathrm{ppbv}$ (by $50 \%-91 \%$ ) in the tropics, from 2.8 to $20.5 \mathrm{ppbv}$ to -1.9 to $3.0 \mathrm{ppbv}$ (by $71 \%-94 \%$ ) at $\mathrm{SH}$ midlatitudes, and from 8.7 to $29.9 \mathrm{ppbv}$ to 1.0 to $4.7 \mathrm{ppbv}$ (by $46 \%-97 \%$ ) at SH high latitudes for 500-200 hPa. The estimated RMSEs (2.5-9.0 ppbv at the SH high latitudes, $3.0-4.3 \mathrm{ppbv}$ at the $\mathrm{SH}$ midlatitudes, $2.5-5.3 \mathrm{ppbv}$ in the tropics, $0.7-3.8 \mathrm{ppbv}$ at the $\mathrm{NH}$ midlatitudes, and 2.6-6.3 ppbv at the $\mathrm{NH}$ high latitudes for $850-500 \mathrm{hPa}$ ) are significantly smaller than the analysis uncertainty (Fig. 2b) in AGCM-CHASER and MIROC-Chem $(10-16 \mathrm{ppb})$ and are comparable to that in GEOS-Chem and MIROC-Chem-H. These results suggest overestimated analysis uncertainty in AGCM-CHASER and MIROC-Chem.
The uncertainty-weighted multi-model integrated fields (Eq. 10) show a closer agreement with the ozonesonde observations than the (non-weighted) multi-model means for the lower troposphere, except at SH high latitudes, as summarized in Table 2. The annual and regional mean bias is smaller by $15 \%-40 \%$ in the uncertainty-weighted fields from the SH midlatitudes to $\mathrm{NH}$ high latitudes, reflecting the larger analysis biases and larger analysis uncertainties in AGCM-CHASER and MIROC-Chem for most cases. The closer agreements suggest improved estimates of ozone in the multi-model integrated fields. In the extratropical middle and upper troposphere, GEOS-Chem revealed the smallest analysis uncertainty and largest analysis errors against the ozonesonde observations and dominated the uncertainty-weighted integrated fields, likely associated with the less complex stratospheric chemistry (i.e., smaller spread growth). This model dominated the uncertainty-weighted integrated fields and led to a degradation of the integrated fields. These results suggest a requirement to optimize the analysis uncertainty in some of the systems, considering the fundamental differences in the model framework such as model complexity and resolution, as discussed above. Increasing the number of models would also help to provide more robust statistics.

Figure 8 shows that the data assimilation introduces similar changes to the seasonal amplitudes of ozone (defined as the difference between the maximum and minimum concentrations) in the four models, such as the increases in the lower and middle troposphere and the decreases in the extratropical upper troposphere and lower stratosphere. Between 850 and $500 \mathrm{hPa}$, the control runs underestimated the seasonal amplitude in the extratropics of both hemispheres compared with the ozonesonde measurements (e.g., by up to $-29 \%$ at the NH midlatitudes). The model underestimates are largely reduced by data assimilation in all the models. Between 500 and $200 \mathrm{hPa}$, data assimilation mostly removed the negative bias in GEOS-Chem $(-8 \%)$ and AGCM-CHASER $(-5 \%)$ and the positive bias of the seasonal amplitude in MIROCChem-H (47\%) against the ozonesonde measurements in the $\mathrm{NH}$ and the large positive bias in MIROC-Chem (22\%) in the SH. Between 200 and $90 \mathrm{hPa}$, positive biases are reduced in all the models globally. In the $\mathrm{NH}$, the range in the bias from $13 \%$ to $40 \%$ is reduced to a range from $-12 \%$ to $3 \%$, with the largest reduction observed in MIROC-Chem$\mathrm{H}$ (from $40 \%$ to $2 \%$ ). In the tropics, the range in the bias is reduced from $20 \%$ to $148 \%$ to $10 \%$ to $25 \%$, with the largest reduction observed in GEOS-Chem (from $148 \%$ to $10 \%$ ). In the $\mathrm{SH}$, the range in bias is reduced from $15 \%$ to $92 \%$ to $-1 \%$ to $19 \%$, with the largest reduction observed in MIROC-Chem (from $92 \%$ to $10 \%$ ).

\subsection{Tropospheric $\mathrm{NO}_{2}$ columns}

For the comparisons with the $\mathrm{OMI} \mathrm{NO}_{2}$ retrievals, the $\mathrm{OMI} \mathrm{NO}_{2}$ AKs from the DOMINO2 products were applied 

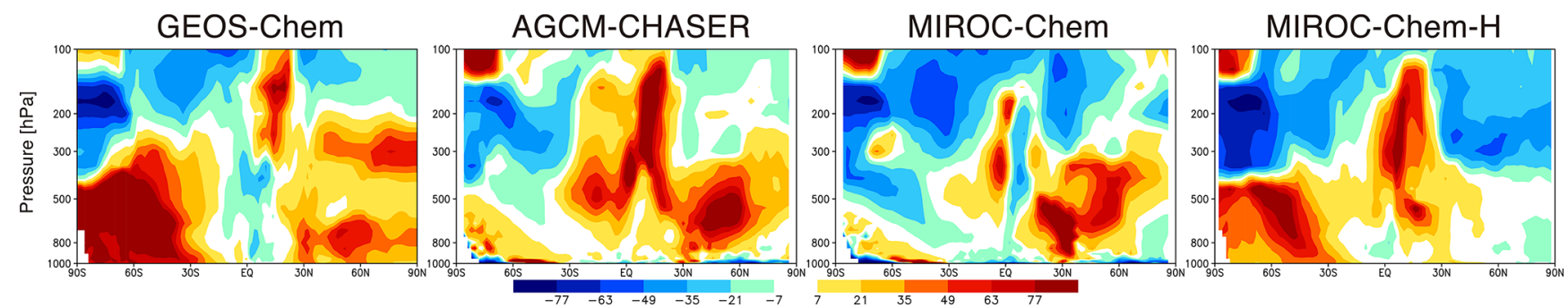

Figure 8. Latitude-pressure cross section of changes in seasonal amplitude of zonal mean ozone concentrations (ppbv) due to data assimilation (data assimilation minus control runs), as estimated from the maximum minus minimum values of the monthly mean ozone concentrations.

to GEOS-Chem, AGCM-CHASER, and MIROC-Chem, whereas those from QA4ECV were applied to MIROCChem- $\mathrm{H}$, corresponding to the assimilated measurements for each system. In Fig. 9, the converted tropospheric $\mathrm{NO}_{2}$ columns from the control and assimilation runs are then compared with the assimilated OMI retrievals: the DOMINO2 product for GEOS-Chem, AGCM-CHASER, and MIROCChem (black line vs. blue, red, and green lines in Fig. 9) and the QA4ECV product for MIROC-Chem-H (gray line vs. yellow line).

As summarized in Table 3, the model bias in tropospheric $\mathrm{NO}_{2}$ column differed largely among the models because of the different model configurations (e.g., chemical lifetime of $\mathrm{NO}_{x}$ ) and input data (e.g., $\mathrm{NO}_{x}$ emissions). The models, other than GEOS-Chem, mostly underestimate tropospheric $\mathrm{NO}_{2}$ columns over polluted areas, same as in most other CTMs (van Noije et al., 2006), with an annual mean bias ranging from -2.07 to $-0.37 \times 10^{15}$ molecules $\mathrm{cm}^{-2}$ over eastern China, -0.51 to $-0.26 \times 10^{15}$ molecules $\mathrm{cm}^{-2}$ over the United States, and -0.82 to $-0.32 \times 10^{15}$ molecules $\mathrm{cm}^{-2}$ over Europe. GEOSChem overestimates tropospheric $\mathrm{NO}_{2}$ columns over some parts of China (with annual and regional mean bias of $0.13 \times 10^{15}$ molecules $\mathrm{cm}^{-2}$ over eastern China), Europe $\left(0.60 \times 10^{15}\right.$ molecules $\left.\mathrm{cm}^{-2}\right)$, and the United States $(0.29 \times$ $10^{15}$ molecules $\mathrm{cm}^{-2}$ ). The model biases in tropospheric $\mathrm{NO}_{2}$ columns can vary with changing the model configurations. For instance, important $\mathrm{NO}_{x}$ sink pathways determining $\mathrm{NO}_{2}$ simulation uncertainties include the $\mathrm{NO}_{2}+\mathrm{OH}$ reaction and the formation of $\mathrm{HNO}_{3}$ in the $\mathrm{NO}+\mathrm{HO}_{2}$ reaction (Lin et al., 2012; Stavrakou et al., 2013), which are represented differently in the models. The columns simulated from MIROC-Chem-H are higher than those from MIROCChem, with the same AKs applied over some parts of the polluted areas such as eastern China; these differences are attributable to the increased model resolution, which suppresses the dilution effects (Sekiya et al., 2018).

Figure 9 compares the seasonal variation in tropospheric $\mathrm{NO}_{2}$. The models, other than GEOS-Chem, underestimate tropospheric $\mathrm{NO}_{2}$ columns throughout the year over eastern China, the United States, and Europe, with the largest nega- tive biases in boreal winter. Over India, GEOS-Chem reproduced the peak observed in April and the rapid decrease from May to July, whereas the other models underpredicted the seasonal variations. The retrieved tropospheric $\mathrm{NO}_{2}$ columns are generally lower in the QA4ECV products than in the DOMINO-2 products over most of major polluted areas. The different retrieved columns can largely be attributed to differences in the a priori profiles and do not directly influence the model-observation differences after applying the AKs (Boersma et al., 2018a). Over Southeast Asia, the models, except for GEOS-Chem, underestimate the peak observed in March, which is associated with biomass burning, by $11 \%$ $55 \%$, whereas the models overestimate the peak over South America in September by $18 \%-31 \%$.

Over northern, central, and southern Africa, all the models underestimate tropospheric $\mathrm{NO}_{2}$ columns throughout the year, with an annual mean bias ranging from -0.32 to $-0.11 \times 10^{15},-0.39$ to $-0.11 \times 10^{15}$, and -1.05 to $-0.89 \times$ $10^{15}$ molecules $\mathrm{cm}^{-2}$, respectively. Over southern Africa, the negative model bias is maximized in austral winter (by $43 \%$ $63 \%$ ), with MIROC-Chem-H giving the smallest bias. The higher spatial resolution of MIROC-Chem-H is considered essential in resolving individual polluted areas in the Highveld region and in accurately simulating the nonlinear effects on $\mathrm{NO}_{2}$ loss rate.

The tropospheric $\mathrm{NO}_{2}$ column retrievals from OMI and SCIAMACHY were assimilated to optimize $\mathrm{NO}_{x}$ emissions, and the assimilation of non- $\mathrm{NO}_{2}$ measurements influence the chemical lifetime of $\mathrm{NO}_{x}$ through changes made to $\mathrm{OH}$. Data assimilation reduced the negative model biases in the models, other than GEOS-Chem, over eastern China (from -2.07$0.37 \times 10^{15}$ to $-0.69-0.39 \times 10^{15}$ molecules $\mathrm{cm}^{-2}$ ), the United States (from -0.51 to $-0.26 \times 10^{15}$ molecules $\mathrm{cm}^{-2}$ to -0.18 to $-0.13 \times 10^{15}$ molecules $\mathrm{cm}^{-2}$ ), and western $\mathrm{Eu}$ rope (from -0.82 to $-0.32 \times 10^{15}$ molecules $\mathrm{cm}^{-2}$ to -0.41 to $-0.24 \times 10^{15}$ molecules $\mathrm{cm}^{-2}$ ). The annual mean positive model biases in GEOS-Chem are reduced by $72 \%$ over the United States and by $65 \%$ over Europe. The temporal correlations are also improved in all the models.

Over India, the data assimilation increases tropospheric $\mathrm{NO}_{2}$ columns in boreal winter-spring and reproduced the 


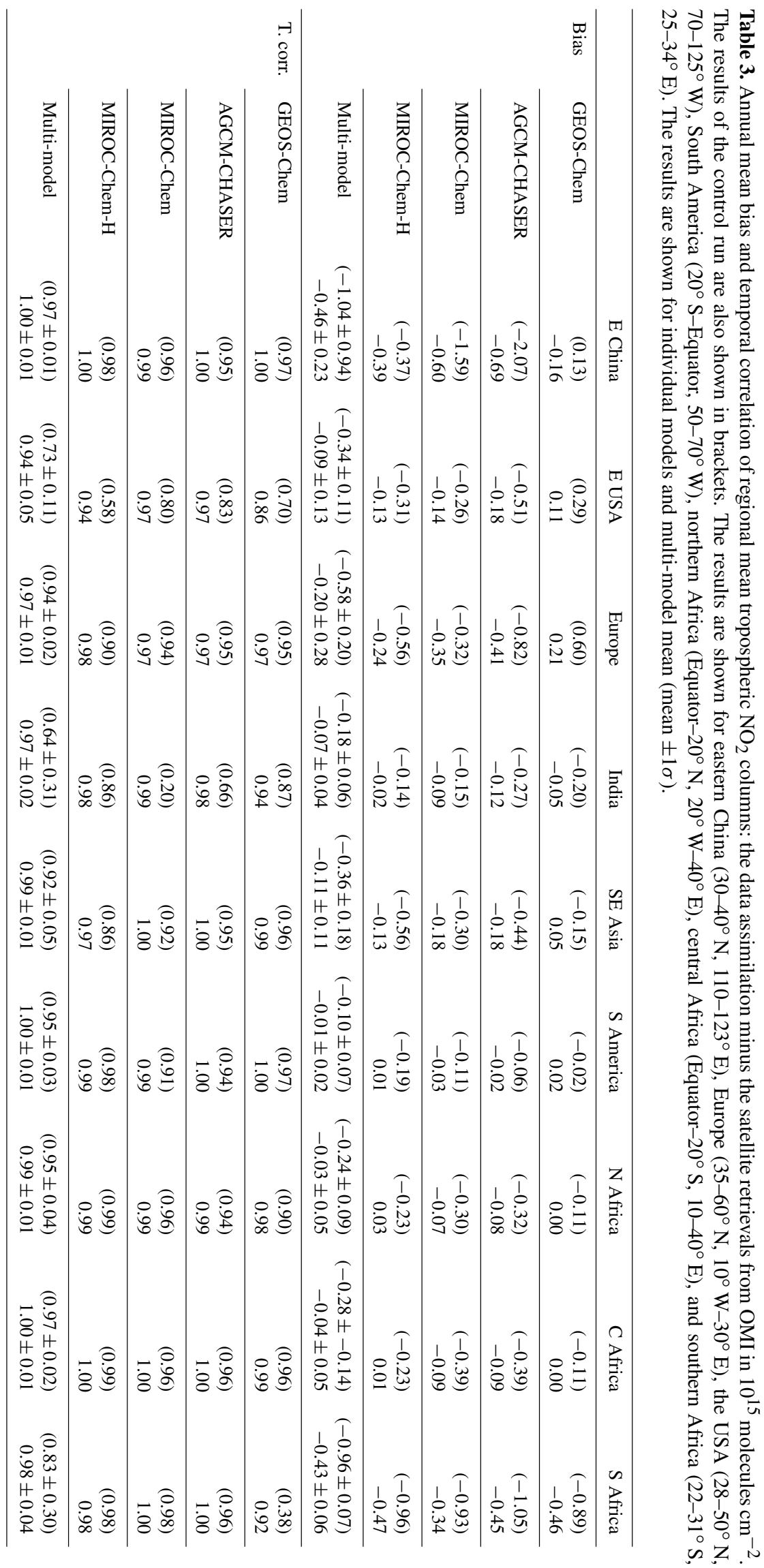



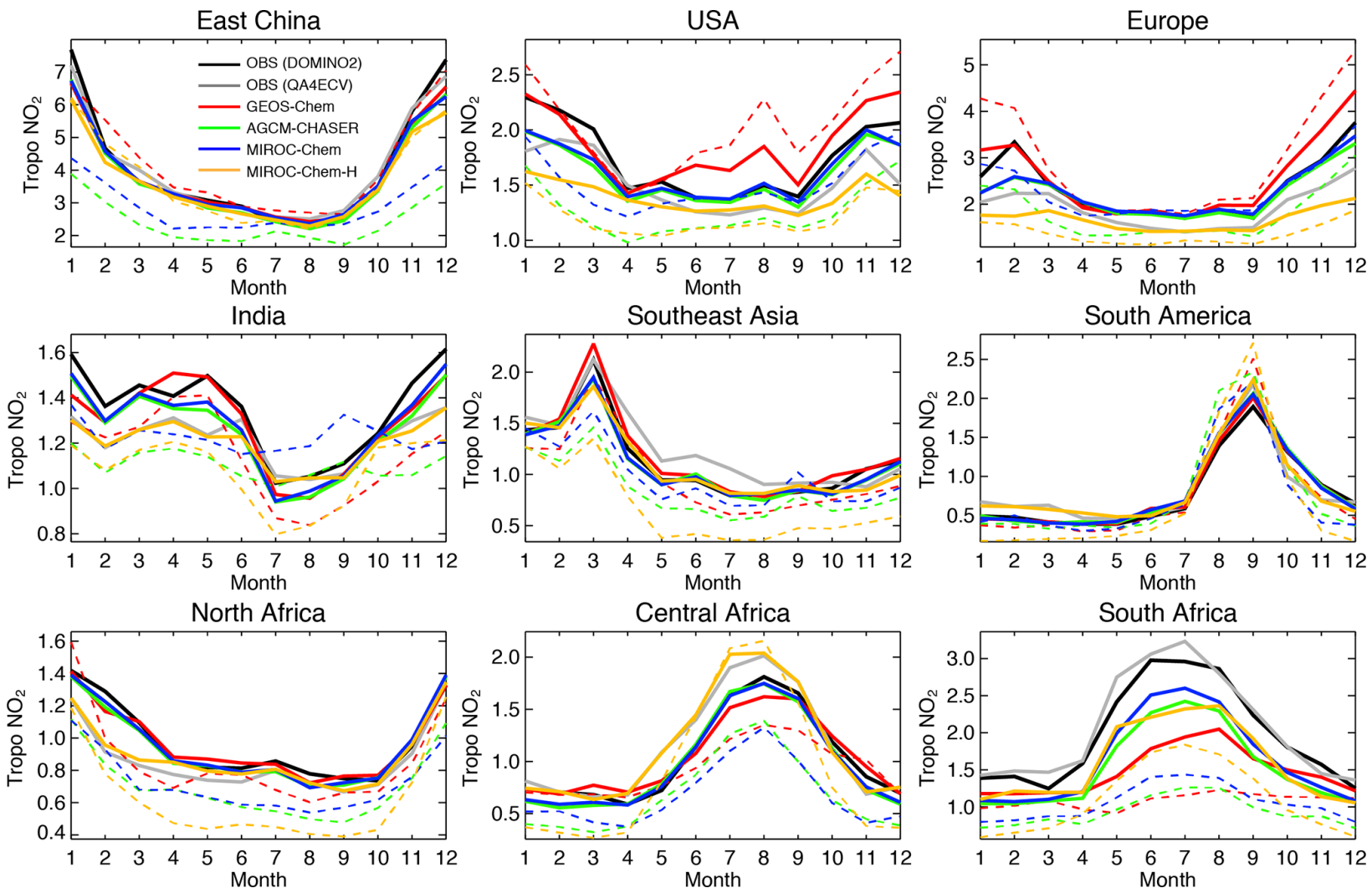

Figure 9. Time series of regional monthly mean tropospheric $\mathrm{NO}_{2}$ columns $\left(10^{15}\right.$ molecules $\left.\mathrm{cm}^{-2}\right)$ from the satellite retrievals (black for OMI QA4ECV and gray for OMI DOMINO v2), control runs (colored dotted lines), and data assimilation analysis (colored solid lines) for 2007. The model simulation and data assimilation results are obtained at the local overpass time of the retrievals by applying the averaging kernel of OMI DOMINO v2 for GEOS-Chem, CHASER, and MIROC, and of OMI QA4ECV for MIROC-H, respectively, corresponding to the assimilated measurements. The multi-model standard deviations are not shown because of the use of different assimilated measurements in the individual systems.

observed local maximum in May and minimum in July in all the models. Consequently, the seasonal amplitude is enhanced, leading to improved temporal correlations (from $0.20-0.87$ to $0.94-0.99)$ while reducing the annual mean bias (from -0.27 to $-0.14 \times 10^{15}$ molecules $\mathrm{cm}^{-2}$ to 0.12 to $-0.02 \times 10^{15}$ molecules $\mathrm{cm}^{-2}$, by $40 \%-86 \%$ ). Over Southeast Asia, the persistent model negative biases are reduced (from -0.56 to $-0.15 \times 10^{15}$ molecules $\mathrm{cm}^{-2}$ to -0.18 to $0.05 \times 10^{15}$ molecules $\mathrm{cm}^{-2}$, by $40 \%-77 \%$ ) with improved temporal correlations (from $0.86-0.96$ to $0.97-1.00$ ) in all the models. Over South America, data assimilation decreases tropospheric $\mathrm{NO}_{2}$ columns by up to $25 \%$ in the biomass burning season in all the models, while the negative model biases in the biomass burning off-season are mostly removed. The OMI $\mathrm{NO}_{2}$ super-observation error is typically about $20 \%-50 \%$ of the tropospheric $\mathrm{NO}_{2}$ columns over polluted areas, which are comparable to or larger than the analysis error.

Over Africa, the annual mean negative model biases are reduced from -0.32 to $-0.11 \times 10^{15}$ molecules $\mathrm{cm}^{-2}$ to -0.08 to $0.03 \times 10^{15}$ molecules $\mathrm{cm}^{-2}$ (by $75 \%-100 \%$ ) over north- ern Africa, from -0.20 to $-0.02 \times 10^{15}$ molecules $\mathrm{cm}^{-2}$ to -0.03 to $0.02 \times 10^{15}$ molecules $\mathrm{cm}^{-2}$ (by $77 \%-$ $100 \%)$ over central Africa, and from -1.05 to $-0.89 \times 10^{15}$ molecules $\mathrm{cm}^{-2}$ to -0.47 to $0.45 \times 10^{15}$ molecules $\mathrm{cm}^{-2}$ (by $48 \%-63 \%$ ) over southern Africa. The bias reductions over central and southern Africa are large in austral winter-spring. Some of the model negative biases $(14 \%-50 \%$, with a standard deviation of $12 \%)$ remain over southern Africa in austral winter. The inadequate corrections of tropospheric $\mathrm{NO}_{2}$ columns could be attributed to the insufficient model resolution, short chemical lifetime of $\mathrm{NO}_{x}$, and biases in the simulated chemical equilibrium state. Spatial resolutions higher than the MIROC-Chem-H resolution $\left(1.1^{\circ} \times 1.1^{\circ}\right)$ would be useful to represent emissions and pollutants over individual sources.

\section{$4.3 \mathrm{CO}$}

Figure 10 compares the latitudinal variations in surface $\mathrm{CO}$ concentration against the WDCGG observations from 59 sta- 
tions. All the models underestimate the zonal and annual mean $\mathrm{CO}$ concentrations by $25-70 \mathrm{ppb}$ in the $\mathrm{NH}$ extratropics and by $10-60 \mathrm{ppb}$ in the tropics (expect for MIROCChem and MIROC-Chem-H), as in most other CTMs (Shindell et al., 2006). In the SH extratropics, GEOS-Chem underestimates surface $\mathrm{CO}$ by $8-15 \mathrm{ppb}$, whereas MIROC-Chem and MIROC-Chem-H overestimate it by 5-20 ppb. Data assimilation reduced most of the model biases for the globe, except for the remaining negative model biases in the tropics in GEOS-Chem and AGCM-CHASER. The different analysis results of $\mathrm{CO}$ at high latitudes could mainly reflect differences in atmospheric transport from midlatitudes among the model. The effect of data assimilation is limited because of the lack of measurements at high latitudes.

Figure 11 compares the seasonal variation in surface $\mathrm{CO}$ for the selected stations. All the models captured the observed seasonal variations well, except for relatively low temporal correlations (Table 4) over Barbados $(r=0.58$ $0.85)$ and Ascension Island $(r=0.72-0.94)$. In the NH extratropics, for most stations, all the models reveal too low $\mathrm{CO}$ throughout the year, with larger biases in boreal winter than in summer in the models. The summertime negative biases are largest in GEOS-Chem. In the tropics, the rapid increases in $\mathrm{CO}$ associated with biomass burning, e.g., in October over Barbados and in September over Ascension Island, are underestimated by all the models. In the SH extratropics, a large multi-model spread in the simulated $\mathrm{CO}$ exists in austral winter-spring, likely due to the different representation of poleward transport.

The reductions in the model negative bias in the $\mathrm{NH}$ owing to data assimilation can be found throughout the year, with annual mean bias reductions of $65 \%-76 \%$ for Utqiagivik, $41 \%-74 \%$ for Cold Bay, and $57 \%-94 \%$ for Iceland, with MIROC-Chem-H exhibiting smaller reductions. The insufficient corrections in MIROC-Chem-H suggest the need to optimize the settings for the assimilation of total column retrievals for the higher-resolution system. Further efforts are clearly needed for improving the $\mathrm{CO}$ analyses in MIROC$\mathrm{Chem}-\mathrm{H}$. The negative model biases are also reduced at $\mathrm{NH}$ low latitudes, i.e., by $68 \%-94 \%$ for Bermuda, $48 \%-97 \%$ for Midway, and $22 \%-63 \%$ for Mauna Loa. Over Barbados, data assimilation corrects the timing of the maximum (in March) and minimum (in August) concentrations and improved the temporal correlation from $0.58-0.85$ to $0.75-0.85$ in all the models, whereas the observed peak in October is not represented by all the systems. In the $\mathrm{SH}$, the multimodel spread is greatly reduced by data assimilation, while showing improved agreements with the observations except for excessively high concentrations over Ascension Island in June-July in MIROC-Chem-H.

The vertical gradients of $\mathrm{CO}$ differ largely among the models (Fig. 12a), with the largest decrease in the annual tropical mean concentrations with height in GEOS-Chem from the lower to upper troposphere. The sharp decrease could be associated with weaker deep convection. In addition, the larger $\mathrm{OH}$ concentrations in GEOS-Chem (Fig. 12b) suggest stronger chemical destruction in the middle and upper troposphere. In models other than GEOS-Chem, the tropical mean concentrations of $\mathrm{CO}$ show a clear maximum around $200 \mathrm{hPa}$. After data assimilation, the CO gradient became even larger in GEOS-Chem, in association with a large increase in $\mathrm{OH}$ in the upper troposphere. In other models, the data assimilation introduced sharper decreases in $\mathrm{CO}$ from about 850 to $600 \mathrm{hPa}$, as a consequence of the enhanced chemical destructions (i.e., the increased $\mathrm{OH}$ ) at those levels. The increase in $\mathrm{OH}$ by data assimilation is larger in MIROCChem-H than in other models in the middle and upper troposphere, which have influenced the vertical profile of $\mathrm{CO}$ substantially.

In summary, the tropical annual mean $\mathrm{CO}$ gradient between the surface and $400 \mathrm{hPa}$ is decreased by $1 \%-7 \%$, whereas the annual mean $\mathrm{OH}$ concentration is increased by $7 \%-20 \%$ in the lower troposphere and $15 \%-120 \%$ in the middle and upper troposphere in all the models. Therefore, the multi-constituent data assimilation provides strong constraints on the vertical profiles of $\mathrm{CO}$ and other species mainly through substantial changes in $\mathrm{OH}$. Changes in $\mathrm{OH}$ are further discussed in Sect. 4.4. It is also suggested that, even after the multi-constituent data assimilation, the representations of the vertical profiles can differ among the models, reflecting both the different model configurations, e.g., in terms of deep convection and chemical reaction rates, and the lack of direct observational constraints on the vertical profiles.

\section{$4.4 \mathrm{OH}$}

Because of the simultaneous assimilation of multiple-species data, the global distribution of various species, including $\mathrm{OH}$, is modified considerably in the assimilation systems. The concentration of $\mathrm{OH}$ is directly related to the concentrations of species determining the primary production (ozone and $\mathrm{H}_{2} \mathrm{O}$ ), removal $\left(\mathrm{CO}\right.$ and $\left.\mathrm{CH}_{4}\right)$, and regeneration of $\mathrm{OH}$ $\left(\mathrm{NO}_{x}\right)$. Figure 13 compares the global distributions of annual and tropospheric mean $\mathrm{OH}$ concentrations (averaged between the surface and $300 \mathrm{hPa}$ ). The multi-model comparisons reveal common characteristics such as higher concentrations in the tropics than in the extratropics and enhanced concentrations over central Africa, Indian Ocean, south and Southeast Asia, and tropical Atlantic. As summarized in Table 5, the simulated $\mathrm{OH}$ is higher in GEOS-Chem and AGCM-CHASER than other models over most of the major polluted areas such as eastern China, India, western Europe, India, Southeast Asia, and Africa. The multi-model standard deviation of $\mathrm{OH}$ is large over central Africa, northern India, and around the Himalayas, Malay peninsula, western United States, Brazil, and over the southern tropics such as the eastern Pacific and northern Australia (right-top figure in Fig. 13). The zonal mean $\mathrm{OH}$ from the tropics to subtropics is lower in MIROC-Chem-H than in other models by approx- 


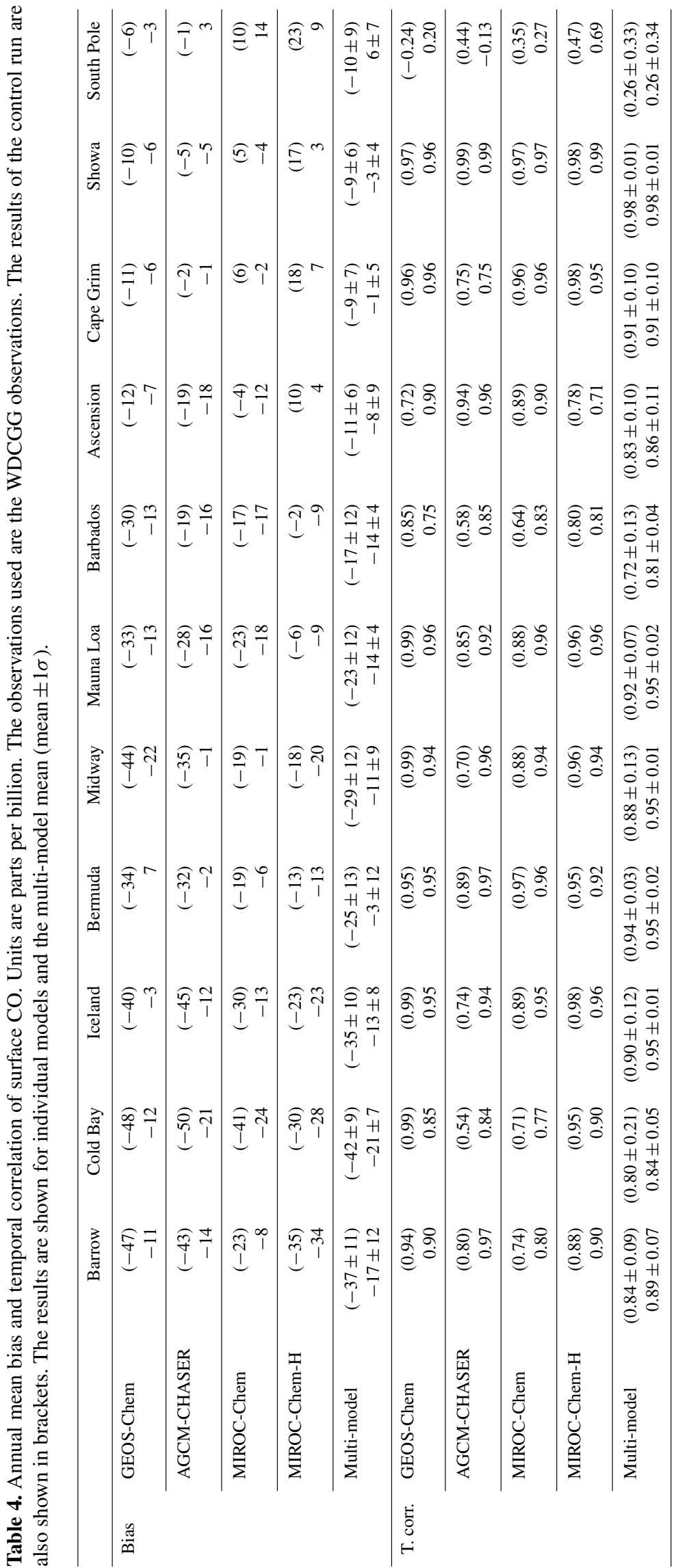



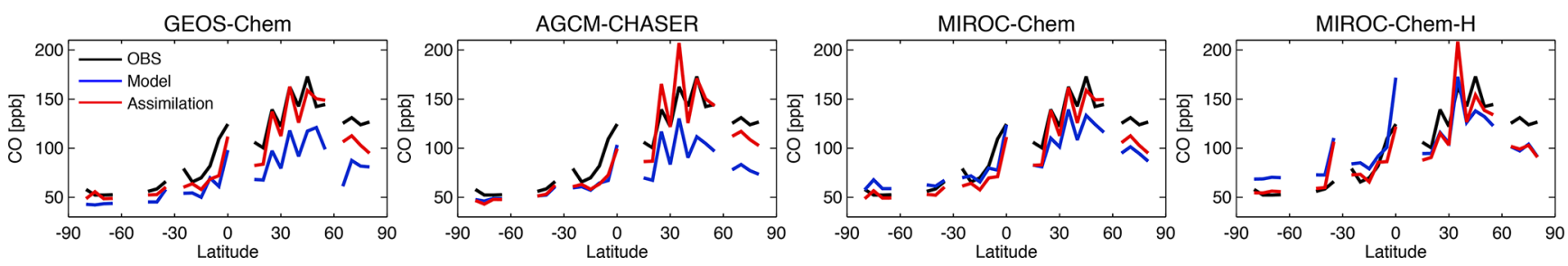

Figure 10. Latitudinal distributions of zonal mean surface CO concentrations (ppbv) averaged over the WDCGG surface measurement sites from the observations (black), control runs (blue), and data assimilation analyses (red).
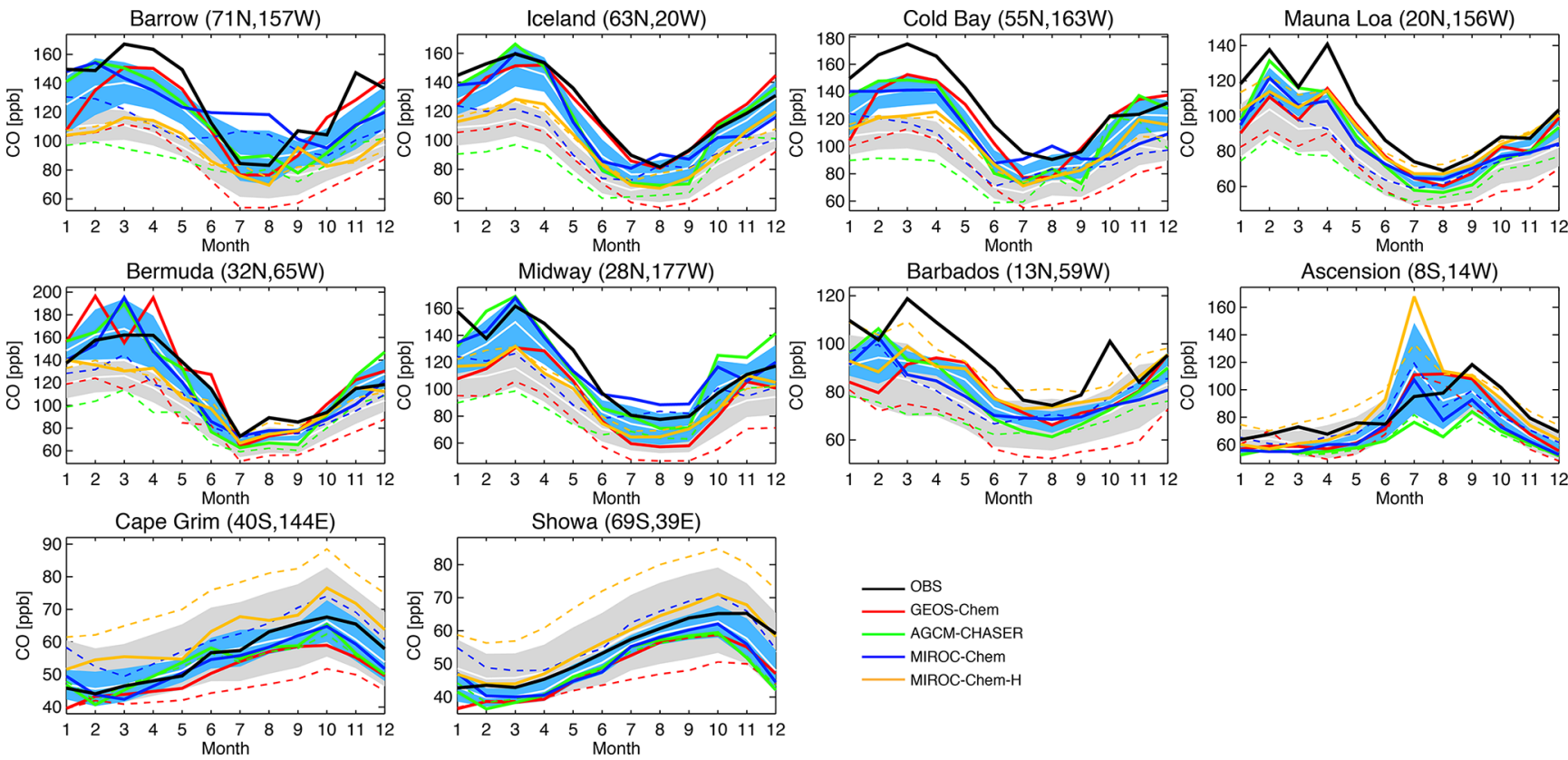

Figure 11. Time series of monthly mean surface CO concentrations (ppbv) from the WDCGG observations (black solid line), control runs (colored dotted lines), and data assimilation analyses (colored solid lines). The $\pm 1 \sigma$ deviation among the four models (i.e., model spread) is shown in gray for the control runs and in light blue for the data assimilation results.

(a) $\mathrm{CO}: 15 \mathrm{~S}-15 \mathrm{~N}$

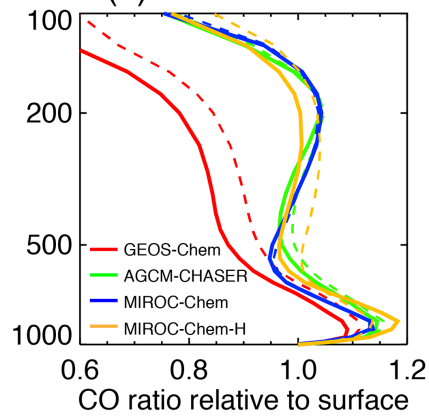

(b) $\mathrm{OH}: 15 \mathrm{~S}-15 \mathrm{~N}$

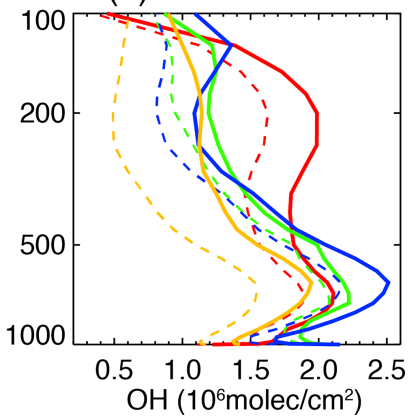

Figure 12. Vertical profiles of (a) annual mean CO concentrations and (b) annual mean $\mathrm{OH}$ concentrations averaged between $15^{\circ} \mathrm{S}$ and $15^{\circ} \mathrm{N}$, obtained from the control runs (dotted lines) and data assimilation analysis (solid line). For CO (a), the relative ratio to the mean surface concentrations is shown. For $\mathrm{OH}(\mathbf{b})$, the unit is $10^{6}$ molecules $\mathrm{cm}^{-3}$.

imately $30 \%-45 \%$ (Fig. 14). The zonal mean OH shows a strong latitudinal gradient around the subtropics. The ratio of $\mathrm{OH}$ in the $\mathrm{NH}$ tropics-subtropics (Equator- $30^{\circ} \mathrm{N}$ ) to the $\mathrm{NH}$ midlatitudes $\left(30-60^{\circ} \mathrm{N}\right)$ ranges from 1.42 (GEOS-Chem) to 1.71 (MIROC-Chem).

Data assimilation largely modified global $\mathrm{OH}$ distributions in all the systems. The analyzed $\mathrm{OH}$ fields and data assimilation increments are often regionally localized, which demonstrates the importance of accurately representing different chemical regimes and local emissions for each region, for estimation of both regional and global $\mathrm{OH}$ distributions. The annual mean $\mathrm{OH}$ is increased in the $\mathrm{SH}$ extratropics by $10 \%-25 \%$ in GEOS-Chem and AGCMCHASER and by $30 \%-50 \%$ in MIROC-Chem and MIROCChem-H, probably because of the increased ozone. MIROCChem-H shows large increases in $\mathrm{OH}$ by $20 \%-40 \%$ over Africa, Southeast Asia, the tropical Pacific, and central and South America, associated with the increased ozone and decreased $\mathrm{CO}$. The NH exhibits large inter-model differences 
Table 5. Annual and regional mean $\mathrm{OH}$ concentration at $700 \mathrm{hPa}$. Units are $10^{6}$ molecules $\mathrm{cm}^{-3}$. The results of the control run are also shown in brackets. The results are shown for individual models, the multi-model mean (mean $\pm 1 \sigma)$, and integrated analysis $\left(\overline{\boldsymbol{x}_{\mathrm{m}}} \pm \overline{\boldsymbol{\sigma}_{\mathrm{m}}^{2}}\right)$ Changes in the multi-model spread due to data assimilation $(\Delta$ spread, $\%)$ are also shown.

\begin{tabular}{lrrrrrrrrr}
\hline & E China & E USA & Europe & India & SE Asia & S America & N Africa & C Africa & S Africa \\
\hline GEOS-Chem & 1.9 & 1.5 & 1.2 & 2.5 & 2.3 & 1.2 & 2.1 & 2.1 & 2.2 \\
& $(2.2)$ & $(1.8)$ & $(1.5)$ & $(2.5)$ & $(2.2)$ & $(1.1)$ & $(2.1)$ & $(2.1)$ & $(2.1)$ \\
\hline AGCM-CHASER & 2.4 & 1.7 & 1.4 & 2.6 & 2.2 & 1.2 & 2.3 & 1.9 & 2.4 \\
& $(2.5)$ & $(1.7)$ & $(1.4)$ & $(2.6)$ & $(2.0)$ & $(1.2)$ & $(2.1)$ & $(1.6)$ & $(2.1)$ \\
\hline MIROC-Chem & 2.1 & 1.5 & 1.3 & 2.4 & 2.1 & 1.3 & 2.4 & 1.9 & 2.1 \\
& $(1.9)$ & $(1.3)$ & $(1.1)$ & $(2.1)$ & $(1.8)$ & $(1.1)$ & $(2.0)$ & $(1.5)$ & $(1.7)$ \\
\hline MIROC-Chem-H & 1.6 & 1.3 & 1.1 & 1.9 & 1.6 & 1.1 & 1.8 & 1.7 & 1.7 \\
& $(1.4)$ & $(1.1)$ & $(1.0)$ & $(1.7)$ & $(1.3)$ & $(0.7)$ & $(1.4)$ & $(1.3)$ & $(1.1)$ \\
\hline Multi-model mean & $2.0 \pm 0.3$ & $1.5 \pm 0.2$ & $1.3 \pm 0.1$ & $2.3 \pm 0.3$ & $2.0 \pm 0.3$ & $1.2 \pm 0.1$ & $2.1 \pm 0.2$ & $1.9 \pm 0.2$ & $2.1 \pm 0.3$ \\
& $(2.0 \pm 0.4)$ & $(1.5 \pm 0.3)$ & $(1.3 \pm 0.2)$ & $(2.2 \pm 0.3)$ & $(1.8 \pm 0.3)$ & $(1.0 \pm 0.2)$ & $(1.9 \pm 0.3)$ & $(1.6 \pm 0.3)$ & $(1.8 \pm 0.4)$ \\
\hline$\Delta$ spread (\%) & -31 & -41 & -44 & -25 & -27 & -58 & -16 & -50 & -24 \\
\hline Integrate analysis & $2.0 \pm 0.2$ & $1.5 \pm 0.1$ & $1.3 \pm 0.1$ & $2.5 \pm 0.2$ & $2.2 \pm 0.2$ & $1.2 \pm 0.1$ & $2.1 \pm 0.1$ & $2.0 \pm 0.2$ & $2.3 \pm 0.2$ \\
\hline
\end{tabular}

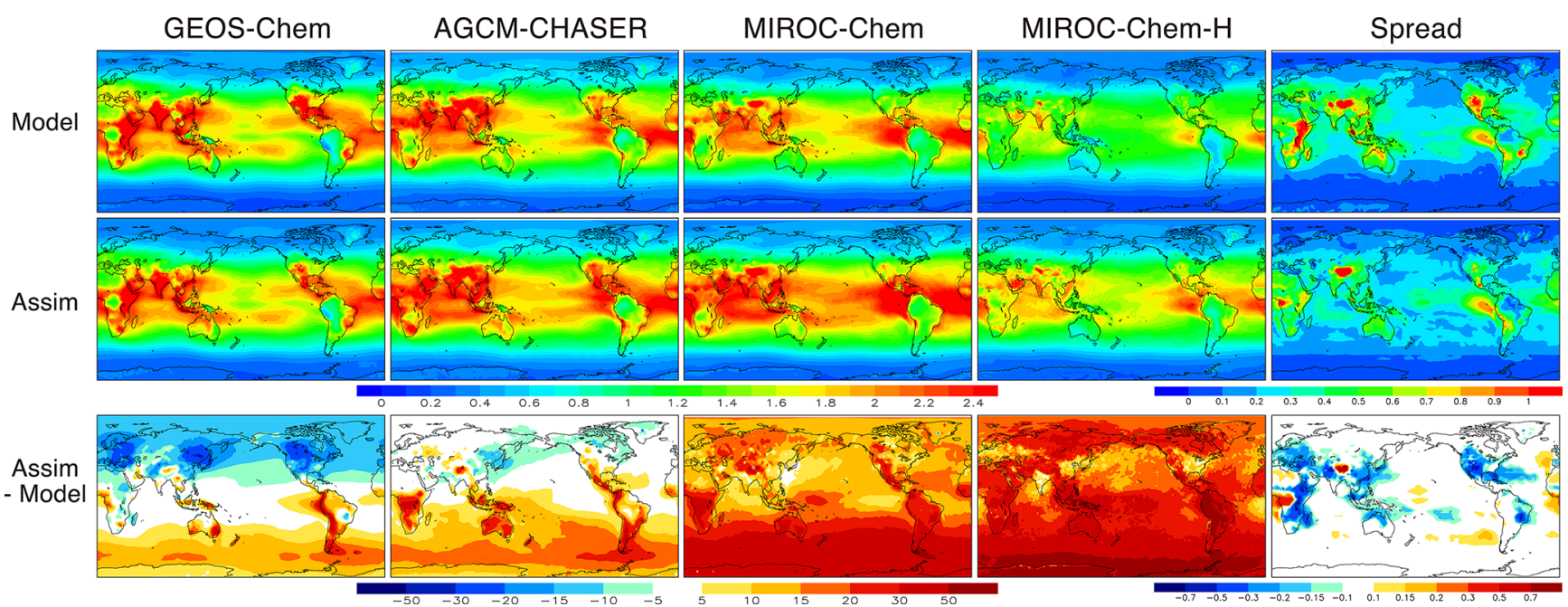

Figure 13. Global distributions of annual mean $\mathrm{OH}$ concentrations $\left(10^{6}\right.$ molecules $\left.\mathrm{cm}^{-3}\right)$ averaged over the troposphere (from the surface to $300 \mathrm{hPa}$ ) from the control runs (upper panels), data assimilation analyses (middle panels), and differences between the data assimilation analyses and the control runs (bottom panels, \%). The figures on the right show the standard deviation among the four systems for the control runs (right top) and data assimilation analyses (right middle). The right bottom figure shows the difference in the multi-model standard deviation between the data assimilation analyses and the control runs $\left(10^{6}\right.$ molecule $\left.\mathrm{cm}^{-3}\right)$.

in $\mathrm{OH}$ increments, decreasing in GEOS-Chem by $10 \%-$ $40 \%$ with large increments over east Asia, the United States, and Europe and increasing in MIROC-Chem and MIROCChem- $\mathrm{H}$ by $15 \%-30 \%$ and by $20 \%-40 \%$ over the continents, respectively. The negative increments in GEOS-Chem are likely associated with the increased $\mathrm{CO}$ and decreased $\mathrm{NO}_{x}$, whereas the positive increments in MIROC-Chem and MIROC-Chem-H could be attributed to the increased ozone and increased $\mathrm{NO}_{x}$. The $\mathrm{NH}$ ratio of $\mathrm{OH}$ of the tropicssubtropics (Equator $-30^{\circ} \mathrm{N}$ ) to midlatitudes $\left(30-60^{\circ} \mathrm{N}\right)$ is in- creased in all the models by $1 \%-15 \%$, with the largest increase in GEOS-Chem (from 1.42 to 1.64).

Because of the data assimilation, the multi-model spread of $\mathrm{OH}$ is reduced by $24 \%-58 \%$ over the major polluted areas of the globe such as over Europe (44\%), China (31\%), the United States $(41 \%)$, central Africa $(50 \%)$, and South America $(58 \%)$. At the local scale, the multi-model spread is reduced largely over central eastern Africa (up to $55 \%$ ), associated with adjustments made to biomass burning plumes, and over Indonesia (up to $40 \%$ ) and the western US (up to $55 \%$ ), corresponding to large changes in local $\mathrm{NO}_{x}$ and 


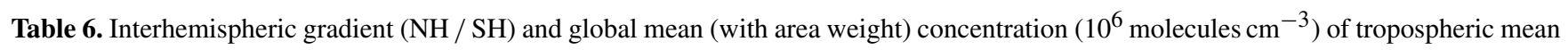
$\mathrm{OH}$ (averaged between the surface and $300 \mathrm{hPa}$ ) from the control and data assimilation runs. The results are shown for individual models and the multi-model mean (mean $\pm 1 \sigma)$.

\begin{tabular}{llrrrrr}
\hline & & GEOS-Chem & AGCM-CHASER & MIROC-Chem & MIROC-Chem-H & Multi-model \\
\hline \multirow{2}{*}{ NH / SH ratio } & Model & 1.30 & 1.36 & 1.29 & 1.31 & $1.29 \pm 0.03$ \\
& assimilation & 1.17 & 1.23 & 1.18 & 1.21 & $1.18 \pm 0.03$ \\
\hline \multirow{2}{*}{ Global mean } & Model & 1.31 & 1.23 & 1.13 & 0.82 & $1.12 \pm 0.18$ \\
& Assimilation & 1.31 & 1.31 & 1.34 & 1.09 & $1.26 \pm 0.10$
\end{tabular}

$\mathrm{CO}$ emissions and consequently in ozone production. The improved multi-model consistency suggests that the multiconstituent data assimilation provides a more similar representation of the tropospheric chemistry system, by removing model errors in the relevant species in the individual systems. The obtained $\mathrm{OH}$ fields, which are less dependent on individual model performance due to reduced model errors in relevant species, demonstrate the potential of the multiconstituent (ozone, $\mathrm{CO}$, and $\mathrm{NO}_{2}$ ) data assimilation for various atmospheric chemistry studies including emission inversion and methane budget analyses. Because the chemical lifetimes of $\mathrm{NO}_{x}$ and $\mathrm{CO}$ are affected by the amount of $\mathrm{OH}$, these changes once more suggest the importance of the simultaneous optimization of the concentration and emissions on the entire tropospheric chemical system and the emission estimates.

The integrated analysis $\overline{\boldsymbol{x}_{\mathrm{m}}}$ shows slightly higher $\mathrm{OH}$ concentrations than the multi-model means for most regions, mainly reflecting the largest $\mathrm{OH}$ spreads and smallest $\mathrm{OH}$ concentrations in MIROC-Chem-H among the models. The analysis spread of $\mathrm{OH}$ is determined by analysis spreads in various species such as ozone (see Sect. 3.2) during model forecasts. Because of the different chemical mechanisms and model responses to given perturbations (see Sect. 5), $\mathrm{OH}$ spreads differed by factor of up to 2.5 among the models for the regional means. The integrated uncertainty $\overline{\sigma_{\mathrm{m}}^{2}}$ is smaller than the multi-model spreads by $20 \%-50 \%$ for most regions.

As summarized in Table 6, the north-to-south gradient of the tropospheric $\mathrm{OH}$ (averaged below $300 \mathrm{hPa}$ ) decreased owing to data assimilation in all the models, i.e., from 1.29$1.36(1.32 \pm 0.03)$ to $1.17-1.23(1.19 \pm 0.03)$, as similarly suggested by our previous analysis (Miyazaki et al., 2015). The $\mathrm{NH} / \mathrm{SH}$ ratio of $\mathrm{OH}$ simulated from the four models is in the range of $1.28 \pm 0.10$ in the ACCMIP multimodel estimates (Naik et al., 2013), whereas the values from the data assimilation runs are significantly lower. The data assimilation estimates are in better agreement with an observational estimate $(0.97 \pm 0.12)$ obtained using methyl chloroform observations (Patra et al., 2014). The significant changes in the global $\mathrm{OH}$ distributions, which are common to all the models, are important in propagating the observational information between various species and mod- ulating the chemical lifetimes of many species, thus improving emission inversion. The simultaneous optimization of emissions and concentrations was essential to modify the global $\mathrm{OH}$ distributions. The increases (by 1\%-32\%) in the global mean $\mathrm{OH}$ concentrations by data assimilation in all the models, with the multi-model mean values of $1.12 \pm 0.18 \times 10^{6}$ molecules $\mathrm{cm}^{-3}$ in the control runs and $1.26 \pm 0.10 \times 10^{6}$ molecules $\mathrm{cm}^{-3}$ in the data assimilation as summarized in Table 6 , suggest overestimated $\mathrm{CH}_{4}$ lifetimes in the model simulations.

\section{Ozone and $\mathrm{NO}_{2}$ response to $\mathrm{NO}_{x}$ emissions}

\subsection{Multi-model comparisons}

From a system analysis perspective, one of the fundamental questions in atmospheric chemistry is the sensitivity of a constituent like ozone to changes in surface emissions such as $\mathrm{NO}_{x}$ emissions. With recent advances in estimating preindustrial ozone (Yeung et al., 2019), model sensitivities are the primary drivers of chemistry-climate estimates of quantities such as ozone radiative forcing (Bowman et al., 2013, Myhre et al., 2013). While these simulations describe relatively slow, equilibrium responses, data assimilation incremental updates provide statistics on "fast" responses within the short data assimilation windows. By simultaneously updating ozone and $\mathrm{NO}_{x}$ emissions, multi-constituent data assimilation can yield insight into this fundamental quantity. We explore this potential by regressing both the ozone and $\mathrm{NO}_{2}$ increments with respect to the $\mathrm{NO}_{x}$ emission analysis increments using the daily mean data assimilation outputs at each grid point.

As summarized in Table 7, the response of ozone and $\mathrm{NO}_{2}$ analysis to emission perturbations (i.e., data assimilation increments) is largely different among the models. The $\mathrm{NO}_{2}$ surface response to $\mathrm{NO}_{x}$ emissions is well correlated (correlation $>=0.93$ for all models) but the response differs by almost a factor of 2 between GEOS-Chem and MIROC-ChemH. Globally, this diversity holds between surface ozone concentration and $\mathrm{NO}_{x}$ emission increments $\left(\frac{\Delta \mathrm{O}_{3}}{\Delta} \mathrm{ENO}_{x}\right)$ for these two models. However, the AGCM-CHASER ozone$\mathrm{NO}_{x}$ emissions response $\left(1.5 \mathrm{ppb}\right.$ per $\left.\left(10^{-11} \mathrm{~kg} \mathrm{~N} \mathrm{~m}^{-2} \mathrm{~s}^{-1}\right)\right)$ 
Table 7. Linear regression of changes in surface $\mathrm{NO}_{x}$ emissions $\left(10^{-11} \mathrm{~kg} \mathrm{~N} \mathrm{~m}^{-2} \mathrm{~s}^{-1}\right.$ ) and surface concentrations of ozone and $\mathrm{NO}_{2}$ (ppb) by data assimilation in May 2007 over areas with $\mathrm{NO}_{x}$ emission changes greater than $5 \times 10^{-13} \mathrm{~kg} \mathrm{~N} \mathrm{~m}^{-2} \mathrm{~s}^{-1}$ in the four models. The results for regions without strong $\mathrm{NO}_{x}$ emission changes (greater than $3 \times 10^{-11} \mathrm{~kg} \mathrm{~N} \mathrm{~m}^{-2} \mathrm{~s}^{-1}$ that could suffer from dilution effects) are shown in brackets.

\begin{tabular}{|c|c|c|c|c|c|}
\hline & & (ppb per $\left(10^{-11} \mathrm{~kg} \mathrm{~N} \mathrm{~m}^{-}\right.$ & $\begin{array}{l}\text { Slope } \\
\left.\left.2 \mathrm{~s}^{-1}\right)\right)\end{array}$ & $\begin{array}{r}\text { Intercept } \\
(\mathrm{ppb})\end{array}$ & Correlation \\
\hline \multirow[t]{4}{*}{ Ozone } & GEOS-Chem & 1.2 & (1.8) & $2.2(2.2)$ & $0.34(0.34)$ \\
\hline & AGCM-CHASER & 1.5 & (3.6) & $3.6(3.0)$ & $0.42(0.45)$ \\
\hline & MIROC-Chem & 1.0 & $(2.5)$ & $3.0(2.7)$ & $0.35(0.42)$ \\
\hline & MIROC-Chem-H & 0.6 & (1.3) & $4.1(3.9)$ & $0.25(0.42)$ \\
\hline \multirow[t]{4}{*}{$\mathrm{NO}_{2}$} & GEOS-Chem & & 0.80 & 0.01 & 0.93 \\
\hline & AGCM-CHASER & & 0.56 & 0.01 & 0.96 \\
\hline & MIROC-Chem & & 0.54 & 0.01 & 0.94 \\
\hline & MIROC-Chem-H & & 0.44 & 0.04 & 0.94 \\
\hline
\end{tabular}

is the largest among all the models. On the other hand, the correlation between surface ozone and $\mathrm{NO}_{x}$ emissions is relatively weak (correlation $<0.43$ ), reflecting the much more complicated chemical and dynamical relationship. For polluted areas (greater than $3 \times 10^{-11} \mathrm{~kg} \mathrm{~N} \mathrm{~m}^{-2} \mathrm{~s}^{-1}$, as shown in the brackets in Table 7), the largest response is AGCMCHASER and MIROC-Chem, which is greater than the other two models by $40 \%-180 \%$, with similar intercepts and correlations. The multi-model diversity reflects the different representation of $\mathrm{NO}_{x}$ and VOC as well as dynamics, leading to different ozone production efficiencies. In the case of GEOS-Chem and MIROC-Chem-H, there appears to be a clearer relationship between $\frac{\Delta \mathrm{NO}_{2}}{\Delta \mathrm{ENO}_{x}}$ and $\frac{\Delta \mathrm{O}_{3}}{\Delta \mathrm{ENO}_{x}}$, suggesting that $\mathrm{NO}_{x}$ chemistry plays a more dominant role in ozone formation than other factors. By separating these two responses, MOMO-Chem is able to quantify the responses of forward models with unique diagnostics, without making any sensitivity calculations.

Different model responses would directly impact the Kalman gain in Eq. (4), leading to a more efficient model error reduction. Given the same predefined minimum values for the surface $\mathrm{NO}_{x}$ emission perturbation (see Sect. 2.6), a larger ozone analysis uncertainty (through a larger forecast model spread) would be obtained in models with a stronger ozone response to $\mathrm{NO}_{x}$ emissions. In fact, stronger ozone response (Table 7) and larger analysis uncertainty (Fig. 2b) are consistently found in AGCM-CHASER and MIROC-Chem. Meanwhile, the ozone response to a given perturbation is dependent on the background condition because of the nonlinear $\mathrm{O}_{3}-\mathrm{NO}_{x}$ chemistry (e.g., Zaveri et al., 2003). The multiconstituent framework allows us to evaluate model ozone response in a realistic condition while considering possible error ranges in precursor emissions using emissions analysis increments (see Sect. 6). The ozone analysis increments be-

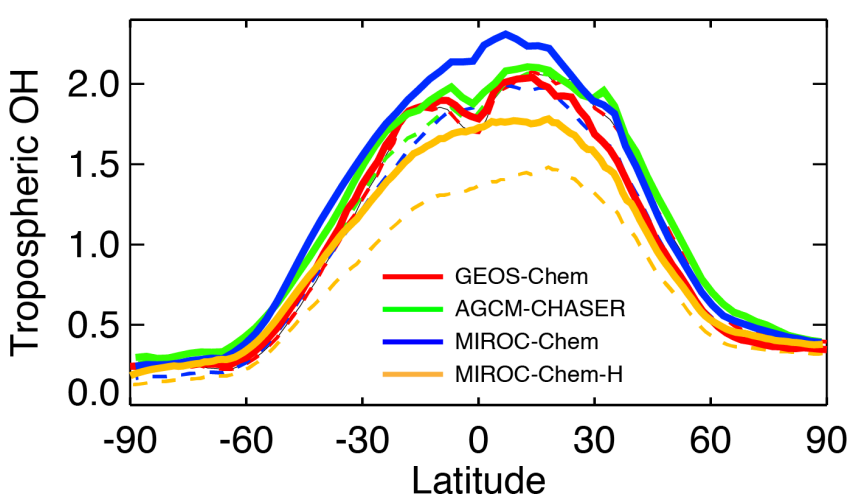

Figure 14. Latitudinal distributions of annual and zonal mean $\mathrm{OH}$ concentrations $\left(10^{6}\right.$ molecules $\left.\mathrm{cm}^{-3}\right)$ averaged over the troposphere obtained from the control runs (dotted lines) and data assimilation analyses (solid lines) for the four systems.

came substantially smaller in all the models for most cases by including the emission optimization, and the increments could be regarded as inherent and persistent model biases of individual models. Therefore, a systematic investigation of model ozone response and analysis increment in the multiconstituent data assimilation framework could benefit evaluation of future prediction of the chemistry-climate system as a hierarchical emergent constraint that uses relationships between future and current climate states to constrain projections of climate response with observations (Bowman et al., 2018). They could also be useful for making effective ozone control strategies.

In addition, tropospheric ozone shows strong correlations with other species such as CO (Zhang et al., 2006) over regions such as continental outflow regions. The relationship can be included in the state vector to improve the tropo- 
spheric ozone analysis. The uncertainty information in the $\mathrm{CO}$ response to ozone obtained from the MOMO-Chem can be expected to provide useful information on model diagnostics and future predictions.

\subsection{Implications for chemistry model predictions}

By applying linear regressions to the multi-model integrated fields (see Sect. 3.3), we evaluated model responses of surface ozone and $\mathrm{NO}_{2}$ concentrations to $\mathrm{NO}_{x}$ emissions. We first produced the daily multi-model integrated fields at $1.1^{\circ} \times 1.1^{\circ}$ resolution and then applied them to linear regressions. As shown by Fig. 15, the estimated model responses from the MOMO-Chem integrated fields provide unique information on fast responses to $\mathrm{NO}_{x}$ emissions. The surface $\mathrm{NO}_{2}$ response exhibits a large seasonal variation in the $\mathrm{NH}$, with a maximum value of about $2 \mathrm{ppb}$ per $\left(10^{-11} \mathrm{~kg} \mathrm{~N} \mathrm{~m}^{-2} \mathrm{~s}^{-1}\right)$ in January, reflecting the longer chemical lifetime of $\mathrm{NO}_{x}$ in winter. The rapid increases from September to December and decreases from January to March can be associated primarily with variations in temperature, $\mathrm{OH}$, and $\mathrm{NO}_{2}$ photolysis. The annual mean slope is about $40 \%$ smaller in the tropics than in the $\mathrm{NH}(0.70 \mathrm{vs}$. $1.15 \mathrm{ppb}$ per $\left.\left(10^{-11} \mathrm{~kg} \mathrm{~N} \mathrm{~m}^{-2} \mathrm{~s}^{-1}\right)\right)$ because of the shorter chemical lifetime of $\mathrm{NO}_{x}$ in the tropics. The surface $\mathrm{NO}_{2}$ and $\mathrm{NO}_{x}$ emissions in the integrated fields are well correlated (coefficients $>0.9$ ) throughout the year in both the $\mathrm{NH}$ and the tropics. The inter-model differences (red shading) increase in winter in the $\mathrm{NH}$, with a maximum standard deviation of $35 \%$ in January, implying strong model dependence of surface $\mathrm{NO}_{2}$ given the same $\mathrm{NO}_{x}$ emissions.

The ozone response shows a seasonal cycle opposite to the $\mathrm{NO}_{2}$ response in the $\mathrm{NH}$. It gradually increased from January to August by about $0.4 \mathrm{ppb}$ per $\left(10^{-11} \mathrm{~kg} \mathrm{~N} \mathrm{~m}^{-2} \mathrm{~s}^{-1}\right)$ per month. It reaches $2.4 \mathrm{ppb}$ per $\left(10^{-11} \mathrm{~kg} \mathrm{~N} \mathrm{~m}^{-2} \mathrm{~s}^{-1}\right)$ in August with relatively large coefficients $(0.3-0.6)$ in MaySeptember. The large ozone response implies substantial photochemical productions of surface ozone over polluted areas in summer. Then, the slope decreases rapidly from $\mathrm{Au}-$ gust to October by about $1.1 \mathrm{ppb}$ per $\left(10^{-11} \mathrm{~kg} \mathrm{~N} \mathrm{~m}^{-2} \mathrm{~s}^{-1}\right)$ per month, and it becomes negative in winter but with low coefficients $(-0.3-0.2)$. The negative slopes, with a minimum value of $-0.6 \mathrm{ppb}$ per $\left(10^{-11} \mathrm{~kg} \mathrm{~N} \mathrm{~m}^{-2} \mathrm{~s}^{-1}\right)$ in January, could be driven by the dilution effects over highly polluted areas.

In the tropics, the ozone response is stronger than in the $\mathrm{NH}\left(3.1\right.$ vs. $0.6 \mathrm{ppb}$ per $\left(10^{-11} \mathrm{~kg} \mathrm{~N} \mathrm{~m}^{-2} \mathrm{~s}^{-1}\right)$ for annual mean), with the strongest responses of about $4.3 \mathrm{ppb}$ per $\left(10^{-11} \mathrm{~kg} \mathrm{~N} \mathrm{~m}^{-2} \mathrm{~s}^{-1}\right)$ in March and October. The different ozone production efficiency implies that any latitudinal shifts in $\mathrm{NO}_{x}$ emissions from the extratropics to the tropics would lead to increases in global tropospheric ozone, as suggested by Zhang et al. (2016), while showing strong seasonality. Our analysis indicates that the mean ozone response is comparable between the $\mathrm{NH}$ and the tropics in $\mathrm{Au}-$

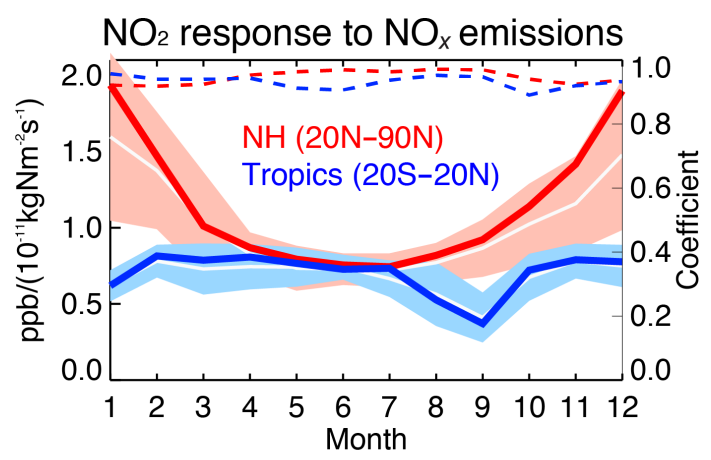

Ozone response to $\mathrm{NO}_{x}$ emissions

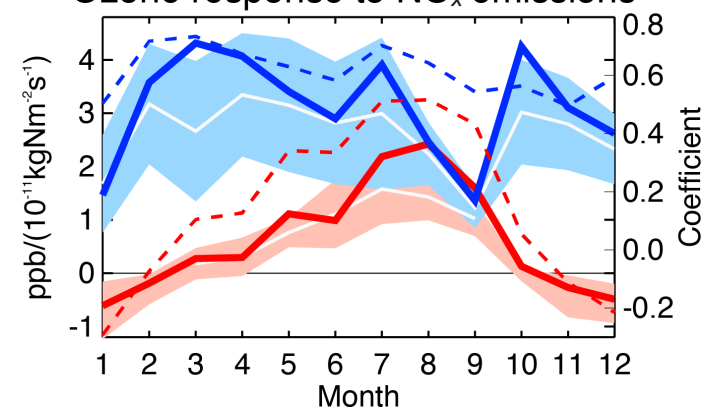

Figure 15. Time series of model response of surface ozone and $\mathrm{NO}_{2}$ concentrations to $\mathrm{NO}_{x}$ emissions estimated from linear regressions using the multi-model integrated fields in 2007 over areas with $\mathrm{NO}_{x}$ emission changes greater than $5 \times 10^{-13} \mathrm{~kg} \mathrm{~N} \mathrm{~m}^{-2} \mathrm{~s}^{-1}$ for the Northern Hemisphere $\left(20-60^{\circ} \mathrm{N}\right.$, red line) and the tropics $\left(20^{\circ} \mathrm{S}-\right.$ $20^{\circ} \mathrm{N}$, blue line). The $\pm 1 \sigma$ deviation among the four models (i.e., model spread) is shown in light red for the $\mathrm{NH}$ and in light blue for the tropics. The multi-model mean value (i.e., an average of individual estimates) is shown by white lines. The correlation is shown by dashed lines.

gust and September. The seasonal variation in the tropics is likely associated with biomass burning events (e.g., Bowman et al., 2009; Jones et al., 2009; Parrington et al., 2012), with enhanced ozone responses over Southeast Asia during February-June (2.3-3.7 ppb per $\left(10^{-11} \mathrm{~kg} \mathrm{~N} \mathrm{~m}^{-2} \mathrm{~s}^{-1}\right)$ ), over central America and tropical South America during AprilJuly (2.8-5.3 ppb per $\left.\left(10^{-11} \mathrm{~kg} \mathrm{~N} \mathrm{~m}^{-2} \mathrm{~s}^{-1}\right)\right)$, over central Africa in March (5.5 ppb per $\left.\left(10^{-11} \mathrm{~kg} \mathrm{~N} \mathrm{~m}^{-2} \mathrm{~s}^{-1}\right)\right)$ and October $\left(7.1 \mathrm{ppb}\right.$ per $\left.\left(10^{-11} \mathrm{~kg} \mathrm{~N} \mathrm{~m}^{-2} \mathrm{~s}^{-1}\right)\right)$, and over India in March and October $\left(5.1 \mathrm{ppb}\right.$ per $\left.\left(10^{-11} \mathrm{~kg} \mathrm{~N} \mathrm{~m}^{-2} \mathrm{~s}^{-1}\right)\right)$. Although the surface ozone and $\mathrm{NO}_{x}$ emissions are well correlated in the multi-model integrated analysis throughout the year (coefficients $>0.5$ ), the large multi-model spreads $(25 \%-55 \%)$ suggest that individual models have large uncertainty in representing strong ozone productions, for instance, associated with VOC emissions and chemistry that could result in different chemical regimes. The correlations of $\Delta \mathrm{ENO}_{x}$ and $\Delta \mathrm{O}_{3}$ among the models estimated at each point at each day were strongly dependent on season and location (not shown), which also provide information on the ro- 
bustness (i.e., multi-model diversity) of the estimated ozone and $\mathrm{NO}_{2}$ responses for each location and season.

Finally, the model responses differ significantly between the MOMO-Chem integrated fields (solid blue and red lines) and the mean of the individual model estimates obtained by averaging the model responses from individual model fields (solid white lines), especially when the model responses are strong. The multi-model integrated fields exhibit about a $20 \%$ larger $\mathrm{NO}_{2}$ response in December and about a $70 \%$ larger ozone response in August than the mean of the individual model estimates in the NH. In the tropics the monthly ozone response is up to about $60 \%$ larger in the multi-model integrated analysis. The different responses reflect non-Gaussian distributions of the individual model fields. The results imply that the observationally constrained, multi-model integrated fields provide fundamentally different fast chemical processes than those in the individual models. Meanwhile, the uncertainty-weighted multi-model integrated ozone fields showed closer agreements with independent observations than the multi-model averages in the lower troposphere (see Sect. 4.1.2). This suggests that the MOMO-Chem framework provides improved estimates of the atmospheric states for many cases. With further investigations of the chemical relationships in the integrated fields, the MOMO-Chem framework would provide insights into ozone production processes to inform chemical predictions through relationships such as emergent constraints (Bowman et al., 2018). This example demonstrates the unique capability of the MOMO-Chem framework for various applications.

\section{Estimated emissions}

\subsection{NO emissions $^{2}$}

As summarized in Table 8 and shown in Fig. 16, the global total $\mathrm{NO}_{x}$ emissions are increased by $12 \%$ in GEOS-Chem, $40 \%$ in AGCM-CHASER, $25 \%$ in MIROC-Chem, and $30 \%$ in MIROC-Chem-H due to data assimilation. The a posteriori global total emissions vary from 39.1 TgN (GEOS-Chem) to $51.9 \mathrm{TgN}$ (AGCM-CHASER) with the multi-model mean of $47.6 \pm 5.8 \mathrm{TgN}$, in contrast to the a posteriori global total emissions varying from $37.1 \mathrm{TgN}$ (GEOS-Chem) to 42.4 TgN (MIROC-Chem-H). The regional $\mathrm{NO}_{x}$ emissions are increased in the models other than GEOS-Chem over the United States (with annual regional total emission increases of $10 \%-22 \%)$, eastern China (2\%-34\%), and western Europe $(7 \%-23 \%)$. The a posteriori emissions over eastern China in these models $(5.8-6.4 \mathrm{TgN})$ are closer to the HTAPv2 2010 inventory $(5.7 \mathrm{TgN})$ than those from EDGAR v4.2 (4.2 TgN). The emissions over Europe are largely increased in MIROC-Chem-H (by 23\%) and AGCM-CHASER (by $24 \%$ ). In GEOS-Chem, the emissions are decreased over most parts of eastern China (by $21 \%$ for regional total emissions), the United States (by $9 \%$ ), and western Europe (by
$21 \%$ ), where the a posteriori emissions are obviously lower than the other estimates. As shown in Fig. 17, the multimodel mean of the a posteriori emissions shows strong $\mathrm{NO}_{x}$ emissions over major polluted areas, while the multi-model spread is large for eastern China, the eastern United States, Mexico City, western Europe, and South Africa. The multimodel spread of the a posteriori regional $\mathrm{NO}_{x}$ emissions is smaller than the assumed a priori emission uncertainty (i.e., by $40 \%$ ) for all the polluted areas (Table 8 ), while the a priori emission spreads could influence the obtained a posteriori emission spreads. From sensitivity calculations, we confirmed that the daily emission updates greatly reduce the dependence of the a priori emissions for many regions (now shown).

For biomass burning areas, the emissions are increased in all the models by $17 \%-25 \%$ over Southeast Asia, by $13 \%-$ $30 \%$ over northern Africa, and by $4 \%-39 \%$ over central Africa. The positive increments over northern and central Africa are smallest in MIROC-Chem-H, likely due to the use of updated biomass burning emission inventories (GFED v4) as well as updated $\mathrm{NO}_{2}$ retrievals. The a posteriori emissions for the biomass burning areas are similar between the four systems: $0.6-0.8 \mathrm{TgN}$ (16\% standard deviation) for Southeast Asia, 2.9-3.2 TgN (4\%) for northern Africa, and 2.2$2.8 \mathrm{TgN}(10 \%)$ for central Africa. Over South Africa, the emissions are increased by $29 \%-50 \%$ in all the systems, with a large multi-model spread of the a posteriori emissions (0.4-0.9 TgN, $31 \%$ standard deviation).

The seasonal variations in $\mathrm{NO}_{x}$ emissions are largely modified by data assimilation for many regions, with common features for all four systems (Fig. 18). Over eastern China, the emissions in early summer (June) and winter (November-January) are enhanced in all the systems, which could be associated with emissions from soils and the use of wintertime heating, respectively. The magnitude of the summertime enhancement differs among the models, which could reflect the different chemical lifetime of $\mathrm{NO}_{x}$ under strong photolysis conditions. Over the United States and Europe, large enhancements in late spring and early summer and subsequently in the seasonal amplitude are commonly found in all the systems. Also, the timing of maximum emissions in summer moves forward by a few months (from 1 to 2 months over eastern China and Europe and from 2 to 3 months over the United States) due to data assimilation in all the systems, likely due to underestimated soil emissions in early summer, which has also been suggested by Oikawa et al. (2015).

Over India, the a posteriori emissions reveal strong increases from April to June in all the systems, which is likely associated with open biomass burning that is not represented by the bottom-up inventories (Venkataraman et al., 2006). Over Southeast Asia, the emissions are mostly increased throughout the year in all the systems, with large increases in the biomass burning season (boreal spring), except in MIROC-Chem-H. Over South America, the emissions in the 


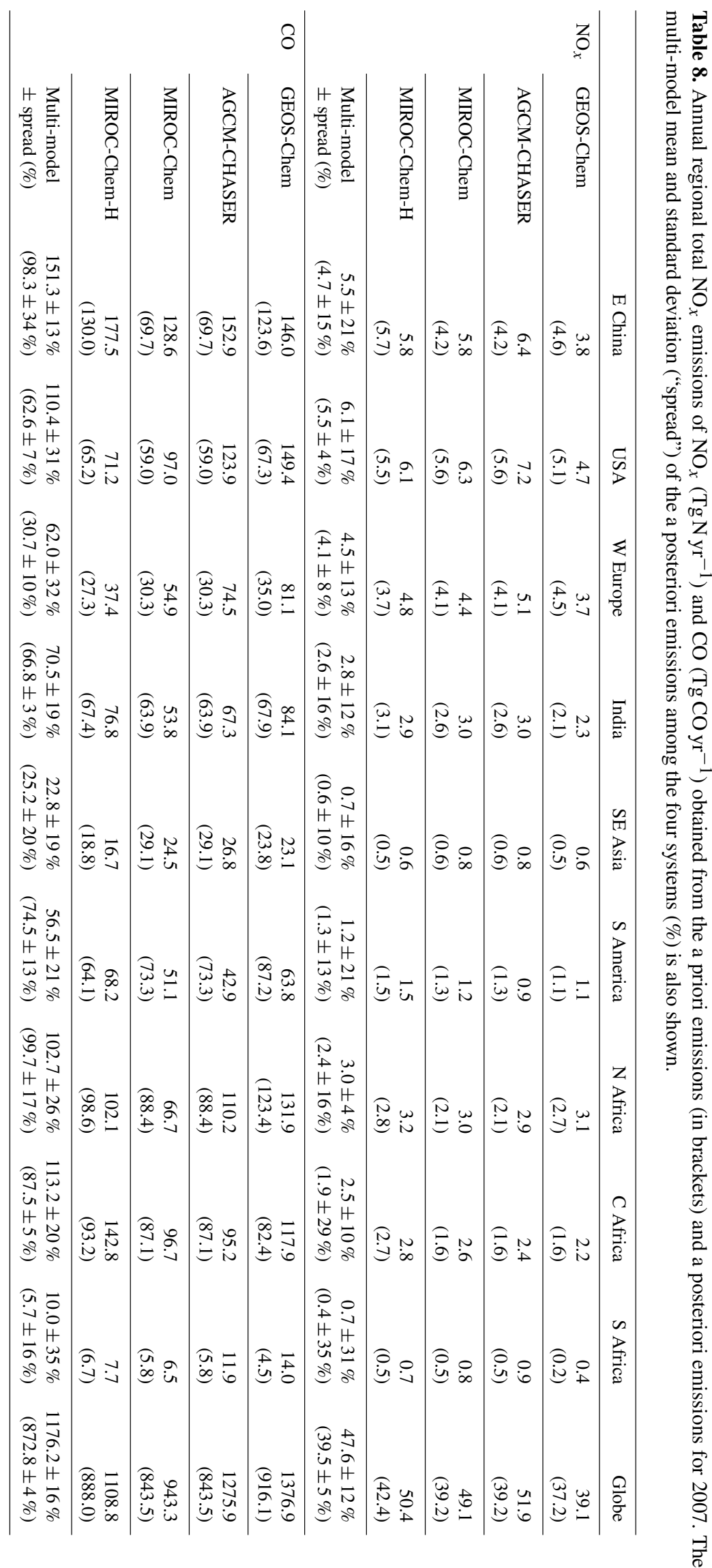




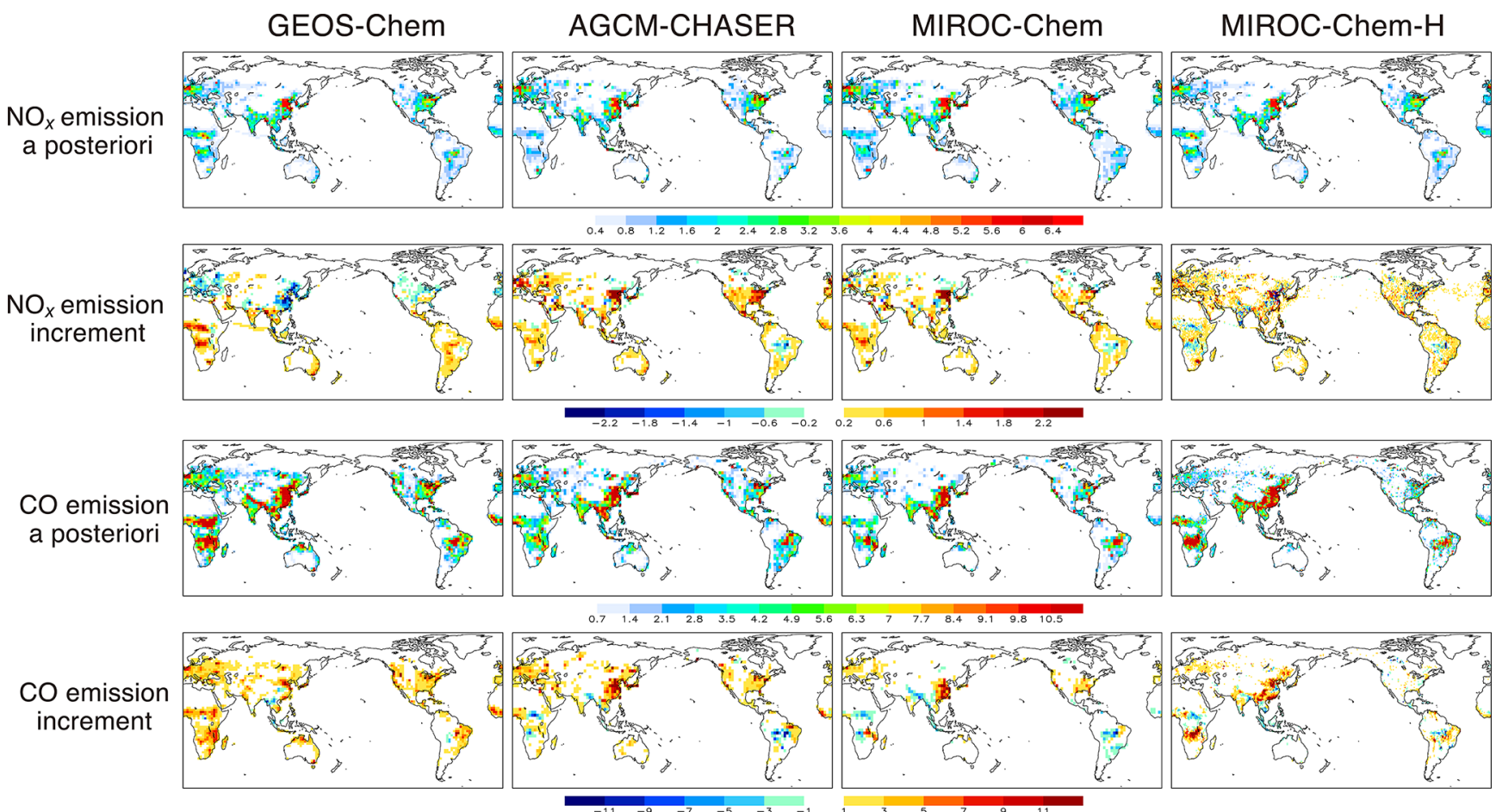

Figure 16. Global distributions of annual mean surface $\mathrm{NO}_{x}$ emissions $\left(10^{-11} \mathrm{~kg} \mathrm{~N} \mathrm{~m}^{-2} \mathrm{~s}^{-1}\right)$ and surface $\mathrm{CO}$ emissions $\left(10^{-10} \mathrm{~kg} \mathrm{CO} \mathrm{m}^{-2} \mathrm{~s}^{-1}\right)$ for 2007. The a posteriori emissions and analysis increment (a posteriori minus a priori emissions) are shown.

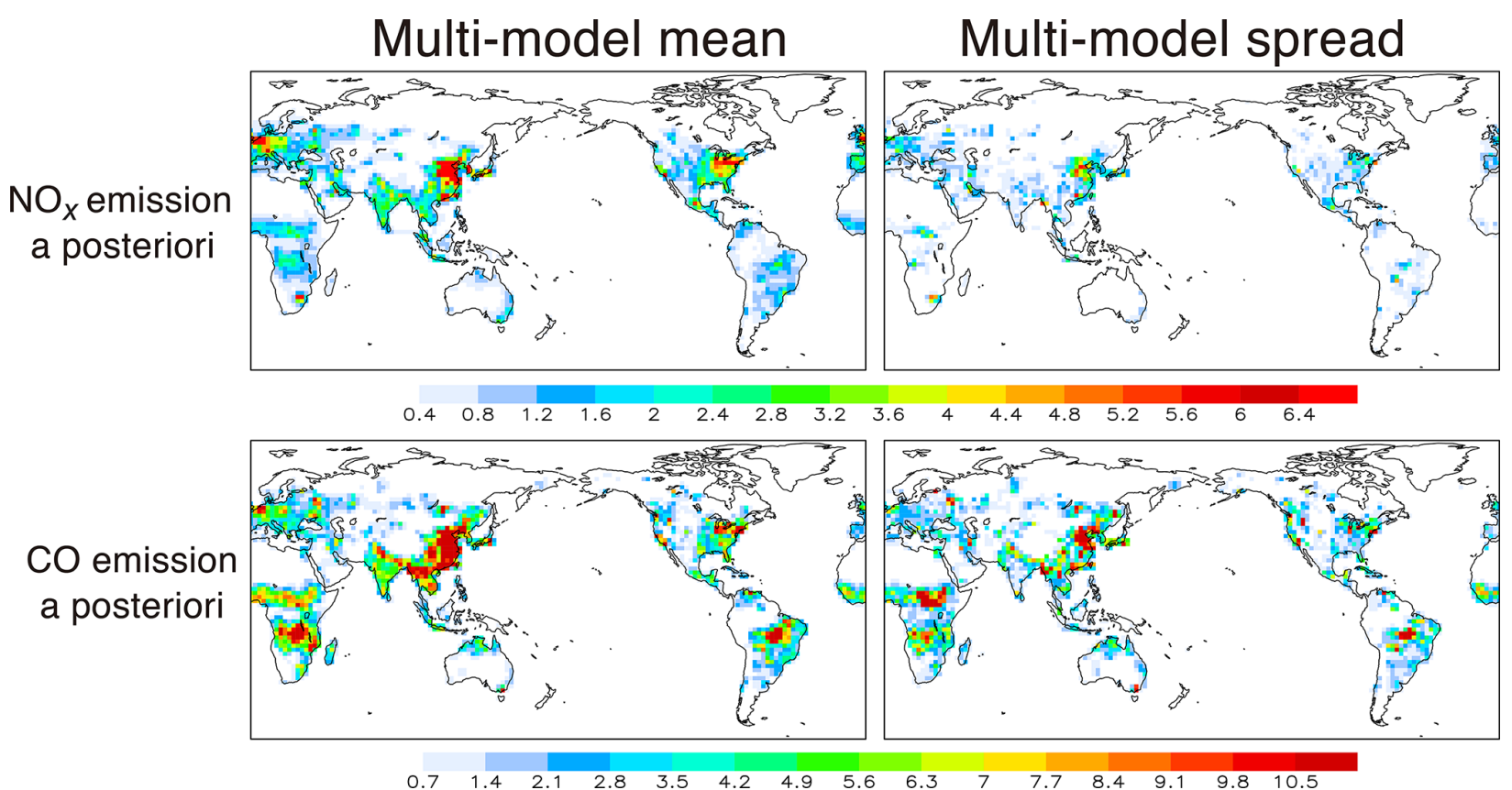

Figure 17. Same as Fig. 16, but for the multi-model mean and spread. 

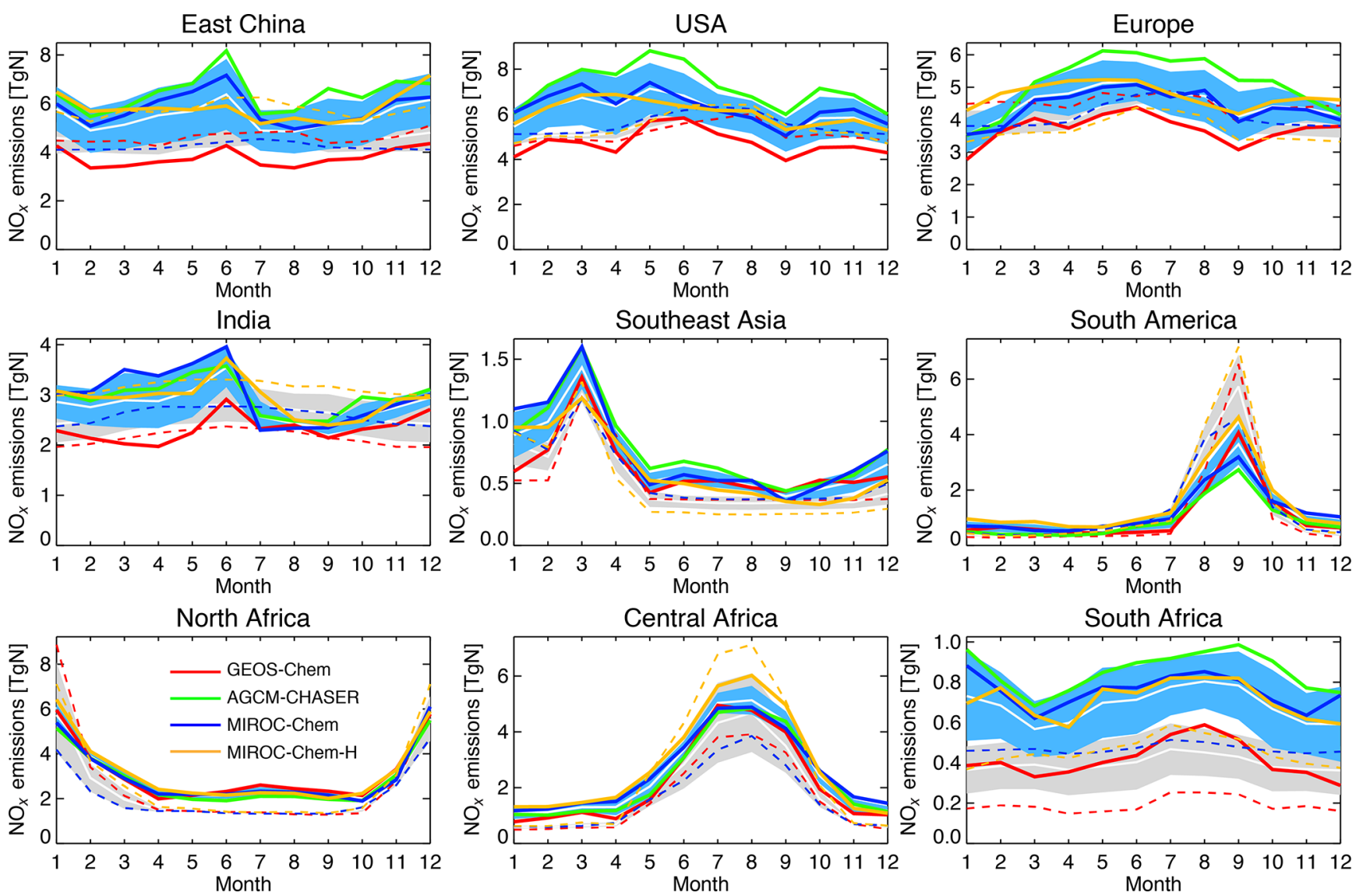

Figure 18. Time series of monthly total regional surface $\mathrm{NO}_{x}$ emissions $\left(\mathrm{Tg} \mathrm{N} \mathrm{yr}^{-1}\right)$ obtained from the a priori emissions (dotted lines) and the a posteriori emissions (solid lines) for 2007 for the four systems. AGCM-CHASER and MIROC-Chem use the same a priori emissions. The $\pm 1 \sigma$ deviation among the four models (i.e., model spread) is shown in gray for the control runs and in light blue for the data assimilation results.

biomass burning season (August-September) are decreased by $30 \%-50 \%$ due to data assimilation in all the systems. The negative increments suggest an overestimation of emissions by forest fires in dry conditions in the GFED v2, v3, and $\mathrm{v} 4$ inventories, as similarly suggested by Castellanos et al. (2014) for the GFED v3 inventory. In contrast, the emissions are increased in the biomass burning off-season by $30 \%-60 \%$ in all the systems.

Over northern Africa, in the biomass burning season (boreal winter), fire-related emission factors in the GFED v3 inventory (AGCM-CHASER, MIROC-Chem) are suggested to be too low by $20 \%-30 \%$, whereas those in the GFED v2 (GEOS-Chem) and v4 (MIROC-Chem-H) inventories are too high by $50 \%$ and by $10 \%$, respectively. The multi-model consistency is high throughout the year over northern Africa. Over central Africa, the emissions in the biomass burning season (July-September) are increased by 30\%-45\% from the GFED v2 and v3 inventories and decreased by $20 \%$ from the GFED $v 4$ inventory.

The differences in the a posteriori emissions could be explained by the different model configurations, such as the chemical lifetime of $\mathrm{NO}_{x}$, vertical mixing, lightning $\mathrm{NO}_{x}$ sources, and model resolutions for many regions. The obtained inter-model differences are generally larger for industrialized areas $(12 \%-31 \%)$ than biomass burning areas (4\%-21\%), suggesting substantial influences of different urban chemistry configurations and/or model settings for anthropogenic $\mathrm{NO}_{x}$ emissions (e.g., $\mathrm{NO}_{2}$ : $\mathrm{NO}$ ratio). Large uncertainties in chemical $\mathrm{NO}_{x}$ loss have strong effects on the simulated $\mathrm{NO}_{x}$ lifetime and the accuracy of top-down $\mathrm{NO}_{x}$ source inversion (Lin et al., 2012; Stavrakou et al., 2013).

As discussed in Sect. 5, the $\mathrm{NO}_{2}$ response to $\mathrm{NO}_{x}$ emissions $\left(\frac{\Delta \mathrm{NO}_{2}}{\Delta \mathrm{ENO}_{x}}\right)$ is stronger in GEOS-Chem than in other models probably associated with a weaker chemical $\mathrm{NO}_{x}$ loss. This suggests that the same levels of tropospheric $\mathrm{NO}_{2}$ columns can be explained by smaller amounts of $\mathrm{NO}_{x}$ emissions, and this could explain the lower a posterior $\mathrm{NO}_{x}$ emissions evaluated in this model with respect to other models. The multi-model differences in simulated $\mathrm{NO}_{x}$ levels could also explain parts of the diversity in model ozone response to $\mathrm{NO}_{x}$ emissions (Sect. 5). In addition, processes such as vertical mixing and lightning $\mathrm{NO}_{x}$ production are strongly 
model-dependent and influence the responses of $\mathrm{NO}_{2}$ to $\mathrm{NO}_{x}$ emissions. Meanwhile, the updated $\mathrm{NO}_{2}$ retrievals were assimilated only in MIROC-Chem-H, whereas the diurnal emission variability was optimized from data assimilation in MIROC-Chem and MIROC-Chem-H. These differences could also lead to model dependence on emission estimates and model responses to the updated emissions. To fully understand the inter-model differences of the a posteriori emissions, their influence needs to be explored.

\subsection{CO emissions}

The global total $\mathrm{CO}$ emissions are increased by $50 \%$ in GEOS-Chem, $51 \%$ in AGCM-CHASER, $12 \%$ in MIROCChem, and $25 \%$ in MIROC-Chem-H due to data assimilation, with a large diversity in the estimated global total emissions (943.3-1376.9 TgCO, with $16 \%$ multi-model standard deviation), as summarized in Table 8 . The $\mathrm{CO}$ emissions are increased by $18 \%-119 \%$ over eastern China, $9 \%-$ $122 \%$ over the United States, and $37 \%-146 \%$ over Europe in all the models, suggesting significant underestimations of anthropogenic $\mathrm{CO}$ emissions in the bottom-up inventories used as a priori emissions. Using the same a priori emission data sets, the positive increments are larger in AGCMCHASER than in MIROC-Chem over eastern China, western Europe, and the United States, likely associated with underestimated (or overestimated) chemical production (destruction), as similarly discussed by Jiang et al. (2015). In fact, AGCM-CHASER reveals relatively high $\mathrm{OH}$ concentrations corresponding to large $\mathrm{CO}$ emissions (see Table 5) over these regions. The multi-model spread of the a posteriori emissions is large over these industrialized regions (13\%-32\%), with the largest spreads over central eastern China (Fig. 17).

The a posteriori emissions exhibit a wintertime peak over eastern China in the models other than MIROC-Chem and over Europe other than GEOS-Chem (Fig. 19). Stein et al. (2014) commonly found that large corrections are needed for $\mathrm{CO}$ emissions in winter-spring seasons for industrialized areas. Because the chemical destructions are weak in these seasons, the results suggest underestimations in the bottom-up inventories rather than model errors in $\mathrm{OH}$. Meanwhile, the distinct differences in the seasonality as well as mean strength of the a posteriori emissions highlight strong model dependence of $\mathrm{CO}$ emission estimations for the anthropogenic emission regions.

Over India, a pronounced peak in boreal spring is commonly introduced, and the a posteriori emissions show similar seasonality between $\mathrm{NO}_{x}$ and $\mathrm{CO}$ in all the systems. Over Southeast Asia, the annual total emissions are decreased by $3 \%-11 \%$ in all the models, with an enhanced multi-model discrepancy in the biomass burning season. Over South America, the annual total emissions are decreased by $27 \%-$ $41 \%$ in the models except for MIROC-Chem-H, with large reductions in the biomass burning season. The results suggest a common overestimation problem in fire-related emission factors for both $\mathrm{CO}$ and $\mathrm{NO}_{x}$ (see Sect. 6.1) in GFED v2 and v3 over South America. In African regions, although the analyzed seasonal variations are similar, the annual total emissions reveal large discrepancies among the models $(20 \%-$ $35 \%$ ). In comparison with the averaged values in other models, the estimated emissions are larger by $28 \%$ in GEOSChem over northern Africa, by $27 \%$ in MIROC-Chem-H over central Africa, and by $40 \%$ in GEOS-Chem over southern Africa. The multi-model spread of the a posteriori emissions is large over major biomass burning regions, such as eastern central Africa, northern Thailand, and the Amazon (Fig. 17). The substantial inter-model differences highlight the importance of chemistry and dynamics in understanding the carbon budget over these regions.

The inter-model differences in data assimilation adjustments and a posteriori emissions are generally larger for $\mathrm{CO}$ than for $\mathrm{NO}_{x}$, which can be associated with different representations of atmospheric transports such as convective transport and vertical mixing (e.g., Jiang et al., 2015) because of the longer chemical lifetime of $\mathrm{CO}$. Also, differences in the chemical production of $\mathrm{CO}$ from the oxidation of NMHCs and the chemical lifetime of $\mathrm{CO}$, which were not optimized by the data assimilation, could lead to large multi-model discrepancies in CO simulations and emission estimates, as similarly discussed by Gaubert et al. (2016). Thus, the differences in various factors can enhance the multi-model discrepancies in the a posteriori $\mathrm{CO}$ emissions.

Our results suggest requirements for further development of the $\mathrm{CO}$ emission optimization framework to obtain more consistent estimates, for instance, by using a longer assimilation window and a larger ensemble size. The data assimilation windows employed (2-6h) are clearly insufficient to optimize surface $\mathrm{CO}$ emissions using remote measurements while considering the influence of atmospheric transports. The estimated $\mathrm{CO}$ emissions were also sensitive to the choice of other parameters such as localization length and covariance inflation factor, while optimal values of these parameters are expected to differ among the models mainly associated with different representations of atmospheric transport among the models. Optimizing these parameters for individual models would thus also be important. Meanwhile, adding observational constraints, for instance on NMHC emissions from formaldehyde measurements (e.g., Stavrakou et al., 2009), and considering interspecies correlations (e.g., between $\mathrm{NO}_{x}$ and $\mathrm{CO}$ ) would help to improve the data assimilation analysis and multi-model consistency. Some of the increments seem to be inadequate in MIROC-Chem-H, which could suggest different optimal settings requirements for the assimilation of total column retrievals and for higherresolution models. 

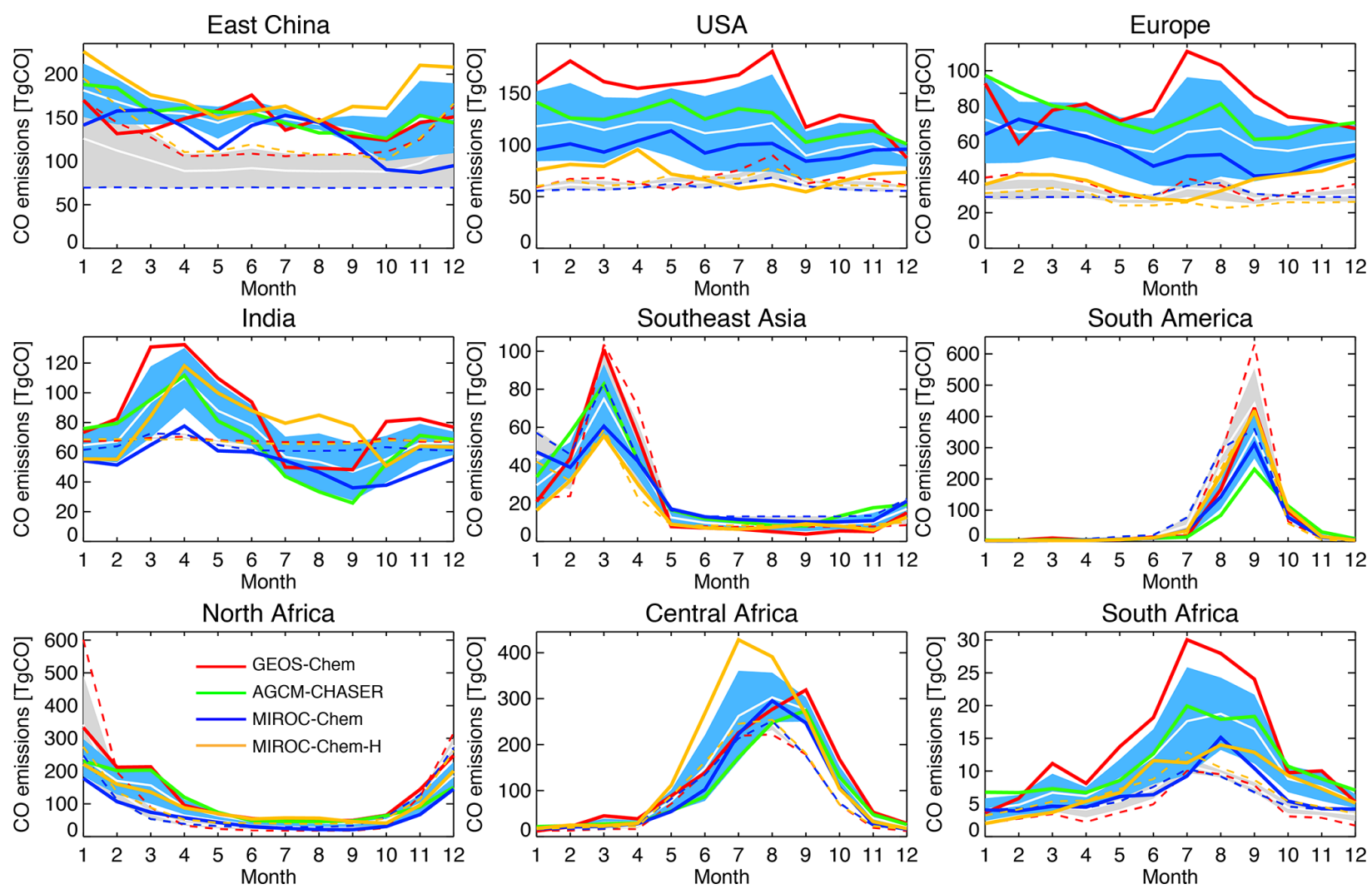

Figure 19. Same as in Fig. 18, but for monthly total regional surface $\mathrm{CO}$ emissions $\left(\mathrm{Tg} \mathrm{CO} \mathrm{yr}^{-1}\right)$.

\section{Conclusions and discussion}

We developed the MOMO-Chem framework to integrate a portfolio of data assimilation analyses obtained using forward CTMs (GEOS-Chem, AGCM-CHASER, MIROCChem, MIROC-Chem-H) in a state-of-the-art ensemble Kalman filter data assimilation system. The data assimilation was used to simultaneously optimize both chemical concentrations and emissions of multiple species through ingestion of a suite of measurements (ozone, $\mathrm{NO}_{2}, \mathrm{CO}, \mathrm{HNO}_{3}$ ) from multiple satellite sensors. The framework was used to demonstrate the importance of the performance of forecast models for tropospheric chemistry data assimilation and to provide multi-model integrated information on the tropospheric chemistry system.

The forecast performance of the models differed for many species because of the different model configurations. In the absence of data assimilation, the multi-model discrepancies and forecast model errors for ozone against the ozonesonde observations were obvious, with annual mean biases ranging from -5.1 to $1.4 \mathrm{ppbv}$ (from -6.2 to $-0.7 \mathrm{ppbv}$ ) in the lower troposphere and from -4.0 to $16.1 \mathrm{ppbv}$ (from 2.8 to $20.5 \mathrm{ppbv}$ ) in the middle and upper troposphere at $\mathrm{NH}(\mathrm{SH})$ midlatitudes. Tropospheric $\mathrm{NO}_{2}$ columns are largely underestimated by the models other than GEOS-Chem over major polluted areas, whereas the simulated column peaks in biomass burning areas are largely biased. For $\mathrm{CO}$, all the models underestimated surface concentrations in the $\mathrm{NH}$ by 20-80 ppb.

Multi-constituent assimilation greatly improved the multimodel consistency and the level of agreements with independent measurements. In comparison with the ozonesonde measurements, the annual mean bias is reduced by about $40 \%-80 \%$ in the $\mathrm{NH}$, by $50 \%-90 \%$ in the tropics, and $45 \%-95 \%$ in the $\mathrm{SH}$ in the middle and upper troposphere, while reducing the multi-model spread of annual mean ozone by $20 \%-60 \%$ in the NH and $30 \%-85 \%$ in the SH. Data assimilation also reduced the model biases in tropospheric $\mathrm{NO}_{2}$ columns by more than $40 \%$ for both major industrialized and biomass burning areas while improving the seasonal variations. The model negative biases of $\mathrm{CO}$ in the $\mathrm{NH}$ are also reduced by about $40 \%-95 \%$ in all the models. These results demonstrate that harnessing the current observing system provides sufficient constraints to greatly reduce the influences of model errors and to provide consistent concentration analysis.

The multi-model comparisons of tropospheric $\mathrm{OH}$ reveal common features of global distributions but with obvious differences in mean concentration levels among the models. Data assimilation increments for $\mathrm{OH}$ differ largely among the models, decreasing in GEOS-Chem by $10 \%-40 \%$ over east Asia, the United States, and Europe and increasing in 
MIROC-Chem and MIROC-Chem-H over most parts of the $\mathrm{NH}$ by $15 \%-40 \%$. In spite of the different increments, the multi-constituent data assimilation reduced the multi-model spread by about $25 \%-60 \%$ over major polluted areas, while the north-to-south hemispheric ratio is reduced in all the models from $1.32 \pm 0.03$ to $1.19 \pm 0.03$. These results suggests that the multi-constituent data assimilation framework can be used to provide a common representation of the tropospheric chemistry system that is less dependent on individual model performance.

The MOMO-Chem framework provides possible uncertainty ranges in the a posteriori emissions in the current data assimilation framework due to model errors, which are quantified in $4 \%-31 \%$ for $\mathrm{NO}_{x}$ and $13 \%-35 \%$ for $\mathrm{CO}$ regional emissions from a multi-model spread of the a posteriori emissions. Meanwhile, the multi-model analysis commonly suggests potential problems in the bottom-up emission inventories, such as underestimation of soil $\mathrm{NO}_{x}$ emissions in early summer at $\mathrm{NH}$ midlatitudes, underestimations of open biomass burning emissions in spring over India, and overestimation of emissions by forest fires in dry conditions over South America. For $\mathrm{NO}_{x}$ emissions, the large intermodel discrepancies are attributable to the chemical lifetime of $\mathrm{NO}_{x}$, vertical mixing, lightning $\mathrm{NO}_{x}$ sources, and model resolution. For $\mathrm{CO}$ emissions, the a posteriori emission differences are largely attributable to different representations of atmospheric transport, such as convective transport and vertical mixing, as well as chemical destruction and production and the use of a short assimilation window. The larger discrepancy for $\mathrm{CO}$ emissions than for $\mathrm{NO}_{x}$ emissions suggest the need to further develop the $\mathrm{CO}$ emission optimization framework, for instance, by using a longer assimilation window and a larger ensemble size.

The response of surface $\mathrm{NO}_{2}$ and ozone concentrations to $\mathrm{NO}_{x}$ emission perturbations is largely different among the models. A stronger ozone response could help to reduce model errors more efficiently through changes in the model ozone equilibrium state from the emission optimization. The multi-constituent framework allows us to evaluate model ozone responses in realistic conditions while considering possible error ranges in precursor emissions. The ozone and emission analysis increment information obtained using the optimized emissions can be used as a diagnostic to quantify model sensitivities related to chemistry and transport. Thus, a systematic investigation of model ozone response and analysis increments in the multi-constituent data assimilation framework could benefit evaluation of future prediction of the chemistry-climate system as a hierarchical emergent constraint (Bowman et al., 2018). By using the multimodel integrated fields from MOMO-Chem and applying the linear regressions, we estimated the surface concentration responses to $\mathrm{NO}_{x}$ emissions in the $\mathrm{NH}$ to be largest in January for $\mathrm{NO}_{2}\left(2.0 \mathrm{ppb}\right.$ per $\left(10^{-11} \mathrm{~kg} \mathrm{~N} \mathrm{~m}^{-2} \mathrm{~s}^{-1}\right)$ and in August for ozone $\left(2.4 \mathrm{ppb}\right.$ per $\left.\left(10^{-11} \mathrm{~kg} \mathrm{~N} \mathrm{~m}^{-2} \mathrm{~s}^{-1}\right)\right)$. The estimated ozone response was larger in the tropics than in the $\mathrm{NH}$, im- plying that any latitudinal shifts in $\mathrm{NO}_{x}$ emissions from the extratropics to the tropics would lead to increases in global tropospheric ozone. The obtained results also suggest that the multi-model integrated fields could provide fundamentally different chemical relationships than those in the individual models, which would inform chemical predictions through relationships such as emergent constraints. Meanwhile, more research is needed to comprehend detailed chemical mechanisms. This example demonstrates the unique capability of MOMO-Chem for various applications.

In summary, the MOMO-Chem framework can be used to generate an ensemble of data assimilation analyses and to provide integrated unique information on the tropospheric chemistry system including precursor emissions while directly accounting for structural uncertainty. Meanwhile, the framework provides uncertainty ranges in data assimilation analyses including the a posteriori emissions due to model errors. The information on the uncertainty obtained from the multi-model framework could be used to suggest requirements for the development of the individual models and observations. To obtain highly consistent data assimilation fields, increasing observational constraints and/or optimization of model parameters, such as VOC emissions, would be needed. Also, improving background error information (e.g., by using multi-model ensembles), considering interspecies emission correlations, and increasing the ensemble size would be useful to improve the performance of the individual data assimilation systems. Comparing different data assimilation methods, such as EnKF vs. 4D-Var, would also be important to investigate whether we are able to produce a consistent data assimilation analysis that is independent of both the data assimilation scheme and forecast model performance.

Data availability. The Tropospheric Chemical Reanalysis (TCR2) data are available at https://tes.jpl.nasa.gov/chemical-reanalysis/ (Jet Propulsion Laboratory, 2019).

Author contributions. KM and KWB designed the study. KM, TW, and $\mathrm{KY}$ developed the data assimilation code and set up the data assimilation experiments. KS developed the model code. KM performed the model simulations and data assimilation experiments. $\mathrm{KM}$ and KWB prepared the manuscript with contributions from all co-authors.

Competing interests. The authors declare that they have no conflict of interest.

Acknowledgements. We acknowledge the use of data products from the NASA Aura and EOS Terra and Aqua satellite missions. We also acknowledge the free use of the tropospheric $\mathrm{NO}_{2}$ column data from the SCIAMACHY, GOME-2, and OMI sensors from http://www. 
qa4ecv.eu (last access: 1 June 2019) and http://www.temis.nl. Part of this work was conducted as the "Post-K computer project Priority Issue 4 - Advancement of meteorological and global environmental predictions utilizing observational Big Data". The Earth Simulator was used for model simulations under the "Strategic Project with Special Support" of the Japan Agency for Marine-Earth Science and Technology. Part of this work was conducted at the Jet Propulsion Laboratory, California Institute of Technology, under contract with the National Aeronautics and Space Administration (NASA). We would also like to thank the editor and the two anonymous reviewers for their valuable comments.

Financial support. This research has been supported by the JSPS KAKENHI (grant nos. 15K05296, 26220101, 26287117, 16H02946, and 18H01285) and the Environment Research and Technology Development Fund of the Ministry of the Environment, Japan (grant no. 2-1803).

Review statement. This paper was edited by Bryan N. Duncan and reviewed by two anonymous referees.

\section{References}

Abida, R., Attié, J.-L., El Amraoui, L., Ricaud, P., Lahoz, W., Eskes, H., Segers, A., Curier, L., de Haan, J., Kujanpää, J., Nijhuis, A. O., Tamminen, J., Timmermans, R., and Veefkind, P.: Impact of spaceborne carbon monoxide observations from the S-5P platform on tropospheric composition analyses and forecasts, Atmos. Chem. Phys., 17, 1081-1103, https://doi.org/10.5194/acp17-1081-2017, 2017.

Anderson, J. L.: An adaptive covariance inflation error correction algorithm for ensemble filters, Tellus, 59A, 210-224, https://doi.org/10.1111/j.1600-0870.2006.00216.x, 2007.

Archibald, A. T., Cooke, M. C., Utembe, S. R., Shallcross, D. E., Derwent, R. G., and Jenkin, M. E.: Impacts of mechanistic changes on $\mathrm{HO}_{x}$ formation and recycling in the oxidation of isoprene, Atmos. Chem. Phys., 10, 8097-8118, https://doi.org/10.5194/acp-10-8097-2010, 2010.

Bocquet, M., Elbern, H., Eskes, H., Hirtl, M., Žabkar, R., Carmichael, G. R., Flemming, J., Inness, A., Pagowski, M., Pérez Camaño, J. L., Saide, P. E., San Jose, R., Sofiev, M., Vira, J., Baklanov, A., Carnevale, C., Grell, G., and Seigneur, C.: Data assimilation in atmospheric chemistry models: current status and future prospects for coupled chemistry meteorology models, Atmos. Chem. Phys., 15, 5325-5358, https://doi.org/10.5194/acp15-5325-2015, 2015.

Boersma, K. F., Jacob, D. J., Eskes, H. J., Pinder, R. W., Wang, J., and van der A, R. J.: Intercomparison of SCIAMACHY and OMI tropospheric $\mathrm{NO}_{2}$ columns: Observing the diurnal evolution of chemistry and emissions from space, J. Geophys. Res., 113, 114, https://doi.org/10.1029/2007JD008816, 2008.

Boersma, K. F., Eskes, H. J., Dirksen, R. J., van der A, R. J., Veefkind, J. P., Stammes, P., Huijnen, V., Kleipool, Q. L., Sneep, M., Claas, J., Leitão, J., Richter, A., Zhou, Y., and Brunner, D.: An improved tropospheric $\mathrm{NO}_{2}$ column retrieval algorithm for the Ozone Monitoring Instrument, Atmos. Meas. Tech., 4, 19051928, https://doi.org/10.5194/amt-4-1905-2011, 2011.

Boersma, K. F., Eskes, H., Richter, A., De Smedt, I., Lorente, A., Beirle, S., Van Geffen, J., Peters, E., Van Roozendael, M., and Wagner, T.: QA4ECV $\mathrm{NO}_{2}$ tropospheric and stratospheric vertical column data from OMI (Version 1.1) [Data set], Royal Netherlands Meteorological Institute (KNMI), https://doi.org/10.21944/qa4ecv-no2-omi-v1.1, 2017a.

Boersma, K. F., Eskes, H., Richter, A., De Smedt, I., Lorente, A., Beirle, S., Van Geffen, J., Peters, E., Van Roozendael, M., and Wagner, T.: QA4ECV $\mathrm{NO}_{2}$ tropospheric and stratospheric vertical column data from GOME-2A (Version 1.1) [Data set], Royal Netherlands Meteorological Institute (KNMI), https://doi.org/10.21944/qa4ecv-no2-gome2a-v1.1, 2017b.

Boersma, K. F., Eskes, H., Ding, J., van der A, R., Miyazaki, K., Visser, A. Ganzeveld, L., Georgoulias, A., Bauwens, M., Stavrakou, T., Compernolle, S., Muller, J.-F., George, M., Coheur, P.-F., and Clerbaux, C.: Report on the impact of Atmospheric ECV records on data assimilation, emission and trend estimates, QA4ECV Report/Deliverable no. D6.3, 24 March 2018a.

Boersma, K. F., Eskes, H. J., Richter, A., De Smedt, I., Lorente, A., Beirle, S., van Geffen, J. H. G. M., Zara, M., Peters, E., Van Roozendael, M., Wagner, T., Maasakkers, J. D., van der A, R. J., Nightingale, J., De Rudder, A., Irie, H., Pinardi, G., Lambert, J.-C., and Compernolle, S. C.: Improving algorithms and uncertainty estimates for satellite $\mathrm{NO}_{2}$ retrievals: results from the quality assurance for the essential climate variables (QA4ECV) project, Atmos. Meas. Tech., 11, 6651-6678, https://doi.org/10.5194/amt-11-6651-2018, 2018 b.

Bovensmann, H., Burrows, J. P., Buchwitz, M., Frerick, J., Noël, S., Rozanov, V. V., Chance, K. V., and Goede, A. P. H.: SCIAMACHY: mission objectives and measurement modes, J. Atmos. Sci., 56, 127-150, 1999.

Bowman, K. W., Rodgers, C. D., Kulawik, S. S., Worden, J., Sarkissian, E., Osterman, G., Steck, T., Lou, M., Eldering, A., Shephard, M., Worden, H., Lampel, M., Clough, S., Brown, P., Rinsland, C., Gunson, M., and Beer, R.: Tropospheric Emission Spectrometer: Retrieval method and error analysis, IEEE T. Geosci. Remote, 44, 1297-1307, https://doi.org/10.1109/TGRS.2006.871234, 2006.

Bowman, K. W., Jones, D. B. A., Logan, J. A., Worden, H., Boersma, F., Chang, R., Kulawik, S., Osterman, G., Hamer, P., and Worden, J.: The zonal structure of tropical $\mathrm{O}_{3}$ and $\mathrm{CO}$ as observed by the Tropospheric Emission Spectrometer in November 2004 - Part 2: Impact of surface emissions on $\mathrm{O}_{3}$ and its precursors, Atmos. Chem. Phys., 9, 3563-3582, https://doi.org/10.5194/acp-9-3563-2009, 2009.

Bowman, K. W., Shindell, D. T., Worden, H. M., Lamarque, J. F., Young, P. J., Stevenson, D. S., Qu, Z., de la Torre, M., Bergmann, D., Cameron-Smith, P. J., Collins, W. J., Doherty, R., Dalsøren, S. B., Faluvegi, G., Folberth, G., Horowitz, L. W., Josse, B. M., Lee, Y. H., MacKenzie, I. A., Myhre, G., Nagashima, T., Naik, V., Plummer, D. A., Rumbold, S. T., Skeie, R. B., Strode, S. A., Sudo, K., Szopa, S., Voulgarakis, A., Zeng, G., Kulawik, S. S., Aghedo, A. M., and Worden, J. R.: Evaluation of ACCMIP outgoing longwave radiation from tropospheric ozone using TES satellite observations, Atmos. Chem. Phys., 13, 40574072, https://doi.org/10.5194/acp-13-4057-2013, 2013. 
Bowman, K. W., Cressie, N., Qu, X., and Hall, A.: A hierarchical statisticalframework for emergent constraints: Application to snow-albedo feedback, Geophys. Res. Lett., 45, 13050-13059, https://doi.org/10.1029/2018GL080082, 2018.

Castellanos, P., Boersma, K. F., and van der Werf, G. R.: Satellite observations indicate substantial spatiotemporal variability in biomass burning $\mathrm{NO}_{x}$ emission factors for South America, Atmos. Chem. Phys., 14, 3929-3943, https://doi.org/10.5194/acp14-3929-2014, 2014.

Coman, A., Foret, G., Beekmann, M., Eremenko, M., Dufour, G., Gaubert, B., Ung, A., Schmechtig, C., Flaud, J.-M., and Bergametti, G.: Assimilation of IASI partial tropospheric columns with an Ensemble Kalman Filter over Europe, Atmos. Chem. Phys., 12, 2513-2532, https://doi.org/10.5194/acp12-2513-2012, 2012.

Dee, D. P., Uppala, S. M., Simmons, A. J., Berrisford, P., Poli, P., Kobayashi, S., Andrae, U., Balmaseda, M. A., Balsamo, G., Bauer, P., Bechtold, P., Beljaars, A. C. M., van de Berg, L., Bidlot, J., Bormann, N., Delsol, C., Dragani, R., Fuentes, M., Geer, A. J., Haimberger, L., Healy, S. B., Hersbach, H., Hólm, E. V., Isaksen, L., Kållberg, P., Köhler, M., Matricardi, M., McNally, A. P., Monge-Sanz, B. M., Morcrette, J.-J., Park, B.-K., Peubey, C., de Rosnay, P., Tavolato, C., Thépaut, J.-N., and Vitart, F.: The ERA-Interim reanalysis: configuration and performance of the data assimilation system, Q. J. Roy. Meteor. Soc., 137, 553-597, https://doi.org/10.1002/qj.828, 2011.

Deeter, M. N., Martínez-Alonso, S., Edwards, D. P., Emmons, L. K., Gille, J. C., Worden, H. M., Pittman, J. V., Daube, B. C., and Wofsy, S. C.: Validation of MOPITT Version 5 thermalinfrared, near-infrared, and multispectral carbon monoxide profile retrievals for 2000-2011, J. Geophys. Res.-Atmos., 118, 6710-6725, 2013.

Deeter, M. N., Edwards, D. P., Francis, G. L., Gille, J. C., Martínez-Alonso, S., Worden, H. M., and Sweeney, C.: A climate-scale satellite record for carbon monoxide: the MOPITT Version 7 product, Atmos. Meas. Tech., 10, 2533-2555, https://doi.org/10.5194/amt-10-2533-2017, 2017.

Emili, E., Barret, B., Massart, S., Le Flochmoen, E., Piacentini, A., El Amraoui, L., Pannekoucke, O., and Cariolle, D.: Combined assimilation of IASI and MLS observations to constrain tropospheric and stratospheric ozone in a global chemical transport model, Atmos. Chem. Phys., 14, 177-198, https://doi.org/10.5194/acp-14-177-2014, 2014.

Eskes, H. J. and Boersma, K. F.: Averaging kernels for DOAS totalcolumn satellite retrievals, Atmos. Chem. Phys., 3, 1285-1291, https://doi.org/10.5194/acp-3-1285-2003, 2003.

Flemming, J., Inness, A., Jones, L., Eskes, H. J., Huijnen, V., Schultz, M. G., Stein, O., Cariolle, D., Kinnison, D., and Brasseur, G.: Forecasts and assimilation experiments of the Antarctic ozone hole 2008, Atmos. Chem. Phys., 11, 1961-1977, https://doi.org/10.5194/acp-11-1961-2011, 2011.

Flemming, J., Benedetti, A., Inness, A., Engelen, R. J., Jones, L., Huijnen, V., Remy, S., Parrington, M., Suttie, M., Bozzo, A., Peuch, V.-H., Akritidis, D., and Katragkou, E.: The CAMS interim Reanalysis of Carbon Monoxide, Ozone and Aerosol for 2003-2015, Atmos. Chem. Phys., 17, 1945-1983, https://doi.org/10.5194/acp-17-1945-2017, 2017.

Gaubert, B., Arellano, A. F., Barré, J.,Worden, H. M., Emmons, L. K., Tilmes, S., Buchholz, R. R., Vitt, F., Raeder,
K., Collins, N., Anderson, J. L., Wiedinmyer, C., Martinez Alonso, S., Edwards, D. P., Andreae, M. O., Hannigan, J. W., Petri, C., Strong, K., and Jones, N.: Toward a chemical reanalysis in a coupled chemistry-climate model: An evaluation of MOPITT CO assimilation and its impact on tropospheric composition, J. Geophys. Res.-Atmos., 121, 7310-7343, https://doi.org/10.1002/2016JD024863, 2016

Graedel, T. E., Bates, T. S., Bouwman, A. F., Cunnold, D., Dignon, J., Fung, I., Jacob, D. J., Lamb, B. K., Logan, J. A., Marland, G., Middleton, P., Pacyna, J. M., Placet, M., and Veldt, C.: A compilation of inventories of emissions to the atmosphere, Global Biogeochem. Cy., 7, 1-26, 1993.

Guenther, A., Karl, T., Harley, P., Wiedinmyer, C., Palmer, P. I., and Geron, C.: Estimates of global terrestrial isoprene emissions using MEGAN (Model of Emissions of Gases and Aerosols from Nature), Atmos. Chem. Phys., 6, 3181-3210, https://doi.org/10.5194/acp-6-3181-2006, 2006.

Henze, D. K., Hakami, A., and Seinfeld, J. H.: Development of the adjoint of GEOS-Chem, Atmos. Chem. Phys., 7, 2413-2433, https://doi.org/10.5194/acp-7-2413-2007, 2007.

Herman, R. L. and Kulawik, S. S. (Eds.): Tropospheric Emission Spectrometer TES Level 2 (L2) Data User's Guide, D-38042, version 5.0, Jet Propulsion Laboratory, California Institute of Technology, Pasadena, CA, available at: http://tes.jpl.nasa.gov/ documents (last access: 30 March 2018), 2013.

Houtekamer, P. L. and Zhang, F.: Review of the ensemble Kalman filter for atmospheric data assimilation, Mon. Weather Rev., 144, 4489-4532, 2016.

Hu, L., Jacob, D. J., Liu, X., Zhange, Y., Zhang, L., Kim, P. S., Sulprizio, M. P., and Yantosca, R. M.: Global budget of tropospheric ozone: Evaluating recent model advances with satellite (OMI), aircraft (IAGOS), and ozonesonde observations, Atmos. Environ., 167, 323-334, https://doi.org/10.1016/j.atmosenv.2017.08.036, 2017.

Hunt, B. R., Kostelich, E. J., and Szunyogh, I.: Efficient data assimilation for spatiotemporal chaos: a local ensemble transform Kalman filter, Physica D, 230, 112-126, 2007.

Inness, A., Baier, F., Benedetti, A., Bouarar, I., Chabrillat, S., Clark, H., Clerbaux, C., Coheur, P., Engelen, R. J., Errera, Q., Flemming, J., George, M., Granier, C., Hadji-Lazaro, J., Huijnen, V., Hurtmans, D., Jones, L., Kaiser, J. W., Kapsomenakis, J., Lefever, K., Leitão, J., Razinger, M., Richter, A., Schultz, M. G., Simmons, A. J., Suttie, M., Stein, O., Thépaut, J.-N., Thouret, V., Vrekoussis, M., Zerefos, C., and the MACC team: The MACC reanalysis: an $8 \mathrm{yr}$ data set of atmospheric composition, Atmos. Chem. Phys., 13, 4073-4109, https://doi.org/10.5194/acp13-4073-2013, 2013.

Inness, A., Benedetti, A., Flemming, J., Huijnen, V., Kaiser, J. W., Parrington, M., and Remy, S.: The ENSO signal in atmospheric composition fields: emission-driven versus dynamically induced changes, Atmos. Chem. Phys., 15, 9083-9097, https://doi.org/10.5194/acp-15-9083-2015, 2015.

Janssens-Maenhout, G., Crippa, M., Guizzardi, D., Dentener, F., Muntean, M., Pouliot, G., Keating, T., Zhang, Q., Kurokawa, J., Wankmüller, R., Denier van der Gon, H., Kuenen, J. J. P., Klimont, Z., Frost, G., Darras, S., Koffi, B., and Li, M.: HTAP_v2.2: a mosaic of regional and global emission grid maps for 2008 and 2010 to study hemispheric trans- 
port of air pollution, Atmos. Chem. Phys., 15, 11411-11432, https://doi.org/10.5194/acp-15-11411-2015, 2015.

Jet Propulsion Laboratory: NASA, Chemical Reanalysis Products, available at: https://tes.jpl.nasa.gov/chemical-reanalysis/, last access: 30 December 2019.

Jiang, Z., Jones, D. B. A., Worden, H. M., and Henze, D. K.: Sensitivity of top-down $\mathrm{CO}$ source estimates to the modeled vertical structure in atmospheric CO, Atmos. Chem. Phys., 15, 15211537, https://doi.org/10.5194/acp-15-1521-2015, 2015.

Jiang, Z., McDonald, B. C., Worden, H., Worden, J. R., Miyazaki, K., Qu, Z., Henze, D. K., Jones, D. B. A., Arellano, A. F., Fischer, E. V., Zhu, L., and Boersma, K. F.: Unexpected slowdown of US pollutant emission reduction in the last decade, P. Natl. Acad. Sci. USA, 115, 5099-5104, https://doi.org/10.1073/pnas.1801191115, 2018.

Jones, D. B. A., Bowman, K. W., Palmer, P. I., Worden, J. R., Jacob, D. J., Hoffman, R. N., Bey, I., and Yantosca, R. M.: , Potential of observa- tions from the Tropospheric Emission Spectrometer to constrain conti- nental sources of carbon monoxide, J. Geophys. Res., 108, 4789, https://doi.org/10.1029/2003JD003702, 2003.

Jones, D. B. A., Bowman, K. W., Logan, J. A., Heald, C. L., Liu, J., Luo, M., Worden, J., and Drummond, J.: The zonal structure of tropical $\mathrm{O}_{3}$ and $\mathrm{CO}$ as observed by the Tropospheric Emission Spectrometer in November 2004 - Part 1: Inverse modeling of CO emissions, Atmos. Chem. Phys., 9, 3547-3562, https://doi.org/10.5194/acp-9-3547-2009, 2009.

Jourdain, L., Worden, H. M., Bowman, K., Li, Q. B., Eldering, A., Kulawik, S. S., Osterman, G., Boersma, K. F., Fisher, B., Rinsland, C. P., Beer, R., and Gunson, M.: Tropospheric vertical distribution of tropical Atlantic ozone observed by TES during the northern African biomass burning season, Geophys. Res. Lett., 34, L04810, https://doi.org/10.1029/2006GL028284, 2007.

Kaiser, J. W., Heil, A., Andreae, M. O., Benedetti, A., Chubarova, N., Jones, L., Morcrette, J.-J., Razinger, M., Schultz, M. G., Suttie, M., and van der Werf, G. R.: Biomass burning emissions estimated with a global fire assimilation system based on observed fire radiative power, Biogeosciences, 9, 527-554, https://doi.org/10.5194/bg-9-527-2012, 2012.

Kalnay, E.: Atmospheric Modeling, Data Assimilation and Predictability, Cambridge University Press, 341 pp., 2003.

Kanamitsu, M., Ebisuzaki, W., Woollen, J., Yang, S.-K., Hnilo, J. J., Fiorino, M., and Potter, G. L.: NCEP-DOE AMIPII Reanalysis (R-2), B. Am. Meteorol. Soc., 83, 1631-1643, https://doi.org/10.1175/BAMS-83-11-1631, 2002.

Kanaya, Y., Miyazaki, K., Taketani, F., Miyakawa, T., Takashima, H., Komazaki, Y., Pan, X., Kato, S., Sudo, K., Sekiya, T., Inoue, J., Sato, K., and Oshima, K.: Ozone and carbon monoxide observations over open oceans on R/V Mirai from $67^{\circ} \mathrm{S}$ to $75^{\circ} \mathrm{N}$ during 2012 to 2017: testing global chemical reanalysis in terms of Arctic processes, low ozone levels at low latitudes, and pollution transport, Atmos. Chem. Phys., 19, 7233-7254, https://doi.org/10.5194/acp-19-7233-2019, 2019.

Kang, J.-S., Kalnay, E., Liu, J., Fung, I., Miyoshi, T., and Ide, K.: Variable localization" in an ensemble Kalman filter: Application to the carbon cycle data assimilation, J. Geophys. Res., 116, D09110, https://doi.org/10.1029/2010JD014673, 2011.

Kiesewetter, G., Sinnhuber, B. M., Vountas, M., Weber, M., and Burrows, J. P.: A long-term stratospheric ozone data set from assimilation of satellite observations: high- latitude ozone anomalies, J. Geophys. Res., 115, D10307, https://doi.org/10.1029/2009JD013362, 2010.

Kuai, L., Bowman, K. W., Miyazaki, K., Deushi, M., Revell, L., Rozanov, E., Paulot, F., Strode, S., Conley, A., Lamarque, J.F., Jöckel, P., Plummer, D. A., Oman, L. D., Worden, H., Kulawik, S., Paynter, D., Stenke, A., and Kunze, M.: Attribution of Chemistry-Climate Model Initiative (CCMI) ozone radiative flux bias from satellites, Atmos. Chem. Phys., 20, 281-301, https://doi.org/10.5194/acp-20-281-2020, 2020.

Lahoz, W. A. and Schneider, P.: Data assimilation: making sense of Earth Observation, Front. Environ. Sci., 2, 16, https://doi.org/10.3389/fenvs.2014.00016, 2014.

Lahoz, W. A., Errera, Q., Swinbank, R., and Fonteyn, D.: Data assimilation of stratospheric constituents: a review, Atmos. Chem. Phys., 7, 5745-5773, https://doi.org/10.5194/acp-7-5745-2007, 2007.

Li, M., Liu, H., Geng, G., Hong, C., Liu, F., Song, Y., Tong, D., Zheng, B., Cui, H., Man, H., Zhang, Q., and He, K.: Anthropogenic emission inventories in China: a review, Natl. Sci. Rev., 4, 834-866, https://doi.org/10.1093/nsr/nwx150, 2017.

Lin, J.-T., Liu, Z., Zhang, Q., Liu, H., Mao, J., and Zhuang, G.: Modeling uncertainties for tropospheric nitrogen dioxide columns affecting satellite-based inverse modeling of nitrogen oxides emissions, Atmos. Chem. Phys., 12, 12255-12275, https://doi.org/10.5194/acp-12-12255-2012, 2012.

Lin, S. J. and Rood, R. B.: Multidimensional flux-form semiLagrangian transport schemes, Mon. Weather Rev., 124, 2046$2070,1996$.

Liu, X., Mizzi, A. P., Anderson, J. L., Fung, I. Y., and Cohen, R. C.: Assimilation of satellite $\mathrm{NO}_{2}$ observations at high spatial resolution using OSSEs, Atmos. Chem. Phys., 17, 7067-7081, https://doi.org/10.5194/acp-17-7067-2017, 2017.

Livesey, N. J., Read, W. G., Froidevaux, L., Lambert, A., Manney, G. L., Pumphrey, H. C., Santee, M. L., Schwartz, M. J., Wang, S., Cofield, R. E., Cuddy, D. T., Fuller, R. A., Jarnot, R. F., Jiang, J. H., Knosp, B. W., Stek, P. C., Wagner, P. A., and Wu, D. L.: Aura Microwave Limb Sounder (MLS), Version 3.3 Level 2 data quality and description document, Tech. Rep. JPL D-33509, Jet Propul. Lab., Pasadena, CA, 2011.

Ménard, R. and Chang, L.-P.: Assimilation of stratospheric chemical tracer observations using a Kalman filter, Part 2: 2-validated results and analysis of variance and correlation dynamics, Mon. Weather Rev., 128, 2672-2686, 2000.

Migliorini, S., Piccolo, C., and Rodgers, C. D.: Use of the Information Content in Satellite Measurements for an Efficient Interface to Data Assimilation, Mon. Weather Rev., 136, 2633-2650, https://doi.org/10.1175/2007MWR2236.1, 2008.

Miyazaki, K. and Bowman, K.: Evaluation of ACCMIP ozone simulations and ozonesonde sampling biases using a satellite-based multi-constituent chemical reanalysis, Atmos. Chem. Phys., 17, 8285-8312, https://doi.org/10.5194/acp-17-8285-2017, 2017.

Miyazaki, K. and Eskes, H.: Constraints on surface $\mathrm{NO}_{x}$ emissions by assimilating satellite observations of multiple species, Geophys. Res. Lett., 40, 4745-4750, https://doi.org/10.1002/grl.50894, 2013.

Miyazaki, K., Eskes, H. J., and Sudo, K.: Global $\mathrm{NO}_{x}$ emission estimates derived from an assimilation of OMI tropospheric $\mathrm{NO}_{2}$ columns, Atmos. Chem. Phys., 12, 2263-2288, https://doi.org/10.5194/acp-12-2263-2012, 2012a. 
Miyazaki, K., Eskes, H. J., Sudo, K., Takigawa, M., van Weele, M., and Boersma, K. F.: Simultaneous assimilation of satellite $\mathrm{NO}_{2}$, $\mathrm{O}_{3}, \mathrm{CO}$, and $\mathrm{HNO}_{3}$ data for the analysis of tropospheric chemical composition and emissions, Atmos. Chem. Phys., 12, 95459579, https://doi.org/10.5194/acp-12-9545-2012, 2012b.

Miyazaki, K., Eskes, H. J., Sudo, K., and Zhang, C.: Global lightning $\mathrm{NO}_{x}$ production estimated by an assimilation of multiple satellite data sets, Atmos. Chem. Phys., 14, 3277-3305, https://doi.org/10.5194/acp-14-3277-2014, 2014.

Miyazaki, K., Eskes, H. J., and Sudo, K.: A tropospheric chemistry reanalysis for the years 2005-2012 based on an assimilation of OMI, MLS, TES, and MOPITT satellite data, Atmos. Chem. Phys., 15, 8315-8348, https://doi.org/10.5194/acp15-8315-2015, 2015.

Miyazaki, K., Eskes, H., Sudo, K., Boersma, K. F., Bowman, K., and Kanaya, Y.: Decadal changes in global surface $\mathrm{NO}_{x}$ emissions from multi-constituent satellite data assimilation, Atmos. Chem. Phys., 17, 807-837, https://doi.org/10.5194/acp-17-8072017, 2017.

Miyazaki, K., Sekiya, T., Fu, D., Bowman, K. W., Kulawik, S. S., Sudo, K., Walker, T., Kanaya, Y., Takigawa, M., Ogochi, K., Eskes, H., Boersma, K. F., Thompson, A. M., Gaubert, B., Barre, J., and Emmons, L. K.: Balance of emission and dynamical controls on ozone during KORUS-AQ from multi-constituent satellite data assimilation, J. Geophys. Res.-Atmos., 124, 387-413, https://doi.org/10.1029/2018JD028912, 2019.

Morgenstern, O., Hegglin, M. I., Rozanov, E., O’Connor, F. M., Abraham, N. L., Akiyoshi, H., Archibald, A. T., Bekki, S., Butchart, N., Chipperfield, M. P., Deushi, M., Dhomse, S. S., Garcia, R. R., Hardiman, S. C., Horowitz, L. W., Jöckel, P., Josse, B., Kinnison, D., Lin, M., Mancini, E., Manyin, M. E., Marchand, M., Marécal, V., Michou, M., Oman, L. D., Pitari, G., Plummer, D. A., Revell, L. E., Saint-Martin, D., Schofield, R., Stenke, A., Stone, K., Sudo, K., Tanaka, T. Y., Tilmes, S., Yamashita, Y., Yoshida, K., and Zeng, G.: Review of the global models used within phase 1 of the Chemistry-Climate Model Initiative (CCMI), Geosci. Model Dev., 10, 639-671, https://doi.org/10.5194/gmd-10-639-2017, 2017.

Myhre, G., Shindell, D., Bréon, F.-M., Collins, W., Fuglestvedt, J., Huang, J., Koch, D., Lamarque, J.-F., Lee, D., Mendoza, B., Nakajima, T., Robock, A., Stephens, G., Takemura T., and Zhang, H.: Anthropogenic and Natural Radiative Forcing, in: Climate Change 2013: The Physical Science Basis. Contribution of Working Group I to the Fifth Assessment Report of the Intergovernmental Panel on Climate Change, edited by: Stocker, T. F., Qin, D., Plattner, G.-K., Tignor, M., Allen, S. K., Boschung, J., Nauels, A., Xia, Y., Bex, V., and Midgley, P. M., Cambridge University Press, Cambridge, United Kingdom and New York, NY, USA, 659-740, https://doi.org/10.1017/CBO9781107415324.018, 2013.

Naik, V., Voulgarakis, A., Fiore, A. M., Horowitz, L. W., Lamarque, J.-F., Lin, M., Prather, M. J., Young, P. J., Bergmann, D., Cameron-Smith, P. J., Cionni, I., Collins, W. J., Dalsøren, S. B., Doherty, R., Eyring, V., Faluvegi, G., Folberth, G. A., Josse, B., Lee, Y. H., MacKenzie, I. A., Nagashima, T., van Noije, T. P. C., Plummer, D. A., Righi, M., Rumbold, S. T., Skeie, R., Shindell, D. T., Stevenson, D. S., Strode, S., Sudo, K., Szopa, S., and Zeng, G.: Preindustrial to present-day changes in tropospheric hydroxyl radical and methane lifetime from the Atmospheric Chemistry and Climate Model Intercomparison Project (ACCMIP), Atmos. Chem. Phys., 13, 5277-5298, https://doi.org/10.5194/acp13-5277-2013, 2013.

Oikawa, P. Y., Ge, C., Wang, J., Eberwein, J. R., Liang, L. L., Allsman, L. A., Grantz, D. A., and Jenerette, G. D.: Unusually high soil nitrogen oxide emissions influence air quality in a high-temperature agricultural region, Nat. Commun., 6, 8753, https://doi.org/10.1038/ncomms9753, 2015.

Olivier, J. G. J. and Berdowski, J. J. M.: Global emissions sources and sinks, in: The Climate System, edited by: Berdowski, J., Guicherit, R., and Heijj, B. J., Balkemea/Swets and Zeitlinger, Lisse, The Netherlands, 33-78, 2001.

Parrington, M., Jones, D. B. A., Bowman, K. W., Thompson, A. M., Tarasick, D. W., Merrill, J., Oltmans, S. J., Leblanc, T., Witte, J. C., and Millet, D. B.: Impact of the assimilation of ozone from the Tropospheric Emission Spectrometer on surface ozone across North America, Geophys. Res. Lett., 36, L04802, https://doi.org/10.1029/2008GL036935, 2009.

Parrington, M., Palmer, P. I., Henze, D. K., Tarasick, D. W., Hyer, E. J., Owen, R. C., Helmig, D., Clerbaux, C., Bowman, K. W., Deeter, M. N., Barratt, E. M., Coheur, P.-F., Hurtmans, D., Jiang, Z., George, M., and Worden, J. R.: The influence of boreal biomass burning emissions on the distribution of tropospheric ozone over North America and the North Atlantic during 2010, Atmos. Chem. Phys., 12, 2077-2098, https://doi.org/10.5194/acp-12-2077-2012, 2012.

Patra, P. K., Krol, M. C., Montzka, S. A., Arnold, T., Atlas, E. L., Lintner, B. R., Stephens, B. B., Xiang, B., Elkins, J. W., Fraser, P. J., Ghosh, A., Hintsa, E. J., Hurst, D. F., Ishijima, K., Krummel, P. B., Miller, B. R., Miyazaki, K., Moore, F. L., Mhle, J., O’Doherty, S., Prinn, R. G., Steele, L. P., Takigawa, M., Wang, H. J., Weiss, R. F., Wofsy, S. C., and Young, D.: Observational evidence for interhemispheric hydroxyl parity, Nature, 513, 219223, 2014.

Price, C. and Rind, D.: A simple lightning parameterization for calculating global lightning distributions, J. Geophys. Res., 97, 9919-9933, https://doi.org/10.1029/92JD00719, 1992.

Randerson, J. T., van der Werf, G. R., Giglio, L., Collatz, G. J., and Kasibhatla, P. S.: Global Fire Emissions Database, Version 4, (GFEDv4), ORNL DAAC, Oak Ridge, Tennessee, USA, https://doi.org/10.3334/ORNLDAAC/1293, 2018.

Sandu, A. and Chai, T.: Chemical data assimilation - an overview, Atmosphere, 3, 426-463, 2011.

Schaap, M., Sauter, F., Timmermans, R. M. A., Roemer, M., Velders, G., Beck, J., and Builtjes, P. J. H.: The LOTOS-EUROS model: description, validation and latest developments, Int. J. Environ. Pollut., 32, 270-290, 2008.

Schenkeveld, V. M. E., Jaross, G., Marchenko, S., Haffner, D., Kleipool, Q. L., Rozemeijer, N. C., Veefkind, J. P., and Levelt, P. F.: In-flight performance of the Ozone Monitoring Instrument, Atmos. Meas. Tech., 10, 1957-1986, https://doi.org/10.5194/amt-10-1957-2017, 2017.

Schultz, M. G., Heil, A., Hoelzemann, J. J., Spessa, A., Thonicke, K., Goldammer, J. G., Held, A. C., Pereira, J. M. C., and van het Bolscher, M.: Global wildland fire emissions from 1960 to 2000, Global Biogeochem. Cy., 22, GB2002, https://doi.org/10.1029/2007GB003031, 2008. 
Schumann, U. and Huntrieser, H.: The global lightning-induced nitrogen oxides source, Atmos. Chem. Phys., 7, 3823-3907, https://doi.org/10.5194/acp-7-3823-2007, 2007.

Sekiya, T., Miyazaki, K., Ogochi, K., Sudo, K., and Takigawa, M.: Global high-resolution simulations of tropospheric nitrogen dioxide using CHASER V4.0, Geosci. Model Dev., 11, 959-988, https://doi.org/10.5194/gmd-11-959-2018, 2018.

Shindell, D. T., Faluvegi, G., Stevenson, D. S., Krol, M. C., Emmons, L. K., Lamarque, J.-F., Pétron, G., Dentener, F. J., Ellingsen, K., Schultz, M. G., Wild, O., Amann, M., Atherton, C. S., Bergmann, D. J., Bey, I., Butler, T., Cofala, J., Collins, W. J., Derwent, R. G., Doherty, R. M., Drevet, J., Eskes, H. J., Fiore, A. M., Gauss, M., Hauglustaine, D. A., Horowitz, L. W., Isaksen, I. S. A., Lawrence, M. G., Montanaro, V., Müller, J.-F., Pitari, G., Prather, M. J., Pyle, J. A., Rast, S., Rodriguez, J. M., Sanderson, M. G., Savage, N. H., Strahan, S. E., Sudo, K., Szopa, S., Unger, N., van Noije, T. P. C., and Zeng, G.: Multi-model simulations of carbon monoxide: Comparison with observations and projected near-future changes, J. Geophys. Res., 111, D19306, https://doi.org/10.1029/2006JD007100, 2006.

Skachko, S., Ménard, R., Errera, Q., Christophe, Y., and Chabrillat, S.: EnKF and 4D-Var data assimilation with chemical transport model BASCOE (version 05.06), Geosci. Model Dev., 9, 28932908, https://doi.org/10.5194/gmd-9-2893-2016, 2016.

Smit, H. G. J., Straeter, W., Johnson, B. J., Oltmans, S. J., Davies, J., Tarasick, D. W., Hoegger, B., Stubi, R., Schmidlin, F. J., Northam, T., Thompson, A. M., Witte, J. C., Boyd, I., and Posny, F.: Assessment of the performance of ECC ozonesondes under quasi flight conditions in the environmental simulation chamber: insights from the Juelich Ozone Sonde Intercomparison Experiment (JOSIE), J. Geophys. Res., 112, D19306, https://doi.org/10.1029/2006JD007308, 2007.

Stavrakou, T., Müller, J.-F., De Smedt, I., Van Roozendael, M., van der Werf, G. R., Giglio, L., and Guenther, A.: Global emissions of non-methane hydrocarbons deduced from SCIAMACHY formaldehyde columns through 2003-2006, Atmos. Chem. Phys., 9, 3663-3679, https://doi.org/10.5194/acp-9-36632009, 2009.

Stavrakou, T., Müller, J.-F., Boersma, K. F., van der A, R. J., Kurokawa, J., Ohara, T., and Zhang, Q.: Key chemical $\mathrm{NO}_{x}$ sink uncertainties and how they influence top-down emissions of nitrogen oxides, Atmos. Chem. Phys., 13, 9057-9082, https://doi.org/10.5194/acp-13-9057-2013, 2013.

Stein, O., Schultz, M. G., Bouarar, I., Clark, H., Huijnen, V., Gaudel, A., George, M., and Clerbaux, C.: On the wintertime low bias of Northern Hemisphere carbon monoxide found in global model simulations, Atmos. Chem. Phys., 14, 9295-9316, https://doi.org/10.5194/acp-14-9295-2014, 2014.

Stevenson, D. S., Young, P. J., Naik, V., Lamarque, J.-F., Shindell, D. T., Voulgarakis, A., Skeie, R. B., Dalsoren, S. B., Myhre, G., Berntsen, T. K., Folberth, G. A., Rumbold, S. T., Collins, W. J., MacKenzie, I. A., Doherty, R. M., Zeng, G., van Noije, T. P. C., Strunk, A., Bergmann, D., Cameron-Smith, P., Plummer, D. A., Strode, S. A., Horowitz, L., Lee, Y. H., Szopa, S., Sudo, K., Nagashima, T., Josse, B., Cionni, I., Righi, M., Eyring, V., Conley, A., Bowman, K. W., Wild, O., and Archibald, A.: Tropospheric ozone changes, radiative forcing and attribution to emissions in the Atmospheric Chemistry and Climate Model Intercompari- son Project (ACCMIP), Atmos. Chem. Phys., 13, 3063-3085, https://doi.org/10.5194/acp-13-3063-2013, 2013.

Streets, D. G., Canty, T., Carmichael, G. R., de Foy, B., Dickerson, R. R., Duncan, B. N., Edwards, D. P., Haynes, J. A., Henze, D. K., Houyoux, M. R., Jacob, D. J., Krotkov, N. A., Lamsal, L. N., Liu, Y., Lu, Z., Martin, R. V., Pfister, G., Pinder, R. W., Salawitch, R. J., and Wecht, K. J.: Emissions estimation from satellite retrievals: a review of current capability, Atmos. Environ., 77, 1011-1042, https://doi.org/10.1016/j.atmosenv.2013.05.051, 2013.

Sudo, K., Takahashi, M., and Akimoto, H.: CHASER: a global chemical model of the troposphere 2. Model results and evaluation, J. Geophys. Res., 107, 4586, https://doi.org/10.1029/2001JD001114, 2002.

Thompson, A. M., Stauffer, R. M., Boyle, T. P., Kollonige, D. E., Miyazaki, K., Tzortziou, M., Herman, J. R., Jordan, C. N., Lamb, B. T., and Duncan, B. N.: Comparison of Near-Surface $\mathrm{NO}_{2}$ Pollution With Pandora Total Column $\mathrm{NO}_{2}$ During the Korea-United States Ocean Color (KORUS OC) Campaign, J. Geophys. Res.-Atmos., 124, 13560-13575, https://doi.org/10.1029/2019JD030765, 2019.

van der A, R. J., Allaart, M. A. F., and Eskes, H. J.: Extended and refined multi sensor reanalysis of total ozone for the period 1970-2012, Atmos. Meas. Tech., 8, 3021-3035, https://doi.org/10.5194/amt-8-3021-2015, 2015.

van der Werf, G. R., Randerson, J. T., Giglio, L., Collatz, G. J., Kasibhatla, P. S., and Arellano Jr., A. F.: Interannual variability in global biomass burning emissions from 1997 to 2004, Atmos. Chem. Phys., 6, 3423-3441, https://doi.org/10.5194/acp-6-34232006, 2006.

van der Werf, G. R., Randerson, J. T., Giglio, L., Collatz, G. J., Mu, M., Kasibhatla, P. S., Morton, D. C., DeFries, R. S., Jin, Y., and van Leeuwen, T. T.: Global fire emissions and the contribution of deforestation, savanna, forest, agricultural, and peat fires (1997-2009), Atmos. Chem. Phys., 10, 11707-11735, https://doi.org/10.5194/acp-10-11707-2010, 2010.

van Noije, T. P. C., Eskes, H. J., Dentener, F. J., Stevenson, D. S., Ellingsen, K., Schultz, M. G., Wild, O., Amann, M., Atherton, C. S., Bergmann, D. J., Bey, I., Boersma, K. F., Butler, T., Cofala, J., Drevet, J., Fiore, A. M., Gauss, M., Hauglustaine, D. A., Horowitz, L. W., Isaksen, I. S. A., Krol, M. C., Lamarque, J.F., Lawrence, M. G., Martin, R. V., Montanaro, V., Müller, J.-F., Pitari, G., Prather, M. J., Pyle, J. A., Richter, A., Rodriguez, J. M., Savage, N. H., Strahan, S. E., Sudo, K., Szopa, S., and van Roozendael, M.: Multi-model ensemble simulations of tropospheric $\mathrm{NO}_{2}$ compared with GOME retrievals for the year 2000, Atmos. Chem. Phys., 6, 2943-2979, https://doi.org/10.5194/acp6-2943-2006, 2006.

Venkataraman, C., Habib, G., Kadamba, D., Shrivastava, M., Leon, J.-F., Crouzille, B., Boucher, O., and Streets, D. G.: Emissions from open biomass burning in India: Integrating the inventory approach with high-resolution Moderate Resolution Imaging Spectroradiometer (MODIS) active-fire and land cover data, Global Biogeochem. Cy., 20, GB2013, https://doi.org/10.1029/2005GB002547, 2006.

Xue, L. and Zhang, D.: A multimodel data assimilation framework via the ensemble Kalman filter, Water Resour. Res., 50, 41974219, https://doi.org/10.1002/2013WR014525, 2014. 
Yeung, L. Y., Murray, L. T., Martinerie, P., Witrant, E., Hu, H., Banerjee, A., Orsi, A., and Chappellaz, J.: Isotopic constraint on the twentieth-century increase in tropospheric ozone, Nature, 570, 224-227, 2019.

Young, P. J., Archibald, A. T., Bowman, K. W., Lamarque, J.-F., Naik, V., Stevenson, D. S., Tilmes, S., Voulgarakis, A., Wild, O., Bergmann, D., Cameron-Smith, P., Cionni, I., Collins, W. J., Dalsøren, S. B., Doherty, R. M., Eyring, V., Faluvegi, G., Horowitz, L. W., Josse, B., Lee, Y. H., MacKenzie, I. A., Nagashima, T., Plummer, D. A., Righi, M., Rumbold, S. T., Skeie, R. B., Shindell, D. T., Strode, S. A., Sudo, K., Szopa, S., and Zeng, G.: Preindustrial to end 21 st century projections of tropospheric ozone from the Atmospheric Chemistry and Climate Model Intercomparison Project (ACCMIP), Atmos. Chem. Phys., 13, 20632090, https://doi.org/10.5194/acp-13-2063-2013, 2013.

Young, P. J., Naik, V., Fiore, A. M., Gaudel, A., Guo, J., Lin, M. Y., Neu, J. L., Parrish, D. D., Rieder, H. E., Schnell, J. L., Tilmes, S., Wild, O., Zhang, L., Ziemke, J. R., Brandt, J., Delcloo, A., Doherty, R. M., Geels, C., Hegglin, M. I., Hu, L., Im, U., Kumar, R., Luhar, A., Murray, L., Plummer, D., Rodriguez, J., Saiz-Lopez, A., Schultz, M. G., Woodhouse, M. T., and Zeng, G.: Tropospheric Ozone Assessment Report: Assessment of global-scale model performance for global and regional ozone distributions, variability, and trends, Elem. Sci. Anth., 6, p. 10, https://doi.org/10.1525/elementa.265, 2018.

Yumimoto, K.: Impacts of geostationary satellite measurements on $\mathrm{CO}$ forecasting: An observing system simulation experiment with GEOS-Chem/LETKF data assimilation system, Atmos. Environ., 74, 123-133, https://doi.org/10.1016/j.atmosenv.2013.03.032, 2013.
Watanabe, S., Hajima, T., Sudo, K., Nagashima, T., Takemura, T., Okajima, H., Nozawa, T., Kawase, H., Abe, M., Yokohata, T., Ise, T., Sato, H., Kato, E., Takata, K., Emori, S., and Kawamiya, M.: MIROC-ESM 2010: model description and basic results of CMIP5-20c3m experiments, Geosci. Model Dev., 4, 845-872, https://doi.org/10.5194/gmd-4-845-2011, 2011.

Zaveri, R. A., Berkowitz, C. M., Kleinman, L. I., Springston, S. R., Doskey, P. V., Lonneman, W. A., and Spicer, C. W.: Ozone production efficiency and $\mathrm{NO}_{x}$ depletion in an urban plume: Interpretation of field observations and implications for evaluating $\mathrm{O}_{3}-\mathrm{NO}_{x}$-VOC sensitivity, J. Geophys. Res., 108, 4436, https://doi.org/10.1029/2002JD003144, 2003.

Zhang, L., Jacob, D. J., Bowman, K. W., Logan, J. A., Turquety, S., Hudman, R. C., Li, Q., Beer, R., Worden, H. M., Rinsland, C. P., Kulawik, S. S., Lampel, M. C., Shephard, M. W., Fisher, B. M., Eldering, A., and Avery, M. A.: OzoneCO correlations determined by the TES satellite instrument in continental outflow regions, Geophys. Res. Lett., 33, L18804, https://doi.org/10.1029/2006GL026399, 2006.

Zhang, Y., Cooper, O. R., Gaudel, A., Thompson, A. M., Nédélec, P., Ogino, S.-Y., and West, J. J.: Tropospheric ozone change from 1980 to 2010 dominated by equatorward redistribution of emissions, Nat. Geosci., 9, 875-879, https://doi.org/10.1038/ngeo2827, 2016. 